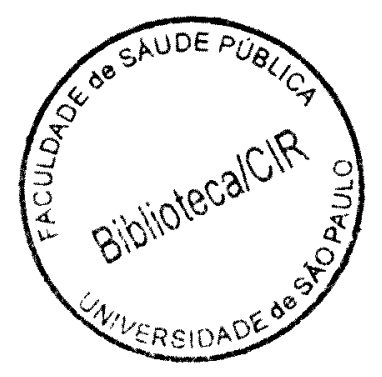

\title{
MORTALIDADE EM MIGRANTES: O CASO DOS JAPONESES NO ESTADO DO PARANÁ
}

FACULdADE de SAÚdE PÚBLICA UNIVERSIDADE DE SÃO PAULO 


\section{MORTALIDADE EM MIGRANTES: O CASO DOS JAPONESES NO ESTADO DO PARANÁ}

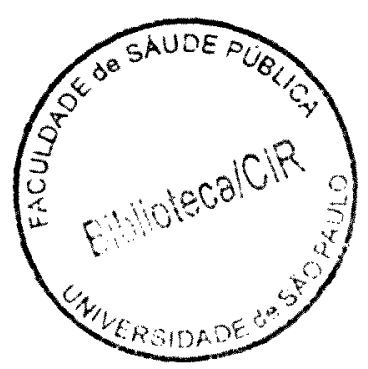

Tese apresentada ao Departamento de Epidemiologia da Faculdade de Saúde Pública da Universidade de São Paulo para obtenção do título de Doutor

ORIENTADORA: Prof ${ }^{\mathrm{a}}$. $\mathrm{Dr}^{\mathrm{a}}$. Sabina Léa Davidson Gotlieb

São Paulo

1997 

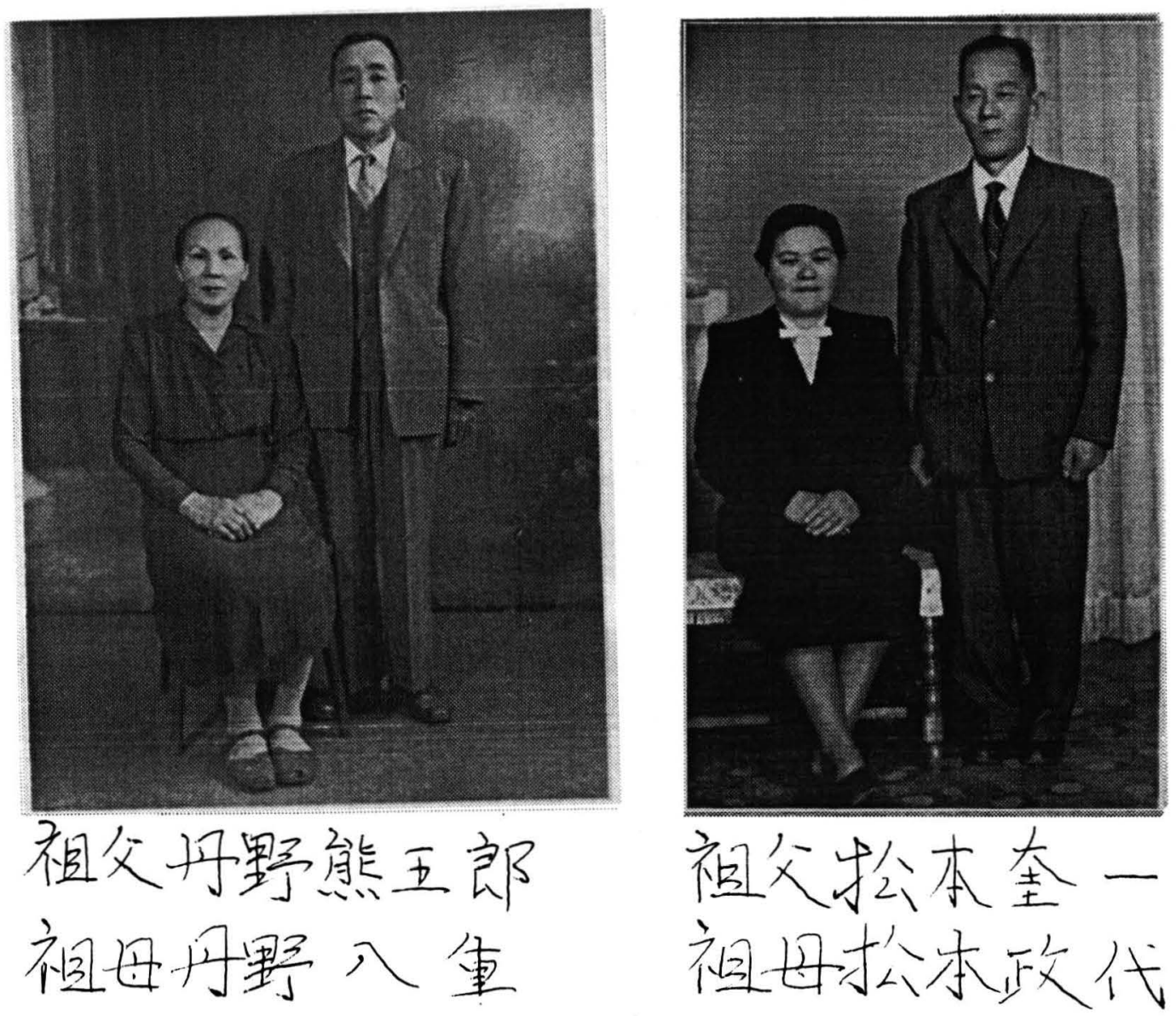

Aos meus ancestrais Kumagoro/Yae Tanno e Keiichi/Masayo Matsumoto que um dia tomaram a decisão de se instalar no Brasil. 


\section{RESUMO}

Introdução - Tendo como premissa o entendimento que o estudo acerca do perfil de morbimortalidade de populações migrantes pode trazer contribuições para melhor compreender a epidemiologia das doenças, principalmente as de natureza crônicodegenerativa, analisou-se a experiência de mortalidade de uma população de nascidos no Japão, residentes no Estado do Paraná, comparativamente à dos habitantes no Japão e no Estado do Paraná.

Material e método - A população analisada foi constituída pelos imigrantes japoneses - isseis - residentes no Estado do Paraná, com 50 anos e mais de idade, identificados por ocasião do X Recenseamento Geral do Brasil, em primeiro de setembro de 1991. Informações sobre óbitos, ocorridos entre primeiro de março de 1990 e 28 de fevereiro de 1993, foram apuradas do banco de dados do Sistema de Informação de Mortalidade do Ministério da Saúde. As principais causas básicas de morte foram analisadas após calcular coeficientes de mortalidade padronizados por idade, ajustados pela população mundial de 50 anos e mais, em cada sexo, para isseis, residentes no Japão e no Paraná. A Razão de Mortalidade Padronizada (RMP) e o respectivo intervalo de $95 \%$ de confiança foram estimados para causas selecionadas entre isseis/residentes no Japão e isseis/residentes no Paraná.

Resultados - Entre os principais resultados, observou-se que o coeficiente padronizado de mortalidade geral das mulheres isseis de 50 anos e mais situou-se em posição intermediária quando comparado ao das residentes no Japão e no Paraná, enquanto que o dos homens apresentou valor bastante próximo ao da população masculina do Japão. No tocante às causas específicas, observou-se entre isseis do sexo masculino, quando comparados com a população do Japão, coeficientes significativamente mais baixos para câncer de estômago, cólon, pulmão e próstata, porém, mais altos para diabetes, doenças 
isquêmicas do coração e doenças cerebrovasculares. Em relação às mulheres isseis de 50 anos e mais, somente o coeficiente de mortalidade por câncer de pulmão apresentou-se significativamente inferior ao das habitantes do Japão. Com exceção de câncer de estômago (mulheres), câncer de cólon e suicídio, para a maioria das outras causas estudadas foram verificados coeficientes de mortalidade entre isseis (de ambos os sexos) comparativamente mais baixos do que da população total do Paraná; esta diferença foi estatisticamente significante. Todavia, especificamente para diabetes mellitus e doenças cerebrovasculares (mulheres), não foram constatadas diferenças significantes.

Conclusão - Os resultados obtidos permitem evidenciar um afastamento do padrão de mortalidade de isseis quando comparado ao de seu país de origem e uma sensível aproximação ao padrão do local de destino. Tais constatações sugerem influência de fatores sócio-culturais, principalmente das práticas dietéticas, no perfil apresentado. 


\begin{abstract}
Introduction - Taking as premise the understanding that the study concerning the morbimortality of migrant populations may bring contributions to a better comprehension of the diseases' epidemiology, mainly the chronic-degenerative ones, the mortality experience in a population formed by people born in Japan, but living in the state of Paraná, was analysed comparatively to the one in Japan and the one in Paraná.
\end{abstract}

Material and Method - The exposed population was formed by the first-generation of Japanese immigrants - isseis - living in the state of Paraná, older than 50 years, identified in the X General Brazilian Census on the first of September, 1991. Information about deaths occurred between the first of March, 1990 to the twenty-eighth of February, 1993, was obtained through the Ministry of Health data base. The main causes of death were analysed after the calculation of the age-adjusted death rates, using the world standard population older than 50 years old, for each sex, for isseis, residents of Japan and Paraná. Standardized Risk Ratio - SRR - and respective $95 \%$ confidence interval were estimated for causes selected among isseis/residents in Japan and isseis/residents in Paraná.

Results - Among the main results, it was observed that the issei women's rate of general mortality ranked in an intermediary position when compared to the ones from Japan and Paraná, while men showed figures quite close to the ones from Japan. Concerning the specific causes, it was observed that among male isseis, when compared to the population from Japan, the rates were significantly lower to stomach, colon, lung and prostate eancer, but higher to diabetes, ischaemic heart diseases and cerebrovascular diseases. Regarding the issei women aged 50 or more years old, only the death rates for lung cancer showed itself significantly lower to the Japanese women from Japan. Excepting the stomach (women) and colon cancer and suicide, for the majority of other causes many rates of mortality among isseis (both sexes) were comparetively lower than 
the ones for the residents in Paraná. This difference was statisticaly significant. However, specificaly for diabetes mellitus, and cerebrovascular diseases (women), significant differences were not noticed.

Conclusions - The obtained results make it possible to assert a deviation from the pattern of issei mortality when compared to their origin country and a sensitive approximation to the pattern of the destination place. Such observations suggest influence of socio-cultural factors, mainly of the dietary habits, in the showed profile. 


\section{SUMÁRIO}

Pág.

1. INTRODUÇÃO

1.1 Área temática e justificativa do estudo $\quad$.......................................................... 2

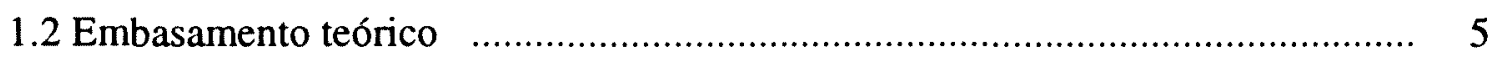

1.2.1 Determinantes gerais da migração ........................................................ 5

1.2.2 Determinantes da imigração internacional japonesa para o Brasil $\quad$............. 7

1.2.3 Processo de aculturação dos imigrantes japoneses no Brasil ................... 9

1.2.4 Ocupação do espaço paranaense pelos imigrantes japoneses $\quad$................... 13

1.2.5 Perfil epidemiológico dos imigrantes japoneses e processo saúde-doença . 16

2.OBJETIVOS

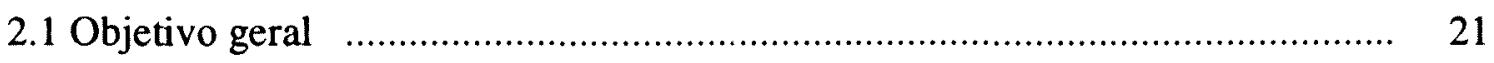

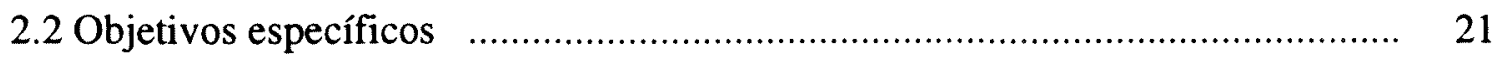

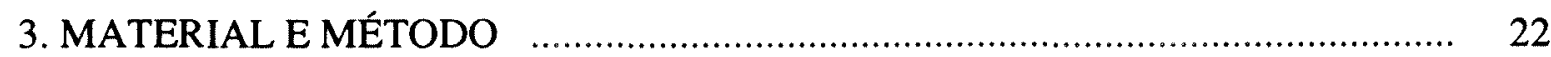

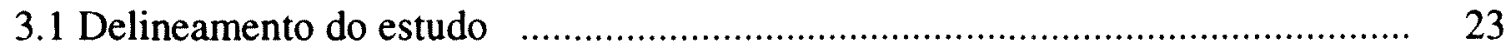

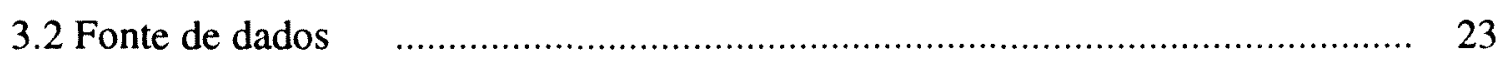

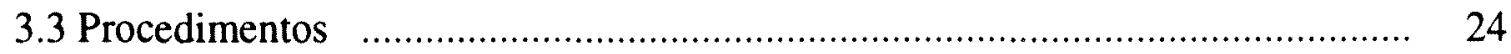

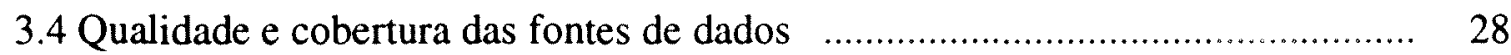

4. RESULTADOS E DISCUSSÃO

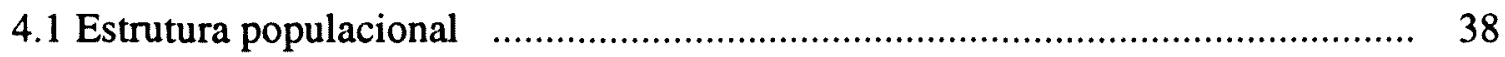

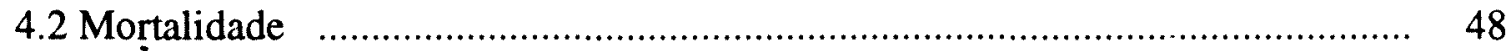

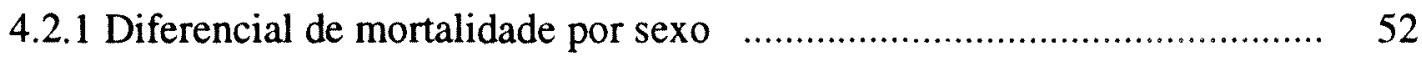

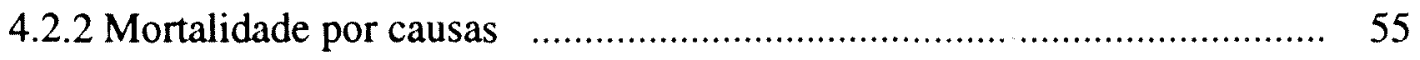

4.2.2.1 Mortalidade por doenças do aparelho circulatório $\quad$........................... 64

- Doenças isquêmicas do coração ...................................................... 65 
- Doenças cerebrovasculares ....................................................... 71

4.2.2.2 Mortalidade por neoplasias malignas ........................................ 75

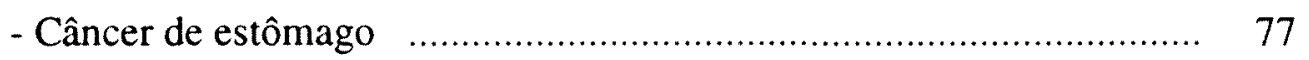

- Câncer de cólon ...................................................................... 84

- Câncer de pulmão ...................................................................... 87

- Câncer de mama e de próstata ....................................................... 89

4.2.2.3 Mortalidade por doenças das glândulas endócrinas, nutricionais e metabólicas ............................................................................. 93

- Diabetes mellitus f.............................................................. 93

4.2.2.4 Mortalidade por causas externas $\quad$................................................. 96

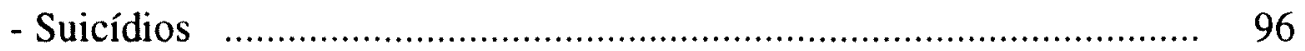

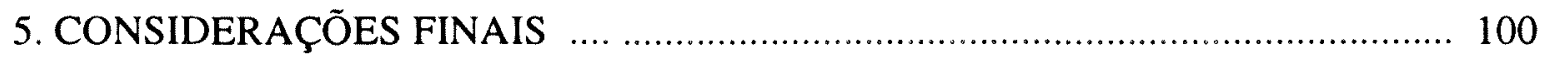

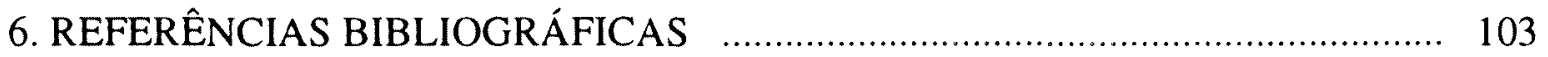

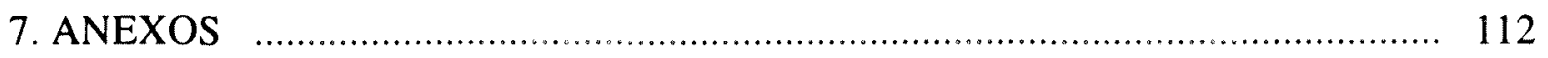




\section{1 ÁREA TEMÁTICA E JUSTIFICATIVA DO ESTUDO}

A busca de uma vida melhor e mais duradoura tem conduzido a humanidade a um processo de desenvolvimento sistemático de conhecimentos, técnicas e recursos (RODRIGUES da SILVA, 1990). Partindo da acepção de que condições de saúde são determinadas pela articulação entre o meio interno e externo, a Higiene, a Medicina Preventiva, através de sua disciplina central a epidemiologia, sempre procuraram identificar e quantificar fatores que pudessem ser isolados por meio de medidas específicas, visando controlar o aparecimento das doenças. No entanto, quando novos problemas de saúde, diferentes das doenças infecciosas, vieram a se tornar importantes, passaram a ser considerados, além dos meios físicos e biológicos, os meios culturais e sócio-políticos, incluindo, como fatores de risco, produtos e comportamentos decorrentes de determinadas organizações sociais (SABROZA e LEAL, 1992).

Tal fato, conforme descreve RODRIGUES da SILVA (1990), ocorreu a partir dos anos 50, com a ruptura do enfoque epidemiológico voltado, até então, aos modos de transmissão das doenças infecto-contagiosas, dando lugar a um período atual denominado epidemiologia dos fatores de risco. Durante décadas, buscou-se produzir conhecimentos para combater as principais causas de morte, cuja atuação apropriada do setor saúde e áreas afins conduziria à importante redução da mortalidade, bem como, da incapacidade prematura.

Tornaram-se abundantes, desta forma, as produções científicas, principalmente em sociedades vivenciando estágios mais avançados da transição epidemiológica, as quais buscavam identificar fatores associados à ocorrência de doenças denominadas crônicodegenerativas, muitas vezes a partir de delineamentos de pesquisas do tipo experimental. No entanto, estudos deste tipo apresentam algumas restrições, principalmente, no tocante à natureza ética, quando envolvem intervenções, ainda não comprovadas quanto à sua 
inocuidade, em determinados grupos de pessoas (ALMEIDA FILHO, 1989; FLETCHER et al, 1989).

Frente a essas questões e à constatação de que populações culturalmente distintas apresentam diferentes formas de adoecer e morrer, muito provavelmente, em conseqüência dos seus hábitos e costumes, as investigações epidemiológicas abordando fenômenos migratórios, envolvendo diferentes nacionalidades (GORDON, 1957 e 1967; FANG et al, 1996) ou religiões (SHATENSTEIN e KARK, 1995), passam a constituir objeto de estudo no âmbito dessa área de conhecimento. Conforme FRANCO (1996), no estudo de grupos populacionais com características bem definidas é possível avaliar o papel dos fatores ambientais, aí incluindo a participação dos aspectos nutricionais, psicossociais e culturais, na etiologia das doenças não transmissíveis, tais como diabetes mellitus, doenças isquêmicas do coração e doenças cerebrovasculares.

Para GOTLIEB (1988), estudos assim desenvolvidos têm por finalidade apontar possíveis "fatores presentes e atuantes no aparecimento do agravo", a partir do confronto do perfil de saúde-doença e dos hábitos e costumes dos nativos residentes em uma dada localidade e dos imigrantes residentes nesta mesma área.

Assim, pelo fato do Japão apresentar diferentes prevalências para determinadas doenças, comparativamente às de outros países, os hábitos e costumes do povo japonês têm merecido atenção especial, no sentido de esclarecer se as diferenças encontradas deve-se à participação dos fatores genéticos (COGGON e ACHESON, 1984) ou ambientais. Todavia, estudos vêm demonstrando que as diferenças observadas devem ser atribuídas, em grande parte, às questões ambientais, uma vez que as taxas de ocorrência de doenças entre os que migraram apresentam notáveis diferenças em relação às taxas do país de origem. Neste sentido, o interesse tem assentado, particularmente, no perfil epidemiológico dos japoneses que deixaram o seu país, para se estabelecerem em novos ambientes culturalmente distintos. A justificativa para condução destes estudos é levantar hipóteses a serem testadas. Com isso, propiciar a implementação de ações de saúde voltadas ao 
retardamento do aparecimento das doenças crônico-degenerativas e/ou protelar o momento das mortes por estas causas, dando uma melhor qualidade na sobrevivência.

No contexto latino-americano, apesar da importância da morbimortalidade por doenças infecciosas e parasitárias, reiteradas pelas doenças emergentes e reemergentes, as doenças crônicas não transmissíveis, principalmente do aparelho circulatório, neoplasias e diabetes, também vêm ocupando posições cada vez mais importantes no perfil de morbimortalidade, constituindo-se em importantes problemas de Saúde Pública, responsáveis inclusive por mortes prematuras (DUNCAN et al, 1993; MARTINS et al, 1995). Assim, no Brasil, em 1990, 38,3\% dos óbitos foram por doenças do aparelho circulatório e neoplasias, percentagem superior à verificada nos fins dos anos 70, ano no qual estas causas haviam sido responsáveis por 33,2\% das mortes (ROUQUAYROL et al, 1993; MINISTÉRIO DA SAÚDE, 1996).

MARTINS e colaboradores (1995), estudando fatores de risco para doenças cardiovasculares arterioscleróticas, com base em vários estudos, vinculam a origem destes fatores às características genéticas e ao estilo de vida/qualidade de vida, ou seja, "modos de viver que conduzem a práticas, hábitos, pressões e desgastes físico-psicológicos". DUNCAN e colaboradores (1993), em referência à área temática semelhante, alertam para a importância de reconhecer a "presença massiva" desses fatores na população brasileira e sugerem necessidade urgente de programas voltados para prevenção das doenças cardiovasculares, em nível coletivo.

Além dos aspectos levantados, cabe, ainda, ressaltar que, com a profunda e rápida transformação que vem ocorrendo na estrutura populacional do país, há também um aumento acentuado de pessoas com idades mais avançadas. Tal fato expressa, em relação às décadas passadas, a existência de mais adultos com maiores possibilidades de adoecer e, até mesmo, de contrair formas mais graves de doenças, devido ao alcance limitado dos programas de prevenção para estas doenças, no país, apesar de sua importância crescente 
(ARAÚJO, 1992; GUIMARÃES, 1990; DUNCAN et al, 1993; BARRETO e CARMO, 1994).

À luz de tais considerações, a realização do presente estudo teve como finalidade contribuir na expansão do conhecimento relativo aos possíveis fatores atuantes no aparecimento dos agravos à saúde, mais especificamente, aos problemas de natureza crônico-degenerativa. Assim sendo, baseou-se na comparação do perfil de mortalidade de três populações distintas quanto ao modo de viver, quais sejam: dos nascidos no Japão que, em algum momento de suas vidas, vieram a se instalar no Estado do Paraná (isseis, termo da língua japonesa que significa a geração que migrou), da população total deste Estado e da população total do Japão, país de origem desses imigrantes.

\subsection{EMBASAMENTO TEÓRICO}

\subsubsection{Determinantes gerais da migração}

A história tem demonstrado que o homem sempre se movimentou (GEORGE, 1977). Dentre as mobilidades espaciais, aquelas relacionadas às populações relativamente estabelecidas no espaço, que mudam de residência em caráter permanente, são as que vêm merecendo maiores atenções, por pressuporem, além de mudanças de residência, alterações nos vínculos associativos de suas vidas, implicando na necessidade de reajustamentos sociais, econômicos e culturais. Daí origina-se o conceito de migração que, segundo a Organização das Nações Unidas, é "uma forma de mobilidade espacial entre uma unidade geográfica e outra, envolvendo mudança permanente de residência", não incluindo, portanto, os povos nômades, as migrações sazonais, o movimento de pessoas com mais de uma residência, os visitantes, turistas, entre outros (RENNER e PATARRA, 1980). 
Dentre os fatores que explicam a ocorrência dos fenômenos migratórios, GEORGE (1977) destaca que as migrações são conseqüências de uma ruptura no equilíbrio econômico e social da comunidade. Para SINGER (1981) as migrações são sempre condicionadas historicamente, resultam de um processo geral de mudanças e se constituem em mecanismos de redistribuição espacial da população que se adapta ao "rearranjo espacial das atividades econômicas" e explicam a quase totalidade das migrações internas e boa parte das migrações internacionais.

Apesar das semelhanças quanto à motivação e efeitos econômicos e sociais de ambos os tipos de migração, a distinção entre migrações internas e internacionais é importante por revelar características culturais da migração, bem como, aspectos legais e condições de viagem dos migrantes. $\mathrm{O}$ sentido dos movimentos migratórios vincula-se aos processos de inscrição dos indivíduos no mercado de trabalho (RENNER e PATARRA, 1980).

Neste sentido, poder-se-iam identificar três dimensões do processo migratório: o individual, com a busca da melhora da situação de vida; o interesse do lugar de partida, geralmente com um mercado de trabalho saturado, para o qual a migração desempenha um papel de válvula de escape; e o interesse do local receptor, muitas vezes carente de mão de obra, que se utiliza do poder sedutor para atrair os insatisfeitos com a sua situação (GEORGE, 1977).

São, porém, os fatores de expulsão que definem a origem dos fluxos migratórios, sendo os fatores de atração os determinantes da orientação destes fluxos. Consequientemente, são as oportunidades econômicas que se constituem em principais fatores de atração (SINGER, 1981).

De maneira geral, a migração provém da necessidade de realizar aquilo que se compreende ser impossível em seu próprio meio, por isso assenta-se em uma esperança. Assim, as migrações internacionais, por representarem geralmente uma ruptura com o país 
de partida, mostram-se mais penosas, sendo a adaptação tanto mais fácil quanto menor a distância inicial. A migração sempre alicerça-se em uma esperança e quanto maior o esforço de ruptura, maior a crença em obter êxito (GEORGE, 1977).

À mobilidade associa-se, enfím, a ruptura com suas origens, determinada pela necessidade de readaptação social, cultural e econômica. Ruptura esta que, segundo SABROZA e LEAL (1992), conduz, muitas vezes, à mudança no comportamento, podendo aumentar o risco de contrair tanto as doenças infecciosas quanto as de natureza crônica. Portanto, conforme ROUQUAYROL (1988), diferentes formas de adoecer e morrer entre grupos étnicos distintos, compartilhando espaço comum, expressam, muito mais, padrões de comportamento apreendidos do que diferenças biológicas geneticamente herdadas.

\subsubsection{Determinantes da imigração internacional japonesa para o Brasil}

No contexto da imigração internacional, os deslocamentos populacionais ocorridos nos séculos XIX e XX constituem os maiores ocorridos na história da humanidade. A migração deste período, iniciada na Europa, foi decorrente das profundas mudanças na mentalidade popular da Europa, onde as idéias de igualdade e liberdade expandiam-se pelos países, influenciadas pelos ideais da Revolução Francesa. É neste período que ocorre, também, a migração japonesa (TAJIRI e Y AMASHIRO, 1992).

No entanto, a história da migração japonesa em comparação a de vários outros países apresenta um visível atraso. O Japão viveu um processo de isolamento, em relação ao mundo ocidental, que durou até 1854. Em 1885 adquire importância a emigração japonesa, a princípio com deslocamentos para o Havaí, depois Estados Unidos, Peru, México e, a partir de 1908, para o Brasil (TAJIRI e YAMASHIRO, 1992). 
YAMOCHI (1991), baseado em alguns autores, descreve que o Japão, após 1886 (restauração Meiji), vivia uma situação dramática, caracterizada por uma superpopulação, desemprego real, seca, altos tributos, levando a um movimento migratório intenso, inicialmente, deslocamentos internos e, posteriormente, para outros países. Os que migravam eram aqueles que não tinham nenhuma possibilidade de ascensão social e política, por isso, nenhuma segurança econômica, como os não sucessores de propriedade (tradicionalmente o sucessor era o primogênito), agricultores ou os não proprietários de terras.

Para HANDA (1987), por trás de uma política de emigração para os paupérrimos habitantes dos campos e das cidades, estavam as razões econômicas e sociais. O surto de modernização do Japão foi impulsionado, em caráter urgente e artificial, pelas classes dirigentes. A transição da era feudal à capitalista trouxe reflexos para a comunidade rural, até então submetida a velhos padrões, onde uns perderam terras e outros ficaram desempregados. Assim, ao mesmo tempo em que emigrantes buscavam outros países, vivia-se no mundo novo uma época em que empresários agrícolas, possuindo enormes extensões de terras, tinham que chamar trabalhadores assalariades para prosseguir com a produção, após abolição da escravatura.

Quanto à situação histórica no Brasil, no final do século XIX, era marcada por profundas transformaçōes na estrutura econômica e política da sociedade brasileira, das quais a substituição da base econômica açucareira pela cafeeira determinou o incremento da imigração estrangeira para as novas frentes de trabalho e ocupação de espaços recémcriados. Também, a promulgação da Lei Áurea (1888), concedendo liberdade a todos os escravos negros do Brasil, gerou a falta de trabalhadores na lavoura, determinando assinatura de vários acordos de imigração (REZENDE, 1991).

A chegada do vapor Kasato-Maru, no porto de Santos, em 18 de junho de 1908, marca 0 início da emigração japonesa para o Brasil Neste período a crise da cafeicultura já havia se manifestado e como conseqüêucia do plantio desordenado, houve uma 
superprodução. Apesar de vários problemas, inclusive relacionados à adaptação à nova realidade (condições de moradia, diferenças culturais de língua), a imigração japonesa no Brasil foi crescente, até atingir o auge entre 1926 e 1940. Mas, a emigração japonesa para vários lugares, comparada à emigração de alguns outros países, foi pequena e teve duração curta. Da era Meiji à II Guerra Mundial (79 anos), o total de emigrados japoneses foi de 1.013.000 pessoas, que pode ser pouco diante dos mais de 10.000 .000 de italianos que emigraram no mesmo período (TAJIRI e YAMASHIRO, 1992).

Para os migrantes japoneses que vieram ao Brasil, os objetivos de sua emigração eram escapar da pobreza dominante na terra natal e um futuro melhor representado pela promessa do café brasileiro. Aliás, foram convencidos a pensar assim pela propaganda promocional dos agentes da emigração. Conforme CGUIDO (1988), os primeiros imigrantes já saíram do Japão contratados para trabalhar nas lavouras cafeeiras do Estado de São Paulo e desejavam fazer fortuna imediata, para regressar ao Japão e viver bem.

YAMOCHI (1991), realizando um estudo sobre a ocupação do espaço de uma localidade do Norte do Paraná pelos imigrantes japoneses, levanta, entre as razões que motivaram a vinda destes japoneses para o Brasil, a dificuldade de sobrevivência no Japão e o desejo de ganhar dinheiro. $\mathrm{O}$ autor conclui afirmando que os processos migratórios são sempre de cunho estrutural e são determinados pelas condições sociais e econômicas impostas a determinadas classes sociais. Atribui, a estas questões, o surgimento do fenômeno "dekassegui" do Brasil para o Japão (deslocamento temporário de japoneses e seus descendentes residentes no Brasil, para o Japão, em busca de emprego), a partir de 1988.

\subsubsection{Processo de aculturação dos imigrantes japoneses no Brasil}

Uma política da imigração deveria "contemplar três fatores: o econômico, o demográfico e o cultural" (GEORGE, 1977). Ao se considerar a existência de uma 
diversidade cultural na humanidade ( variável conforme povos ou grupos étnicos) e que, através do conhecimento e da partilha de um sistema cultural, os membros de uma sociedade se relacionam (LARAIA, 1993), a migração de vizinhança cultural (parentesco lingüístico, a identidade ou semelhança dos sistemas de valores e crenças) promoveria mais facilmente a assimilação. Porém, as questões culturais, no interior de uma política de imigração, têm lugar mais ou menos importante, conforme a necessidade imediata da economia (GEORGE, 1977).

No caso da imigração japonesa para o Brasil, à época do início da entrada destes imigrantes, havia uma preferência pelo europeu, em razão da maior proximidade cultural. Além disso, as experiências negativas da imigração chinesa para os Estados Unidos, como manutenção de costumes, da religião, da língua, e da prática de suicídio em situação de desespero, contribuíram para a formação de um estereótipo dos orientais de modo geral (NOGUEIRA, 1992).

Porém, há de se considerar que o panorama das imigrações mundiais, ocorridas nos finais do século XIX e início do século XX, caracterizava-se como uma fase de desenvolvimento econômico cuja exigência era por grandes massas de trabalhadores, para cultivar espaços virgens (GEORGE, 1977), o que justifica de certa forma a aceitação dos imigrantes japoneses no Brasil.

Dentre os povos migrantes que vieram ao Brasil, a singularidade cultural do povo japonês, no entender de Saito citado por YAMOCHI (1991), representou a que apresentava maior distância relativamente à cultura brasileira e certamente isto dificultou a integração e a adaptação ao país de chegada. Há de se ressaltar que o povo japonês, através de séculos, manteve-se isolado, conforme explica sua história; desenvolveu instituições, costumes e características que lhes proporcionaram um acentuado espírito de identidade e propósito comum, com uma atitude de pouca assimilação e adoção de novas idéias ao seu meio ambiente cultural particular. A sua geografia (figura 1) também contribuiu para o processo de isolamento, pois a mesma é formada por quatro ilhas principais (Hokkaido, 
Honshu, Shikoku e Kyushu) além de numerosas cadeias de ilhas e ilhotas (MINISTÉRIO DOS NEGÓCIOS ESTRANGEIROS DO JAPÃO, 1972).

\section{Figura 1}

Mapa do Japão

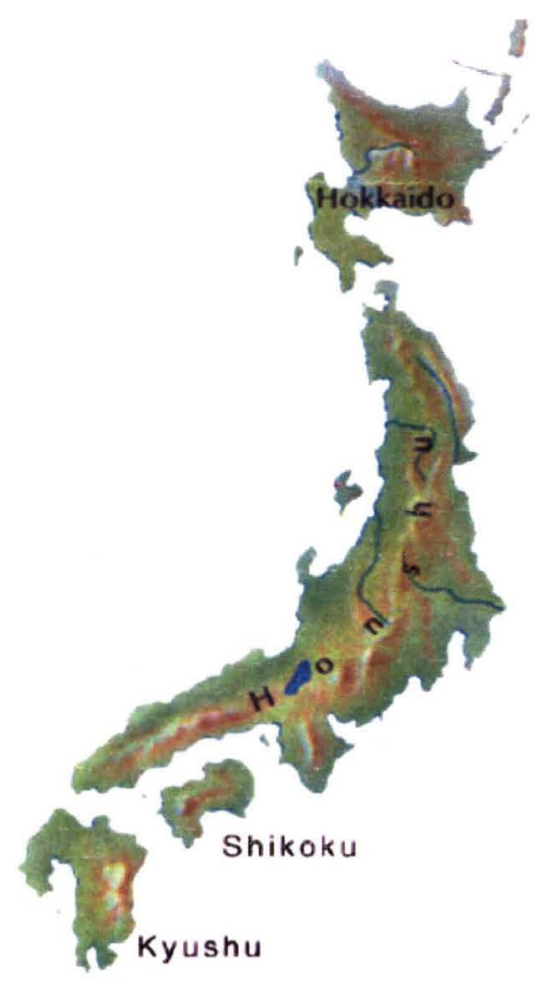

O processo de aculturação do imigrante japonês no Brasil encontrou fortes barreiras no início (KIYOTANI e YAMASHIRO, 1992); estas poderiam ser atribuídas a algumas questões colocadas por GEORGE (1977) quanto à aculturação do povo migrante, de modo geral, ao local de chegada. Neste sentido, levanta que:

- a assimilação ocorre com maior facilidade quando há parentesco lingüístico e semelhança no sistema de valores e crenças. A integração do imigrante à população do país é mais fácil e rápida se não for excessivamente grande a distância inicial entre as culturas;

- a manutenção da língua do país de origem nas famílias de imigrados representa, de certa forma, a intensidade de persistência dos laços da tradição original; 
- a manutenção das coletividades etnoculturais é, seguramente, um dos indicadores da dificuldade e lentidão da integração. Todavia, certas circunstâncias impõem a ruptura com a cultura do país de partida, como a consciência do imigrante de ter atingido uma situação irreversível criando a obrigação de se interagir ao meio. A vida dos imigrantes no país que os recebe é muito diferente, conforme se considerem eles próprios residentes, temporários e estrangeiros de longo prazo ou futuros nacionais.

Relativamente à imigração japonesa, as profundas diferenças entre uma cultura e outra obrigaram os japoneses a abrir mão de muitos hábitos e costumes (OGUIDO, 1988). Os primeiros imigrantes chegavam cheios de esperança às fazendas de café do Estado de São Paulo; entretanto, antes mesmo de transcorrer um mês, emergiam vários problemas, tais como, más condições de habitação e alimentação, dificuldade de entendimento da língua, diferenças nos usos e costumes, cafeeiros velhos de reduzida produtividade. Além disso, o sentimento de superioridade dos imigrantes, que se julgavam súditos de uma potência, pelo fato do Japão ter sido vitorioso das guerras contra China (1894-5) e Rússia (1904-5), aos poucos, foi fenecendo diante das dificuldades enfrentadas (KIYOTANI e YAMASHIRO, 1992).

É interessante ressaltar que, por causa da idéia do caráter temporário de sua permanência no país, não se preocupavam em adaptar-se à sociedade brasileira, nem em participar mais efetivamente dos problemas gerais do país (OGUIDO, 1988). O café brasileiro representava a promessa de futuro melhor para os imigrantes que vieram com o objetivo de ganhar dinheiro e regressarem ricos, por isso, a educação dos filhos colocava-se como prioridade, para evitar que houvesse problemas de comunicação com parentes e amigos, ạo regressarem ao Japão. Formavam-se, assim, colônias, abriam-se escolas e ensinavam as crianças a ler e escrever em japonês, no sentido de preservar costumes (KIYOTANI e YAMASHIRO, 1992).

Apesar de muitos problemas e de terem chegado no momento em que a crise da cafeicultura já havia se manifestado, a imigração japonesa no Brasil foi crescente. Em 36 
anos (1904-40) entraram no país mais de 170.000 japoneses (KIYOTANI e YAMASHIRO, 1992). No entanto, após alguns anos a esperança de enriquecer e retornar à pátria foi gradativamente abandonada, diante das péssimas condições de vida e de trabalho. Compreenderam, então, que o regresso ao Japão não aconteceria a curto ou médio prazo. Se na fase de colonos tivessem sido bem sucedidos, a maioria teria retornado ao Japão. Em 1937, um levantamento realizado com 24 mil imigrantes revelava que $85 \%$ pretendiam retornar ao Japão, $10 \%$ fixar-se no Brasil e 5\% não sabiam o que fazer. Entretanto, é importante ressaltar que tratava-se de uma época de regime autoritário, no Brasil, com nacionalismo bastante presente, onde ocorriam, inclusive, limitações quanto ao ensino da língua estrangeira (UCHIYAMA et al, 1992)

A idéia de se fixar no Brasil veio com o tempo, na medida em que se tornaram proprietários de terra ou, ainda, segundo YAMOCHI (1991), quando passaram a participar direta ou indiretamente do processo de "produção e reprodução do espaço na formação econômica da sociedade capitalista no Brasil".

Para OGUIDO (1988) a derrota do Japão na II Guerra Mundial foi determinante para que se desse uma assimilação gradual e integração dos hábitos e costumes brasileiros pelos isseis, acentuando a necessidade de permanecer no Brasil.

\subsubsection{Ocupação do espaço paranaense pelos imigrantes japoneses}

A entrada dos japoneses no Estado do Paraná foi impulsionada, principalmente, a partir da grave crise na cafeicultura brasileira e queda do preço do café, devido à superprodução e recessão na economia, iniciada em 1929. Em 1932, foi proibida a plantação do café no Estado de São Paulo e muitos agricultores deslocaram-se para o Norte do Paraná, onde existiam terras roxas e a plantação não estava proibida (UCHIYAMA et 
al, 1992). Neste período é que tem início a colonização do Norte do Paraná, acelerando também a penetração dos japoneses na região.

Além da questão econômica, dois outros fatores contribuíram para a instalação dos japoneses no Norte do Paraná:

- o primeiro refere-se à atração exercida pela Companhia de Terras do Norte do Paraná, subsidiária no Brasil da companhia inglesa "Brazil Plantation Syndicate Ltd". Esta empresa, após aquisição de grandes áreas de terras, revendia a pequenos proprietários, com a finalidade de cultivar o algodão para atender às necessidades de matéria-prima da indústria têxtil da Inglaterra (SOUZA, 1980). As terras comercializadas ficavam entre Jataizinho e Maringá, tendo como ponto central o Município de Londrina (figura 2), abrangiam uma área de 550.000 alqueires e propiciaram a entrada de imigrantes de 33 países, como pequenos proprietários rurais. Dentre os colonizadores, os de nacionalidade japonesa ocuparam a quarta posição, inferiores apenas aos brasileiros, italianos e alemães. Os japoneses, até 1950, haviam adquirido 7,9\% da área total (HANDA, 1987);

- o segundo fator relaciona-se à facilidade viabilizada pela Federação das Associações Ultramarinas, fundada em Tóquio, frente à necessidade de impulsionar o movimento migratório nas províncias japonesas. Esta federação era representada na cidade de São Paulo pela Sociedade Colonizadora do Brasil (BRATAC), que encaminhava os interessados no Japão para núcleos planejados. A BRATAC, além de financiar imigrantes, abria escolas, estradas e organizava serviços médicos. Vendia lotes localizados, no início de suas atividades (1928), no interior de São Paulo e no Norte do Paraná, a serem pagos, anualmente em um prazo de oito anos (VIEIRA, 1973). Especificamente quanto à motivação para a atuação da Companhia de Terras do Norte do Paraná, destaca-se a ascensão dos preços do algodão no mercado nacional e internacional, a partir de 1930 (SOUZA, 1980). A Fazenda Três Barras, posteriormente Municípios de Assaí e Uraí, instalada pela BRATAC, desenvolvia-se principalmente em função da cotonicultura. Assaí e Uraí (que significam, respectivamente, na língua japonesa, Sol Nascente e Por do Sol) constituem duas cidades do norte do Paraná colonizadas pelos imigrantes japoneses (OGUIDO, 1988). 
Figura 2

Mapa do Brasil e do Estado do Paraná.
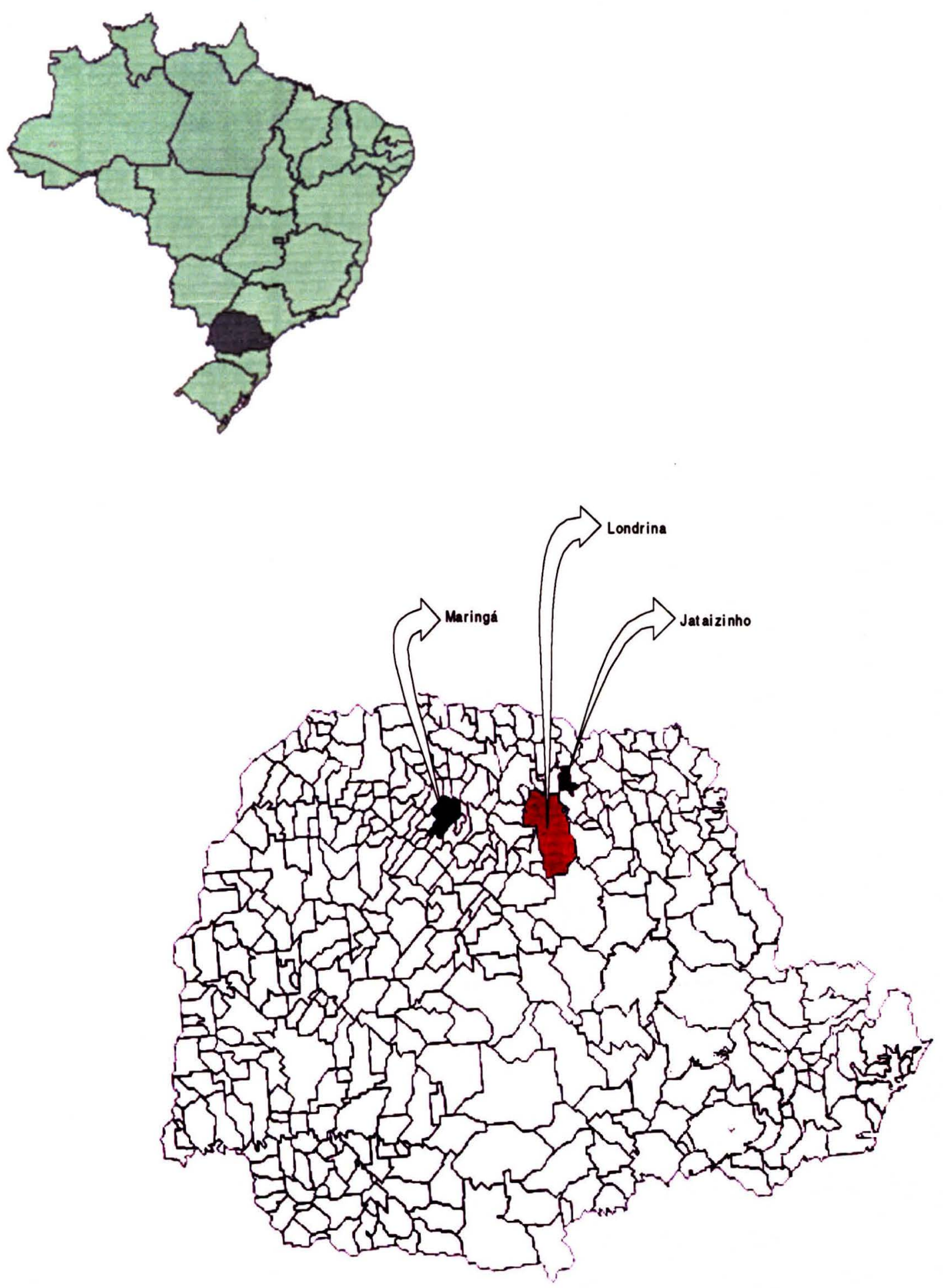
A atuação das companhias foi decisiva para a participação dos japoneses na colonização da região. Dos que se instalaram no norte do Estado, a maioria insere-se dentro de um processo migratório interno. Entraram como proprietários de suas terras, mas a grande parte era constituída de colonos de café que chegaram ao Brasil entre 1924 e 1933 e haviam trabalhado nas lavouras cafeeiras do Estado de São Paulo como colonos. De acordo com Saito, citado por YAMOCHI (1991), das 365 famílias japonesas que se instalaram na Fazenda Três Barras, entre 1932 e 1939, somente onze procediam diretamente do Japão.

Atualmente, as maiores concentrações de japoneses e seus descendentes, no Paraná, estão em Londrina, Curitiba, Maringá e Assaí. Em 1987, pesquisa realizada pelo CENTRO DE ESTUDOS NIPO-BRASILEIRO (1990) revelou que no Estado do Paraná residiam $8,96 \%$ dos 1.228.000 japoneses e seus descendentes do país, valor inferior apenas ao do Estado de São Paulo, que concentrava $72,23 \%$ da população japonesa radicada no Brasil.

\subsubsection{Perfil epidemiológico dos imigrantes japoneses e processo saúde- doença}

A idéia de que migração para novos lugares leva a mudança no padrão de doenças produziu uma vasta literatura científica sobre o perfil de morbimortalidade da população japonesa, sendo pioneiros os estudos realizados por GORDON $(1957,1967)$. São resultados de investigações desenvolvidas com a finalidade de melhor compreender os fatores associados à ocorrência das doenças crônico-degenerativas, mais especificamente as doençà isquêmicas do coração que, neste século, nos países industrializados, passaram a se constituir em uma das primeiras causas de morte (MARMOT, 1985). Por conseguinte, os japoneses, por apresentarem taxas de mortalidade relativamente baixas por doenças isquêmicas do coração, seus hábitos e costumes dos nativos e migrantes, têm sido referenciados com certa freqüência. 
Neste sentido, GORDON (1957, 1967), ainda nas décadas de 50 e 60, estabeleceu uma comparação entre a situação de mortalidade dos japoneses residentes em três áreas distintas (Japão, Havaí e Estados Unidos) e americanos. Em seus estudos observa uma notável diferença entre mortalidade de japoneses e americanos, por doenças cardíacas (menores taxas nos japoneses) e por lesões vasculares afetando o sistema nervoso central (maiores taxas nos japoneses).

Posteriormente, baseados nos achados de GORDON (1957, 1967), SYME e colaboradores (1975) analisam alguns fatores associados à ocorrência de tais doenças nos americanos e nos japoneses residentes nas mesmas áreas. Reafirmam os resultados apresentados por GORDON $(1957,1967)$ quanto às menores taxas de mortalidade por doenças isquêmicas do coração entre japoneses residentes no Japão, comparativamente àquelas dos isseis residentes nos Estados Unidos que, por sua vez, são inferiores às apresentadas pelos americanos "brancos" (WORTH et al, 1975). Quanto aos valores de taxas referentes às variáveis bioquímicas (colesterol sérico, glicose, ácido úrico e triglicérides) as mais baixas foram verificadas também para japoneses do Japão, relativamente às dos residentes no Havaí e na Califórnia (MICHAMAN et al, 1975).

Ainda dentro desta linha, MARMOT e SYME (1976) analisaram a participação dos fatores sócio-culturais nos diferenciais observados na ocorrência das doenças isquêmicas do coração. Constataram que os japoneses residentes nos Estados Unidos considerados mais tradicionais (de acordo com os índices de aculturação pré-definidos) tinham uma prevalência de doenças isquêmicas do coração tão baixa quanto a observada no Japão.

REED e colaboradores (1982), utilizando o mesmo protocolo de pesquisa de MARMOT e SYME (1976) em japoneses residentes na Califórnia, desenvolveram uma análise sobre a situação de aculturação dos japoneses residentes no Havaí. Evidenciam uma associação entre graus de aculturação e vários fatores de risco para doenças isquêmicas do coração, de tal forma que os japoneses mais tradicionais eram aqueles que 
apresentavam taxas mais baixas de colesterol e ácido úrico, menos obesidade, maior atividade física e menor consumo de cigarros.

Também no Brasil, linha de pesquisa semelhante foi adotada. GOTLIEB (1974), ao analisar a mortalidade proporcional de imigrantes japoneses residentes no Município de São Paulo, em 1968, constatou que o padrão de mortalidade dos japoneses e seus descendentes situava-se em nível intermediário quando comparado ao do Japão e ao da população em geral do Município de São Paulo. Outros estudos, abordando incidência de câncer (TSUGANE et al, 1990a; SOUZA et al, 1991) e mortalidade (TSUGANE et al., 1990b) em japoneses residentes na cidade de São Paulo, revelaram, entre outros achados, que as taxas de incidência de câncer de estômago e reto destas populaçōes são mais baixas do que a dos residentes no Japão e que as taxas de mortalidade de câncer de mama e próstata são mais altas. Sugerem, os autores, novas investigações que levem em consideração as mudanças nos padrões ambientais, incluindo hábitos alimentares.

Um estudo mais abrangente sobre o padrão de mortalidade, realizado por GOTLIEB (1990), compara as principais causas de óbito entre os residentes no Japão, Município de São Paulo e nos migrantes japoneses e seus descendentes residentes no Município, em 1980. Observa comportamentos distintos da mortalidade nas populações de estudo. Os isseis apresentam um padrão que se aproxima mais ao existente no Japão do que aquele em São Paulo, apesar de um afastamento paulatino dos isseis, relativamente ao padrão de mortalidade no Japão. Conclui destacando a necessidade de melhor compreensão da influência das mudanças sócio-culturais sobre a mortalidade e incidência de doenças nos migrantes.

Mais recentemente, TSUGANE e colaboradores (1994) desenvolveram um estudo seccional, sobre a situação dos fatores relativos ao estilo de vida de japoneses e seus descendentes residentes no Município de São Paulo, a fim de elucidar as razões que conduziram às mudanças nas causas de morte e na incidência de doenças. Evidenciam mudanças nos hábitos dietéticos, com maior ingestão de calorias total e gorduras entre 
japoneses de São Paulo em relação aos do Japão, às quais atribui a responsabilidade por um provável incremento na incidência das doenças isquêmicas do coração, câncer de próstata e mama e redução da ocorrência de doenças cerebrovasculares.

$\mathrm{Na}$ atualidade, a população japonesa ainda tem sido consideravelmente referenciada no contexto das discussões sobre a frequência das doenças crônicas e diferenças nos estilos de vida e cuidados com a saúde. LANDS e colaboradores (1992), discutindo a importante redução na mortalidade por doenças cerebrovasculares nos japoneses como consequiência da incorporação de hábitos salutares (no caso redução de alimentos altamente salgados na dieta), colocam que é inadequado assumir as características da dieta tradicional japonesa de 25 anos atrás como atual. Assim, à semelhança dos japoneses que migraram geograficamente para o Havaí e São Francisco (USA), os que permaneceram no Japão também mudaram os padrões de consumo, com consequêencias para a saúde.

HATANO (1989), discutindo mudanças na mortalidade por doenças cardíacas no Japão, destaca que, embora o coeficiente de mortalidade bruto aumente, o coeficiente de mortalidade padronizado por idade revela tendência a um declínio. Com base nestes dados, BEAGUEHOLE (1990) atribui tal declínio a uma provável mudança nos padrões alimentares de alguns segmentos da população japonesa. A partir destas considerações, ressalta a necessidade de, ao instituir programas de saúde voltados para a prevenção de doenças cardiovasculares, também enfatizar criação de ambientes saudáveis. Condições de saúde desiguais dentro de um mesmo país refletem a focalização dos tradicionais programas sobre os padrões individuais de comportamento. Novas abordagens devem, a partir do conhecimento dos efeitos deletérios, exercer influência para assegurar aos vários segmentos populacionais opção pelos comportamentos saudáveis.

Frente às questões colocadas, o presente estudo foi desenvolvido com a finalidade de analisar o perfil de mortalidade dos migrantes japoneses residentes em uma área específica e apontar alguns possíveis fatores que contribuíram para desenvolver agravos distintos quando comparados aos do seu país de origem. 
2. OBJETIVOS 
Frente ao pressuposto de que o padrão de mortalidade dos imigrantes japoneses residentes no Estado do Paraná, a exemplo do citado na literatura, também vem paulatinamente se diferenciando do padrão dos residentes no seu país de origem, os objetivos são:

\subsection{OBJETIVO GERAL}

- Analisar o padrão de mortalidade de isseis residentes no Estado do Paraná.

\subsection{OBJETIVOS ESPECÍFICOS}

- Comparar o padrão de mortalidade de isseis residentes no Estado do Paraná com o padrão apresentado pelos residentes no Japão e pelos residentes no Estado do Paraná.

- Descrever e analisar a mortalidade dos isseis segundo sexo, grupos etários e causas básicas, comparativamente às dos residentes no Japão e dos residentes no Estado do Paraná. 
3. MATERIAL E MÉTODO 


\subsection{DELINEAMENTO DO ESTUDO}

Estudo epidemiológico do tipo descritivo, onde são comparadas as experiências de mortalidade em três grupos: nascidos no Japão e residentes no Estado do Paraná (isseis), residentes no Japão e todos os residente no Estado do Paraná.

\subsection{FONTE DE DADOS}

As fontes consultadas foram as seguintes:

-ISSEIS - A população de isseis residentes no Estado do Paraná foi estimada a partir dos dados relativos à amostra da população residente no Estado do Paraná, por ocasião do X Recenseamento Geral do Brasil, realizado pela Fundação IBGE. De posse dos disquetes contendo dados amostrais, foi inferida a população de isseis segundo sexo e grupo etário (intervalos qüinquenais) para primeiro de setembro de 1991.

As informações quanto à mortalidade foram selecionadas no Sistema de Informação de Mortalidade do Ministério da Saúde - SIM/MS - e apuradas a partir do campo referente à naturalidade do falecido (código 152 ) da declaração de óbito. Fizeram parte do estudo todos os isseis residentes no Estado do Paraná, falecidos em qualquer unidade da Federação entre primeiro de março de 1990 e 28 de fevereiro de $1993(n=969)$. Este período foi estabelecido de tal forma que a data do Recenseamento Geral do Brasil (01/09/91) correspondesse ao meio do período estudado, conforme recomendam LAURENTI e colaboradores (1987), quando do cálculo de coeficientes, no qual o denominador da equação deve ser representado pela população de expostos, no meio do período estudado.

- JAPÃO - O número de residentes no Japão em primeiro de julho de 1991 foi estimado com base nos dados dos Censos de 1 de outubro de 1985 e 1990, datas de 
realização dos Recenseamentos no Japão, utilizando-se método geométrico de projeção de população (LAURENTI, 1987). Após obtenção da população total, estimou-se a distribuição por grupos etários (intervalos qüinqüenais), aplicando-se a proporção relativa a cada estrato, por ocasião do recenseamento de 1990 (anexo 1).

Quanto aos óbitos, compreendem os óbitos de residentes no Japão em 1991. Estes dados foram extraídos do Japan Vital Statistics (JAPAN, 1992).

- ESTAdO DO PARANÁ - A população do Estado do Paraná foi estimada (01/07/91) a partir dos dados do IX e X Recenseamentos Gerais do Brasil (primeiro de setembro de 1980 e de 1991), utilizando os mesmos procedimentos descritos para a população japonesa (Anexo 1).

Os óbitos referem-se a todos os residentes no Estado do Paraná, falecidos no país em 1991, identificados a partir do estado de residência constante na declaração de óbito, no banco de dados do Sistema de Informação de Mortalidade do Ministério da Saúde.

\subsection{PROCEDIMENTOS}

Após obtenção dos dados relativos às populações de estudo, procedeu-se à construção dos seguintes indicadores: proporções; coeficientes de mortalidade específicos por grupos de idades e causas; coeficientes de mortalidade padronizados em indivíduos de 50 anos e mais; razão de mortalidade padronizada em indivíduos de 50 anos e mais e respectivo intervalo de confiança.

Todos os dados apresentados foram estratificados por sexo. Tal decisão deveu-se ao fato das populaçōes estudadas apresentarem diferenças expressivas na composição por sexo, conforme observa-se nos dados que se seguem. Autores como BERQUÓ (1980) e 
LAURENTI e colaboradores (1987) comentam que na maioria dos processos migratórios observa-se um excedente de homens em relação às mulheres. Este diferencial traduz-se na alteração do padrão de mortalidade da população geral quando analisados conjuntamente, como resultado da participação maior ou menor de cada sexo, com seus riscos específicos, sócio-cultural ou geneticamente determinados.

Outra questão que se reveste de importância no presente estudo refere-se às marcantes diferenças nas estruturas etárias das três populaçōes. Buscou-se contornar tal problema a partir da comparação de coeficientes padronizados por idade, em indivíduos de 50 anos e mais. Tal decisão, deveu-se à peculiaridade da população migrante que, no caso do estudo, é representada em quase sua totalidade (90\%) por pessoas de 50 anos e mais.

As causas de óbito analisadas foram aquelas já selecionadas e codificadas como causa básica, pelo Sistema de Informação de Mortalidade do Ministério da Saúde com base na Classificação Internacional de Doenças (CID) - Nona Revisão (ORGANIZAÇĀO MUNDIAL DA SAÚDE, 1978). A apresentação dos dados de mortalidade segundo causas foi de acordo com 17 Seções ou Capítulos da CID e segundo Agrupamentos de causas, de interesse do estudo.

\subsubsection{Do cálculo da mortalidade proporcional}

Foi calculada, para indivíduos de 50 anos e mais, a proporção de b́bitos por Capítulos da CID - 9 e de algumas Categorias de três algarismos ou Agrupamentos de causas, a-fim de avaliar o peso de determinadas causas no conjunto do obituário das populações estudadas. Este cálculo foi realizado separadamente para cada sexo, em função do comportamento distinto das causas de morte em cada sexo. 


\subsubsection{Do cálculo de coeficientes de mortalidade por grupos etários}

Foram calculados coeficientes de mortalidade em cada grupo etário (intervalos quiinqüenais) para alguns Agrupamentos de causas, para cada sexo, a fim de buscar uma aproximação ao risco de morte em determinadas idades. No caso dos isseis, para cálculo de coeficientes, o denominador da equação foi constituído, pelo triplo da população estimada para primeiro de setembro de 1991, tendo em vista o período de abrangência dos óbitos.

\subsubsection{Do cálculo de coeficientes de mortalidade padronizados}

Para análise comparativa da mortalidade por causas, foram calculados, para cada sexo, coeficientes de mortalidade padronizados em indivíduos de 50 anos e mais, ajustados por idade, considerando como padrão a população mundial de 50 anos e mais (SMITH, 1992), apresentada no anexo 2.

Para PEREIRA (1995), é preciso cuidado na escolha da população padrão, uma vez que uma opção inadequada pode introduzir distorções nos resultados, favorecendo uma ou a outra população, por questão de maior ponderação de certas categorias etárias. Recomenda, até mesmo, o uso de mais de uma população, para esses cálculos, de modo a verificar a concordância dos resultados das padronizações. No tocante ao presente estudo optou-se pela apresentação dos coeficientes ajustados pela população mundial de 50 anos e mais. Este procedimento permitiu a comparação das taxas de mortalidade entre os grupos populacionais estudados, assim como, entre os sexos na mesma população.

\subsubsection{Razões de mortalidade padronizadas por idade e respectivos intervalos de confiança}

Foram calculadas razões de mortalidade padronizadas para algumas causas de óbito, entre as populações estudadas, como recurso para estimativa de diferentes níveis de 
exposição a possíveis fatores de risco. Tal procedimento teve por base as proposições de RUMEL (1988) que, após revisão, recomenda o uso das razōes de mortalidade padronizadas (RMP) como um instrumento para comparação de níveis de saúde entre duas populações (a de estudo e a de referência), que diferem quanto à exposição a um possível fator de risco para determinadas doenças. Considera uma "medida de intensidade da associação", semelhante ao risco relativo, que pode ser obtida por meio da divisão de coeficientes gerais de mortalidade padronizados, por idade, da população de estudo e da população de referência.

Após obtenção de RMP para algumas causas selecionadas de óbito entre populações de estudo, procedeu-se o cálculo de intervalos de confiança (95\%), com base em SMITH (1992), de tal forma que a inclusão do valor igual a unidade, no intervalo, significa inexistência de diferença entre as taxas comparadas em um nível de significância de $5 \%$. As fórmulas para cálculo dos limites do intervalo de confiança - IC - foram as seguintes:

$$
\begin{aligned}
& \text { - limite superior do } \mathrm{IC}_{95 \%} \text { da RMP }=\left(\frac{R_{1}}{R_{2}}\right)^{1+z / \chi} \\
& \text { - limite inferior do IC } 95 \% \text { da RMP }=\left(\frac{R_{1}}{R_{2}}\right)^{1-z / \chi}
\end{aligned}
$$

onde:

$$
\chi=\left(\frac{R_{1}-R_{2}}{\sqrt{\left(S_{1}^{2}+S_{2}^{2}\right)}}\right)
$$

$R_{1}=$ Taxa padronizada na população de estudo e $S_{1}{ }^{2}$ sua respectiva variância $R_{2}=$ Taxa padronizada na população de referência e $S_{2}{ }^{2}$ sua respectiva variância $z=1,96$ em nível de $5 \%$ 


\subsection{QUALIDADE E COBERTURA DAS FONTES DE DADOS}

No tocante ao presente estudo, alguns aspectos relativos às fontes de dados merecem ser discutidos:

a) a representatividade da população analisada - É provável que os números de residentes no Japão, no Estado do Paraná e de isseis residentes no Paraná, obtidos das fontes consultadas, sejam representativos pois são provenientes de recenseamentos considerados de boa qualidade e cobertura.

b) a representatividade dos óbitos de isseis residentes no Estado do Paraná - Um primeiro aspecto a ser discutido refere-se ao procedimento adotado para a identificação dos isseis, residentes no Estado do Paraná, no período de abrangência do estudo. Uma noção da representatividade pode ser fornecida estabelecendo-se uma comparação entre o procedimento adotado neste estudo e naquele conduzido por GOTLIEB (1988) que, para a definição dos óbitos de isseis residentes no Município de São Paulo, analisou todas as declarações de óbito (DO) a partir do nome, selecionando aquelas que se referiam a imigrantes japoneses. Deste modo, identificou 2346 óbitos de residentes no Município de São Paulo, falecidos entre primeiro de janeiro de 1979 e 31 de dezembro de 1981. Na fonte aqui consultada, SIM/MS, os óbitos de japoneses residentes no Município de São Paulo, identificados a partir do campo da DO referente à naturalidade do falecido, para o mesmo período, totalizaram 2535 casos. Tal fato é indicativo da sensibilidade do código relativo à naturalidade, constante na DO, na identificação da população de estudo, dado que os procedimentos adotados por GOTLIEB (1988) levaram em consideração, além da naturalidade, o nome e sobrenome do falecido. Por outro lado, uma possível explicação para o excedente aqui obtido de 189 eventos poderia ser atribuído aos residentes no Município de São Paulo que vieram a falecer fora do mesmo, pois da investigação de GOTLIEB (1988) não fizeram parte os eventos ocorridos fora do Município, por partir das Declarações de Óbito arquivadas, única e exclusivamente, por local de ocorrência e registro, na Fundação Sistema Estadual de Análise de Dados Estatísticos (FSEADE). 
Corroboram tais questões os dados das tabelas 1 e 2 , onde verifica-se que, com exceção de pequenas diferenças para algumas faixas etárias, as maiores freqüências são observadas no Sistema de Informações de Mortalidade do Ministério da Saúde. Porém há de ressalvar que a qualidade das informações do Município de São Paulo é, reconhecidamente, de qualidade superior à da maioria dos estados da Federação (CASTRO PAUlA et al, 1994), mas o Sistema de Informação de Mortalidade em nível de Estado do Paraná vem sendo objeto de constante melhoria (DOUSTDAR e PEREIRA, 1991), indicando que é possível buscar uma aproximação, quanto à qualidade dos dados, na situação observada em São Paulo.

\section{Tabela 1}

Número de óbitos em japoneses residentes no Município de São Paulo segundo sexo, grupo etário e fonte de informação, 1979-81.

\begin{tabular}{crrrr}
\hline \multirow{2}{*}{ Grupo etário } & \multicolumn{2}{c}{ SIM/MS* } & \multicolumn{2}{c}{ Gotlieb** } \\
& Masc. & Fem. & Masc. & Fem. \\
\hline 0 a 4 & 2 & 1 & 1 & - \\
5 a 9 & - & - & - & - \\
10 a 14 & - & - & - & - \\
15 a 19 & 1 & 1 & - & - \\
20 a 24 & 4 & 1 & 4 & 1 \\
25 a 29 & 7 & 2 & 8 & 2 \\
30 a 34 & 8 & 1 & 8 & 2 \\
35 a 39 & 5 & 1 & 4 & 1 \\
40 a 44 & 18 & 7 & 16 & 7 \\
45 a 49 & 36 & 25 & 33 & 24 \\
50 a 54 & 84 & 47 & 73 & 40 \\
55 a 59 & 117 & 67 & 103 & 60 \\
60 a 64 & 167 & 83 & 161 & 72 \\
65 a 69 & 228 & 118 & 222 & 108 \\
70 a 74 & 214 & 133 & 195 & 129 \\
75 a 79 & 196 & 177 & 175 & 166 \\
80 a 84 & 203 & 204 & 184 & 195 \\
85 e + & 135 & 242 & 126 & 226 \\
\hline Total & 1425 & 1110 & 1313 & 1033 \\
\hline
\end{tabular}

* Ministério da Saúde - Sistema de Informaçōes de Mortalidade ** GOTLIEB, 1988. p.13 


\section{Tabela 2}

Mortalidade proporcional (\%) em japoneses residentes no Município de São Paulo segundo principais causas básicas (capítulos da CID-9) e fonte de informação, 1979-81.

\begin{tabular}{lccrr}
\hline \multirow{2}{*}{ Causas de morte } & \multicolumn{3}{c}{ SIM/MS* } & \multicolumn{2}{c}{ Gotlieb** } \\
& Masc. & Fem. & Masc & Fem. \\
\hline Infecciosas e parasitárias & 2,2 & 1,4 & 1,9 & 1,1 \\
Neoplasmas & 21,6 & 15,3 & 22,2 & 16,6 \\
Endócrinas*** & 3,2 & 7,0 & 3,3 & 6,6 \\
Aparelho circulatório & 45,1 & 53,2 & 45,2 & 52,9 \\
Aparelho respiratório & 10,6 & 9,2 & 10,7 & 9,7 \\
Aparelho digestivo & 5,9 & 4,6 & 5,8 & 4,4 \\
Mal definidas & 1,4 & 2,4 & 2,2 & 1,9 \\
Externas & 6,8 & 2,3 & 6,1 & 2,1 \\
\hline * Ministério da Saúde - Sistema de Informações de Mortalidade \\
** GoTLIEB, 1988. p.48-9
\end{tabular}

Quanto à diferença entre as proporções de óbitos por causas externas, em que os valores mais elevados, para ambos os sexos, são observados nos dados apurados do Sistema de Informação de Mortalidade, reforça a idéia da qualidade e sugere que as diferenças foram função dos casos de evasão de óbitos, principalmente por acidentes de trânsito de veículos a motor, isto é, ocorreram fora do município e, por conseguinte, as declarações de óbito (DO) estavam arquivadas no local de ocorrência.

Relativamente à cobertura da mortalidade de isseis do Estado do Paraná, mesmo sem se reportar a estudos específicos, uma noção pode ser fornecida na conferência da listagem de nomes das pessoas classificadas como naturais do Japão, falecidas em 1992. Embora, habitualmente, nos processamentos das informações das DO pelo Sistema Estadual de Mortalidade, não conste o nome das pessoas falecidas, observa-se que, entre os dados relativos ao ano de 1992, está contido o nome completo da pessoa. Deste modo, com a impressão da listagem dos nomes, daqueles nascidos no Japão, verificou-se que, na sua 
totalidade, tanto os nomes quanto os sobrenomes eram de origem japonesa, demonstrando uma alta sensibilidade do código da DO, referente à naturalidade, para identificação dos imigrantes japoneses.

Quanto à representatividade do período estudado, um outro importante fator a ser discutido no uso de coeficientes, para expressar resultados coerentemente, refere-se à presença de estabilidade, o que interfere na questão da validade externa (ou seja, os dados analisados refletem a situação de mortalidade dos isseis do Paraná ou representam apenas o período analisado). Segundo PEREIRA (1995), quando indicadores são calculados para períodos curtos ou a população é de tamanho reduzido ocorre o que se denomina de coeficientes de pouca estabilidade. No estudo, a opção pela análise da mortalidade de japoneses do Estado do Paraná como um todo (sem estratificação por região geográfica ou por municípios com certa especificidade cultural e possivelmente em sua nosografia) e abrangendo um período de três anos deveu-se à tentativa de minimizar tal efeito, dado o fato do número de pessoas expostas ser bastante reduzido, diferentemente, da população do Japão e do Estado do Paraná.

No caso do presente estudo, a análise da série histórica, entre 1979 e 1993, da mortalidade proporcional por principais causas demonstra a instabilidade do dado relativo a um único ano, o que justifica agrupar os dados a fim de evitar analisar anos atípicos. As figuras 3 e 4 permitem verificar que este problema pode ser atenuado ao agrupar por períodos de três anos.

Apesar de tais recursos, no caso da mortalidade por causas específicas de ocorrêncią menos freqüente, como por exemplo, câncer de colo uterino e câncer de pulmão no sexo feminino, mesmo considerando os dados do triênio, a discussão sobre a relevância destas causas, na população de isseis, foi inviabilizada, conforme permite averiguar o exame dos indicadores que se segue. Ressalte-se que a padronização de coeficiente por idade, recurso utilizado para minimizar o efeito da estruturas etárias desiguais entre as 
populações estudadas, foi capaz, no caso das doenças de ocorrência limitada, acentuar a distorção.

\section{Figura 3}

Mortalidade proporcional segundo principais causas*. Isseis do sexo masculino, Estado do Paraná, 1979-93.

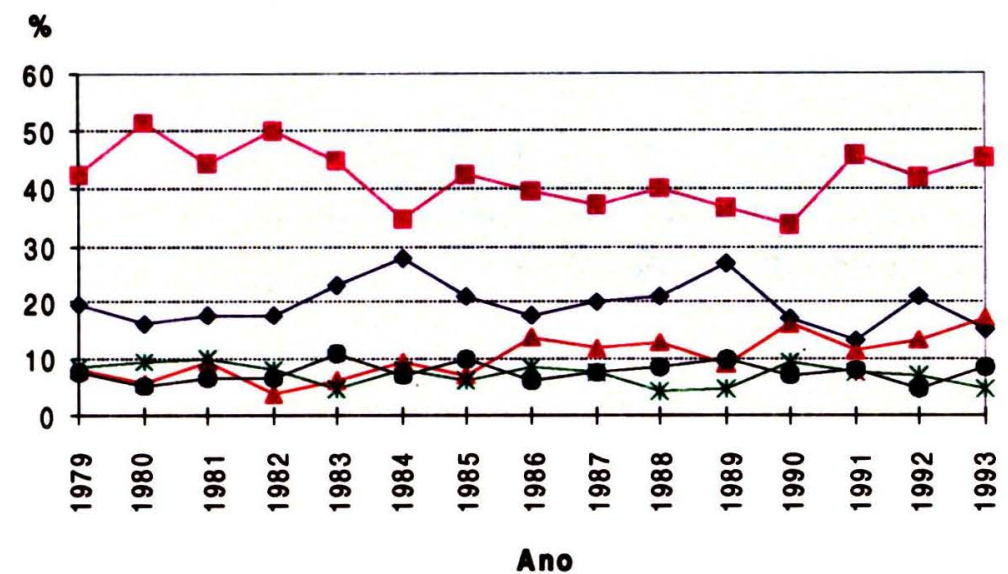

$$
\begin{aligned}
& - \text { II } \\
& -- \text { VII } \\
& -- \text { VIII } \\
& - \text { XVI } \\
& - \text { XVII }
\end{aligned}
$$

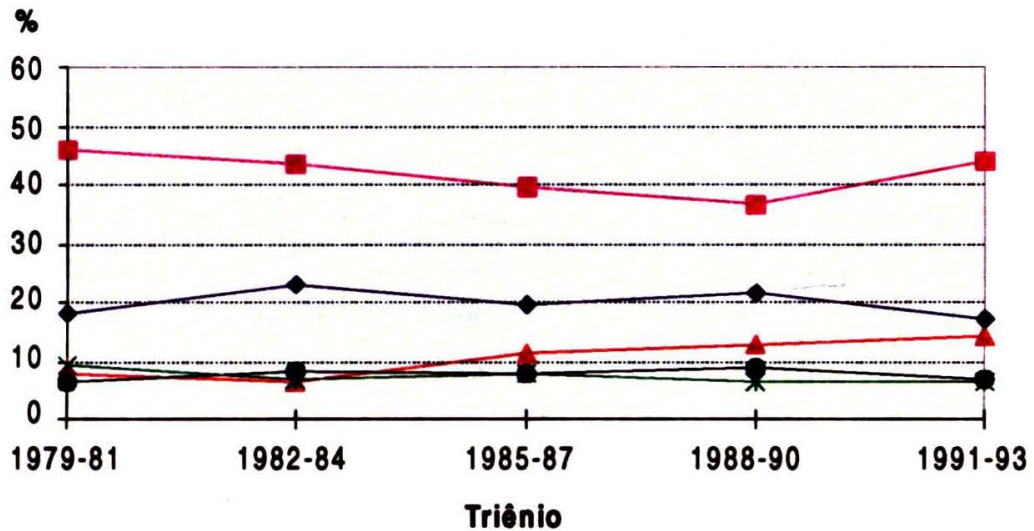

*Capítulos da CID - 9

II - Neoplasmas (140-239)

VII - Doenças do aparelho circulatório (390-459)

VIII - Doenças do aparelho respiratório (460-519)

XVI - Sintomas, sinais e afecções mal definidas (780-799)

XVII - Causas externas (E800-E999) 


\section{Figura 4}

Mortalidade proporcional segundo principais causas*. Isseis do sexo feminino,

Estado do Paraná, 1979-93.

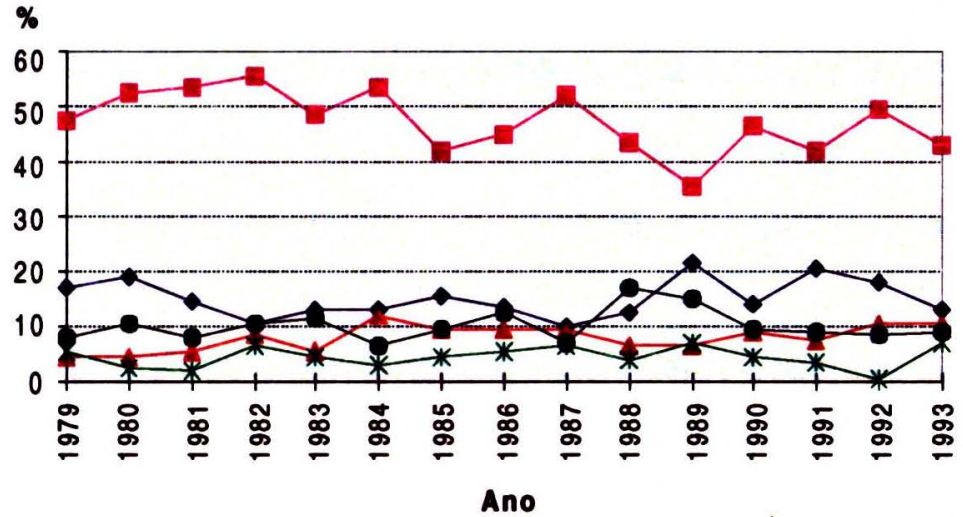

$\rightarrow$ II
$--\mathrm{VII}$
$-\mathrm{VIII}$
$-\mathrm{XVI}$
$-\mathrm{XVII}$

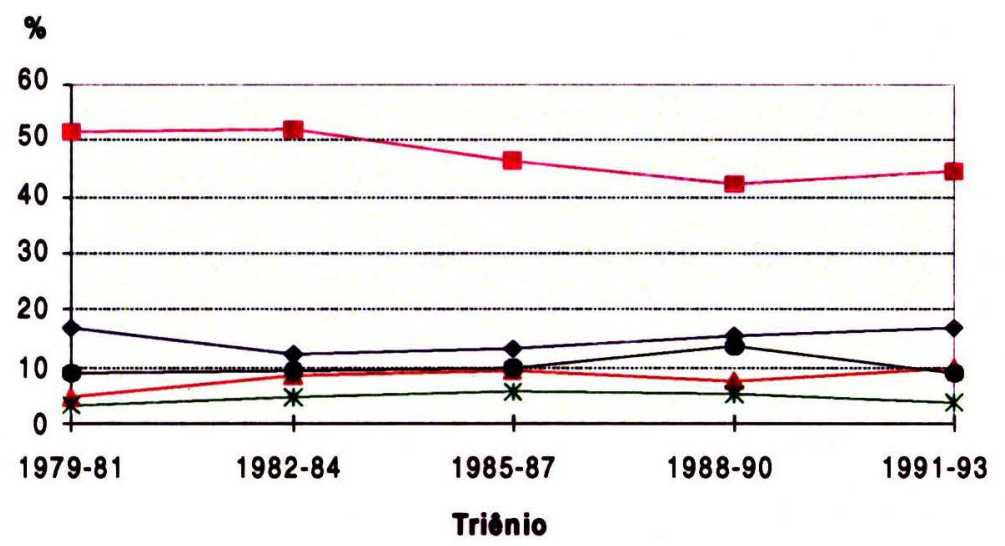

*Capítulos da CID - 9

II - Neoplasmas (140-239)

VII - Doenças do aparelho circulatório (390-459)

VIII - Doenças do aparelho respiratório (460-519)

XVI - Sintomas, sinais e afeç̧ões mal definidas (780-799)

XVII - Causas externas (E800-E999) 
Outro importante problema é aquele que pode advir do preenchimento incorreto das causas de óbito nas declarações de óbito, impossibilitando as comparações. Autores como Tsugane, que vem realizando inúmeras investigações comparativas de áreas geográficas, salienta que as diferenças nas práticas diagnósticas e de codificação da declaração de óbito constituem-se maiores problemas para comparações internacionais. No caso específico das comparações entre Japão e Brasil, ressalta que não existem dados disponíveis sobre a comparabilidade da acurácia do diagnóstico entre os dois países, mas que estudos desenvolvidos em São Paulo, no tocante às doenças do aparelho circulatório, são compatíveis com aqueles sobre japoneses morando nos Estados Unidos. As diferenças mudam na mortalidade por câncer entre imigrantes do Brasil comparada com a observada nos Estados Unidos, o que atribui à presença de diferentes respostas para imigração para países ocidentalizados (TSUGANE et al, 1990b).

No Brasil, embora a qualidade dos dados apresente grandes disparidades regionais, o Estado do Paraná, a exemplo de São Paulo, relativamente ao conjunto do país, apresenta estatísticas de mortalidade de melhor confiabilidade. No caso da fonte consultada, um paralelo poderia ser traçado tendo como parâmetro a qualidade dos dados do Município de São Paulo. Ainda recorrendo à pesquisa realizada por GOTLIEB (1988), é importante notar que as causas de óbito não revelam diferenças expressivas quanto à posição ocupada por cada grupo, seja em nível de capítulos ou agrupamentos da CID, quando comparada à da fonte consultada (tabela 3 ). 


\section{Tabela 3}

Mortalidade proporcional (\%) em japoneses residentes no Município de São Paulo segundo principais causas básicas (agrupamentos da CID-9), sexo e fonte de informação, 1979-81.

\begin{tabular}{|c|c|c|c|c|}
\hline \multirow{3}{*}{ Causas de morte } & \multicolumn{4}{|c|}{ Sexo } \\
\hline & \multicolumn{2}{|c|}{ Masculino. } & \multicolumn{2}{|c|}{ Feminino } \\
\hline & SIM/MS* & Gotlieb** & SIM/MS* & Gotlieb** \\
\hline Infecciosas e parasitárias. & 2,2 & 1,9 & 1,4 & 1,1 \\
\hline Neoplasmas & 21,6 & 22,2 & 15,3 & 16,6 \\
\hline Estômago & 7,4 & 7,8 & 3,9 & 4,3 \\
\hline Cólon & 0,7 & 1,1 & 1,1 & 1,2 \\
\hline Pulmão & 3,6 & 3,7 & 0,7 & 0,8 \\
\hline Mama feminina & - & -- & 0,7 & 0,7 \\
\hline Colo do útero & - & -- & 0,9 & 1,0 \\
\hline Próstata & 0,6 & 1,2 & - & -- \\
\hline Endócrinas $* * *$ & 3,2 & 3,3 & 7,0 & 6,6 \\
\hline Diabetes mellitus & 2,0 & 2,1 & 5,3 & 5,0 \\
\hline Doenças do aparelho circulatório & 45,1 & 45,2 & 53,2 & 52,9 \\
\hline D. isquêmicas do coração & 16,6 & 17,1 & 17,3 & 17,3 \\
\hline D. cerebrovasculares & 18,2 & 18,5 & 23,0 & 22,6 \\
\hline Doenças do aparelho respiratório & 10,6 & 10,7 & 9,2 & 9,7 \\
\hline Doenças do aparelho digestivo & 5,9 & 5,8 & 4,6 & 4,4 \\
\hline Causas externas & 6,8 & 6,1 & 2,3 & 2,1 \\
\hline Ac. transporte veículo a. motor & 3,2 & 3,0 & 1,4 & 1,1 \\
\hline Suicídios & 0,8 & 0,7 & 0,5 & 0,6 \\
\hline Homicídios & 0,5 & 0,6 & 0,1 & 0,1 \\
\hline Todas as causas & 100,0 & 100,0 & 100,0 & 100,0 \\
\hline
\end{tabular}

* Ministério da Saúde - Sistema de Informações de Mortalidade

** GOTLIEB, 1988. Al e A2

*** Doenças das glândulas endócrinas, da nutrição e do metabolismo e transtomos imunitários

Um outro aspecto a ser analisado refere-se à frequêencia dos óbitos por causas mal definidas. Observou-se um aumento progressivo desta proporção com o avançar da idade, nas três populações estudadas, indicando que o problema não foi ocasionado exclusivamente por mau preenchimento da DO ou ausência de assistência médica. Quando 
os óbitos ocorrem em pessoas com idades avançadas, muitas vezes, a causa básica da morte informada é a senilidade que, após codifícação, será considerada dentro do capítulo das causas mal definidas. Ainda assim, valores referentes à mortalidade proporcional por essas causas no Japão são marcadamente menores do que os dos isseis que, por sua vez, mostram-se inferiores aos do Estado do Paraná como um todo (tabela 4).

\section{Tabela 4}

Mortalidade proporcional $(\%)$ por causas mal definidas em indivíduos de 50 anos e mais segundo sexo e população de estudo, 1991.

\begin{tabular}{ccc}
\hline População de estudo & Masculino & Feminino \\
\hline Japão & 2,7 & 5,1 \\
Isseis* & 7,0 & 9,0 \\
Paraná & 14,1 & 13,6 \\
\hline
\end{tabular}

*Refere-se aos óbitos ocorridos entre 01/03/90 e 28/02/93

As evidências aqui apresentadas fornecem indícios de que os óbitos, objeto de análise deste estudo, refletem a situação de mortalidade de isseis residentes no Estado do Paraná. 
4. RESULTADOS E DISCUSSÃO 


\subsection{ESTRUTURA POPULACIONAL}

Os dados do X Recenseamento Geral do Brasil revelaram que residiam, em 1991, no Estado do Paraná, 9962 imigrantes nascidos no Japão. A tabela 5 e o mapa (figura 5) permitem averiguar que os municípios localizados nas regiões norte e noroeste do Paraná constituem as localidades de residência da grande parte dos japoneses. Apesar da fixação dos japoneses ser registrada em todo o estado, 21 municípios constituem local de residência de $74,8 \%$ dos isseis, destacando-se os municípios de Londrina, Maringá e Assaí, que concentravam mais de $33 \%$ dos imigrantes do Estado.

\section{Figura 5}

Distribuição de isseis residentes no Estado do Paraná segundo município de residência, 1991.

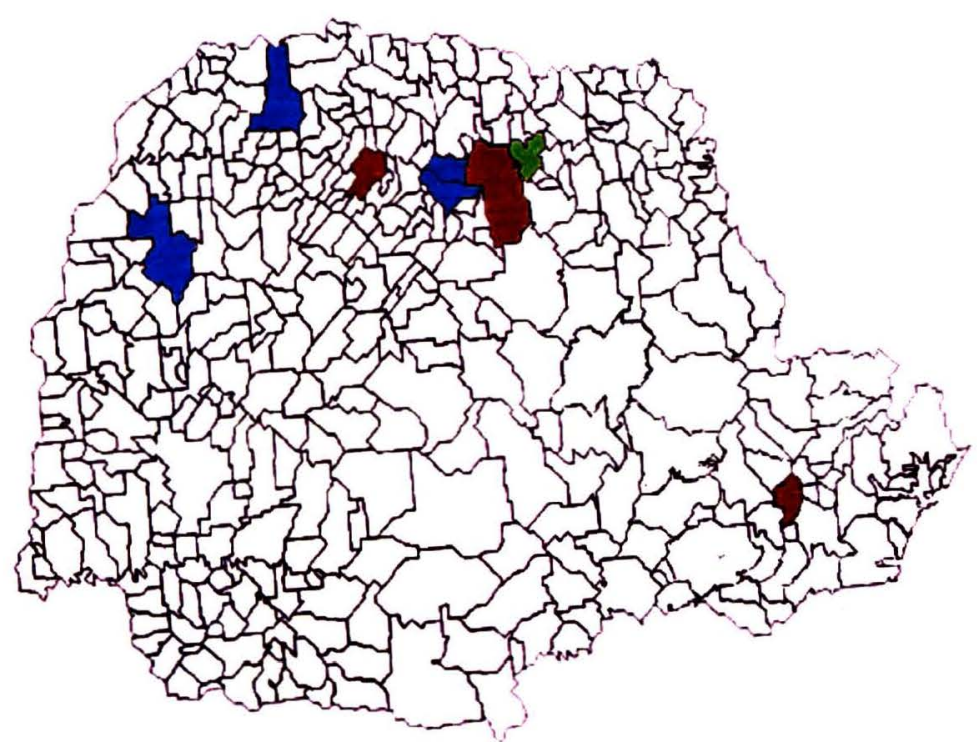

Fonte: FIBGE 
A distribuição atual vai ao encontro do processo de ocupação do espaço paranaense pelos imigrantes japoneses que historicamente ocorreu principalmente na Região Norte do Estado, em função do tipo de solo, adequado para a cultura do café. Ressalte-se que a maioria já estava acostumada ao desenvolvimento desta atividade pelo fato de, quando da chegada ao Brasil, terem trabalhado em lavouras cafeeiras (YAMOCHI, 1991). O mesmo não ocorreu na região Sul do Estado, sendo o número de imigrantes que para lá se deslocaram bem menor.

\section{Tabela 5}

$\mathrm{N}^{\mathrm{o}}$ e \% de habitantes segundo município de residência, Isseis do Estado do Paraná, 1991.

\begin{tabular}{|c|c|c|}
\hline Município & $\mathrm{N}^{\mathrm{o}}$ & $\%$ \\
\hline Londrina & 1644 & $\overline{16,5}$ \\
\hline Curitiba & 1450 & 14,6 \\
\hline Maringá & 1290 & 13,0 \\
\hline Assaí & 407 & 4,1 \\
\hline Paranavaí & 286 & 2,9 \\
\hline Umuarama & 257 & 2,6 \\
\hline Arapongas & 240 & 2,4 \\
\hline Apucarana & 229 & 2,3 \\
\hline Ibiporã & 183 & 1,8 \\
\hline Uraí & 183 & 1,8 \\
\hline Marialva & 159 & 1,6 \\
\hline Cambé & 149 & 1,5 \\
\hline Guaíra & 133 & 1,3 \\
\hline Ponta Grossa & 121 & 1,2 \\
\hline Nova Esperança & 118 & 1,2 \\
\hline Goioerê & 114 & 1,1 \\
\hline Rolândia & 103 & 1,0 \\
\hline Ubiratã & 101 & 1,0 \\
\hline Paranaguá & 96 & 1,0 \\
\hline São José dos Pinhais & 95 & 1,0 \\
\hline Cianorte & 95 & 1,0 \\
\hline Subtotal & 7453 & 74,8 \\
\hline Outros & 2508 & 25,2 \\
\hline Total & $9961 *$ & 100,0 \\
\hline
\end{tabular}


A estrutura populacional de isseis residentes no Estado do Paraná, em 1991, por faixas etárias e sexo está retratada na pirâmide populacional (figura 6) e na tabela 6. Aproximadamente $90 \%$ são pessoas com 50 anos e mais e uma alta percentagem é representada por indivíduos de no mínimo 65 anos $(59,6 \%)$. A distribuição, segundo sexo nas faixas etárias, mostra-se pouco homogênea (razão centesimal de sexo de 115 homens para 100 mulheres), sendo que a proporção de mulheres entre 25 e 39 anos supera a de homens. A partir de 40 anos, exceto entre 80 e 84 anos, a razão centesimal de sexo é bastante superior a 100 homens/100 mulheres.

Esta estrutura difere marcadamente da população do Japão, que por sua vez apresenta-se distinta quando comparada à estrutura etária do Estado do Paraná, conforme revelam as formas assumidas pelas pirâmides etárias (figura 6). Verifica-se que a população do Paraná mostra grande proporção de pessoas até 15 anos $(33,3 \%)$ em relação à do Japão $(18,3 \%)$ e a do Japão apresenta um excesso de pessoas com 65 anos e mais (12\%, no Japão, e 4,4\%, no Paraná). A percentagem de mulheres idosas (65 anos e mais) em relação à população total no Estado do Paraná é igual à de homens $(2,2 \%)$ e no Japão é de $7,2 \%$, superior à proporção de homens (5\%); entre as isseis esta proporção é de $28,8 \%$, inferior à proporção de homens ( $31 \%$ ) (tabelas 7 e 8 ).

A situação observada para isseis é diferente da presente na maioria das populações, nas quais, apesar da importância crescente dos idosos, predominam indivíduos de 20 a 49 anos e mulheres entre os idosos. A estrutura dos isseis é comum às populações decorrentes de processos migratórios, onde o número de homens é geralmente superior ao de mulheres. Outro fator que poderia interferir, aumentando a razão centesimal de sexo, relaciona-se à possível sobremortalidade feminina. No entanto, o valor assumido pela Razão de Mortalidade Padronizada entre sexos, relativamente aos isseis com 50 anos e mais em 1991, de 1,16 (Coeficiente de mortalidade masculina e feminina de 20,9 e 18,0 por 1000 isseis, respectivamente), indica que o número de homens que migrou, muito provavelmente, foi superior ao de mulheres. 
Figura 6

Pirâmides Populacionais
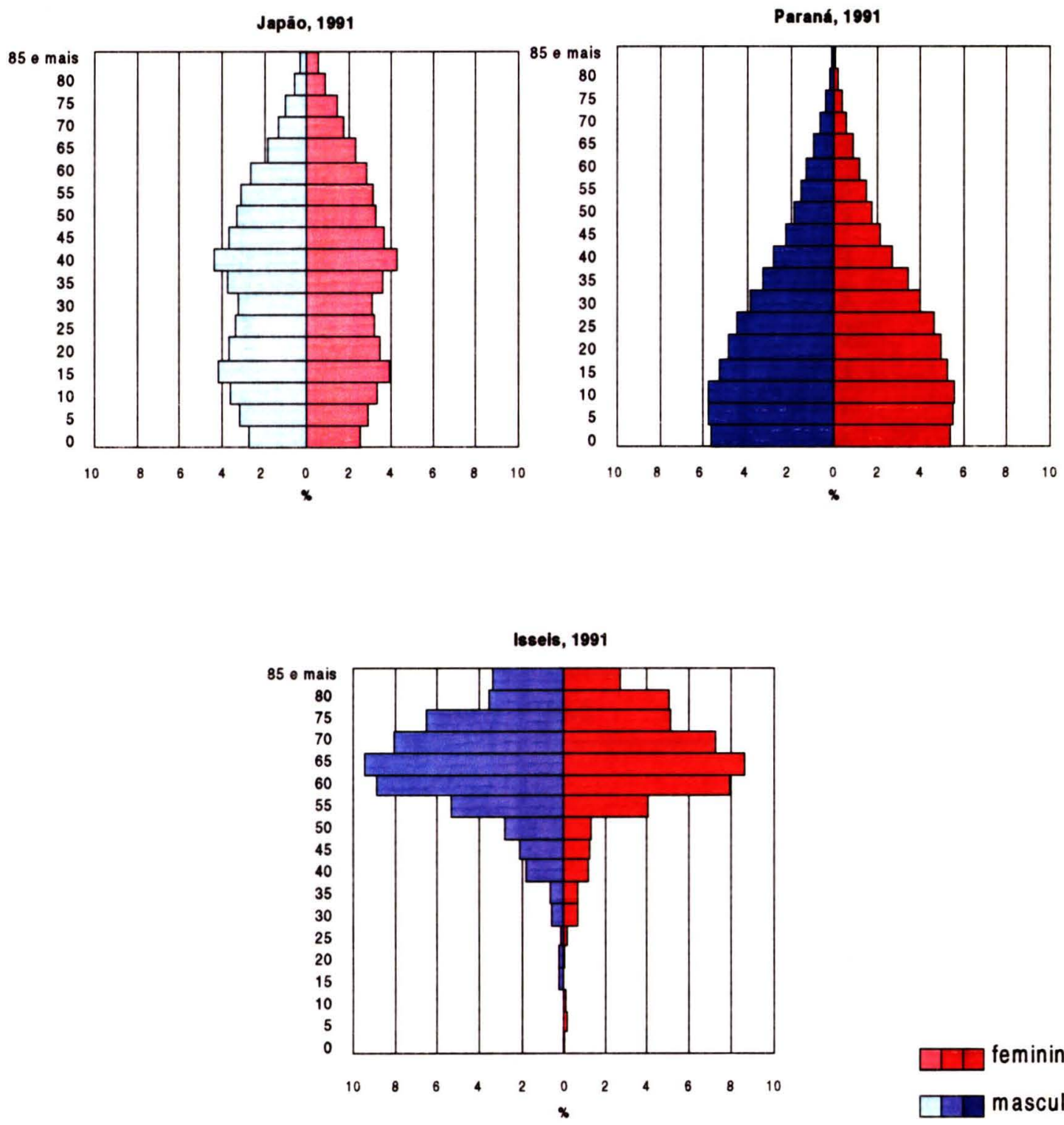

feminino 


\section{Tabela 6}

$\mathrm{N}^{\mathrm{o}}$ e \% de habitantes segundo sexo, grupo etário e respectiva razão centesimal de sexo (RS)*. Isseis do Estado do Paraná, 1991.

\begin{tabular}{|c|c|c|c|c|c|c|c|}
\hline \multirow[t]{2}{*}{ Grupo etário } & \multicolumn{2}{|c|}{ Masculino } & \multicolumn{2}{|c|}{ Feminino } & \multicolumn{2}{|c|}{ Total } & \multirow[t]{2}{*}{ RS } \\
\hline & $\mathrm{N}^{\circ}$ & $\%$ & $\mathrm{~N}^{\mathrm{o}}$ & $\%$ & $\mathrm{~N}^{\mathrm{o}}$ & $\%$ & \\
\hline $0 \mathrm{a} 4$ & - & - & 8 & 0,1 & 8 & 0,1 & - \\
\hline 5 a 9 & - & - & 16 & 0,2 & 16 & 0,2 & - \\
\hline 10 a 14 & - & - & 13 & 0,1 & 13 & 0,1 & - \\
\hline 15 a 19 & 21 & 0,2 & - & - & 21 & 0,2 & - \\
\hline 20 a 24 & 21 & 0,2 & 8 & 0,1 & 29 & 0,3 & 262,5 \\
\hline 25 a 29 & 12 & 0,1 & 19 & 0,2 & 31 & 0,3 & 63,2 \\
\hline 30 a 34 & 55 & 0,6 & 70 & 0,7 & 125 & 1,3 & 78,6 \\
\hline 35 a 39 & 63 & 0,6 & 67 & 0,7 & 130 & 1,3 & 94,0 \\
\hline 40 a 44 & 177 & 1,8 & 119 & 1,2 & 296 & 3,0 & 148,7 \\
\hline 45 a 49 & 208 & 2,1 & 124 & 1,2 & 332 & 3,3 & 167,7 \\
\hline 50 a 54 & 275 & 2,8 & 130 & 1,3 & 405 & 4,1 & 211,5 \\
\hline 55 a 59 & 531 & 5,3 & 404 & 4,1 & 935 & 9,4 & 131,4 \\
\hline 60 a 64 & 884 & 8,9 & 789 & 7,9 & 1673 & 16,8 & 112,0 \\
\hline 65 a 69 & 941 & 9,4 & 856 & 8,6 & 1797 & 18,0 & 109,9 \\
\hline 70 a 74 & 802 & 8,1 & 725 & 7,3 & 1527 & 15,3 & 110,6 \\
\hline 75 a 79 & 648 & 6,5 & 510 & 5,1 & 1158 & 11,6 & 127,1 \\
\hline 80 a 84 & 354 & 3,6 & 505 & 5,1 & 859 & 8,6 & 70,1 \\
\hline $85 e+$ & 337 & 3,4 & 270 & 2,7 & 607 & 6,1 & 124,8 \\
\hline Total & 5329 & 53,5 & 4633 & 46,5 & 9962 & 100,0 & 115,0 \\
\hline
\end{tabular}

O grande fluxo migratório de estrangeiros que entrou no país, até o final da década de 20 , tinha por objetivo suprir necessidade de mão-de-obra à lavoura cafeeira, sendo seletivo, incluindo, portanto, predominantemente famílias jovens e homens solteiros e era incomuma entrada no país de mulheres e casais de idosos (TELAROLLI Jr et al, 1996).

Entretanto, conforme relatam UCHIYAMA e colaboradores (1992), uma característica dos imigrantes japoneses que chegaram ao Brasil antes da II Guerra Mundial é o fato de a maioria ser membro de famílias, representando os solteiros menos de $6 \%$, 
diferindo, por exemplo, dos japoneses que migraram para o Havaí, Estados Unidos e outros países. Contudo, no início, o número de homens foi superior porque a entrada de famílias estava condicionada a ter pelo menos três pessoas capazes de trabalhar. Criavam-se assim condições artificiais entre famílias jovens e como havia mais jovens do sexo masculino como componente artificial das famílias produzia-se desequilíbrio na distribuição por sexo. Todavia, após 1925, ao assumir o governo japonês a emigração como política de estado, podiam emigrar tanto idosos quanto crianças, de modo que aos poucos a disparidade entre sexo foi se diluindo. Este fato pode explicar uma razão centesimal de sexo superior a 100 entre pessoas em idades mais avançadas, ainda na atualidade, o mesmo não se observando entre as pessoas com menos de 40 anos (tabela 6 ).

O elevado percentual de idosos deve-se ao fato de o processo migratório ter sido mais intenso no período 1925-41, com auge no quinquênio 1930-35. Ressalte-se que de 1908 a 1941 (33 anos) ingressaram no Brasil 188.309 imigrantes japoneses. A partir de 1925, registra-se crescente aumento e, no prazo de 16 anos, até 1941, entraram dois terços do total; no pico entre 1930-35, chegou mais de um terço do conjunto. Somente em 1933, ingressaram 24.484 imigrantes japoneses, um recorde no período. Dado que a maioria dos que se deslocaram para o Estado do Paraná eram imigrantes que haviam chegado no país por volta dos anos 30, em 1991, tinham mais de 61 anos. A geração que em 1991 estava com aproximadamente 60 a 74 anos veio provavelmente para o Brasil ainda criança, fato que explica uma razão centesimal de sexo próxima a 100, diferindo das demais faixas etárias pois, no caso das crianças, não existiam razões aparentes para privilegiarem meninos.

A redução drástica de isseis, a partir de 64 anos, reflete a mudança na política de imigração ocorrida no país e reflexo da II Guerra Mundial. Jovens deixaram de sair do Japão, como consequêencia da política governamental que estava voltada para a reconstrução do país (quem tinha 64 anos em 1991, em 1945 estava com 18 anos), o que explica a quase inexistência de registro de entrada de japoneses após 1941. Do total de 
244.172 emigrados japoneses entre 1891 e 1950 para a América Central e do Sul, menos de $1 \%$ (1551) emigraram entre 1941 e 1950 (TAJIRI e YAMASHIRO, 1992).

A estrutura etária e a respectiva pirâmide populacional do Japão, na atualidade, ilustra a situação de um país desenvolvido com número reduzido de crianças, muitos adultos e idosos, baixa natalidade, razão de dependência com significativa expressão do grupo de pessoas em idades avançadas e baixa mortalidade, tendo concluído sua transição demográfica, isto é, queda da mortalidade e posterior queda da fecundidade.

Quanto à razão centesimal de sexo, no Japão em 1990, observa-se predomínio de homens até a faixa etária de 40 a 44 anos; a partir desta idade passa a exibir, progressivamente, maior percentual de mulheres relativamente aos homens e, entre maiores de 85 anos, o número de mulheres é praticamente o dobro do contingente de homens. Esta distribuição por sexo assemelha-se à encontrada na maioria das populações do mundo, que se caracteriza por mais nascimento de crianças do sexo masculino ( 5 a $6 \%$, a mais) e, a partir do nascimento, em decorrência de fatores que se modificam, ao longo do ciclo vital, a mortalidade masculina é superior à feminina. $\mathrm{Na}$ faixa etária de 60 anos e mais, o predomínio feminino vai se acentuando progressivamente, podendo chegar a proporções próximas de 2 para 1 no grupo etário 80 e mais anos (TELAROLLI Jr, 1996).

O efeito da II Guerra Mundial sobre o Japão pode ser visto na pirâmide afetando os grupos etários a partir de 65 anos, onde há uma acentuada redução de homens em relação à faixa etária imediatamente anterior e que correspondiam a pessoas de 18 e mais anos em 1939/1945. Para BERQUÓ (1980), o surpreendente aumento da população japonesa de 40 a 44 anos corresponde à coorte de nascimentos após a Segunda Guerra Mundial (fenômeno conhecido como "baby boom"). A acentuada redução de pessoas entre 30 e 34 anos reflete a situação do Japão, em 1960, quando ocorreu redução drástica da fecundidade, em consequência da abertura de clínicas de controle de natalidade e da legalização do aborto provocado. 


\section{Tabela 7}

$\mathrm{N}^{\mathrm{o}}$ e \% de habitantes segundo sexo, grupo etário e respectiva razão centesimal de sexo (RS)*. Japão, 1990.

\begin{tabular}{cccccccc}
\hline Grupo etário & \multicolumn{2}{c}{ Masculino } & \multicolumn{2}{c}{ Feminino } & \multicolumn{2}{c}{ Total } & RS \\
& $\mathrm{N}^{\mathrm{o}}$ & $\%$ & $\mathrm{~N}^{\mathrm{0}}$ & $\%$ & $\mathrm{~N}^{\mathrm{o}}$ & $\%$ & \\
\hline 0 a 4 & 3337729 & 2,7 & 3171967 & 2,6 & 6509696 & 5,3 & 105,2 \\
5 a 9 & 3835026 & 3,1 & 3650504 & 3,0 & 7485530 & 6,1 & 105,1 \\
10 a 14 & 4384951 & 3,5 & 4163485 & 3,4 & 8548436 & 6,9 & 105,3 \\
15 a 19 & 5141504 & 4,2 & 4893153 & 4,0 & 10034657 & 8,1 & 105,1 \\
20 a 24 & 4487660 & 3,6 & 4339987 & 3,5 & 8827647 & 7,1 & 103,4 \\
25 a 29 & 4095197 & 3,3 & 3999329 & 3,2 & 8094526 & 6,5 & 102,4 \\
30 a 34 & 3940200 & 3,2 & 3868811 & 3,1 & 7809011 & 6,3 & 101,8 \\
35 a 39 & 4541293 & 3,7 & 4486286 & 3,6 & 9027579 & 7,3 & 101,2 \\
40 a 44 & 5369719 & 4,3 & 5317154 & 4,3 & 10686873 & 8,6 & 101,0 \\
45 a 49 & 4499227 & 3,6 & 4543420 & 3,7 & 9042647 & 7,3 & 99,0 \\
50 a 54 & 4012193 & 3,2 & 4098015 & 3,3 & 8110208 & 6,6 & 97,9 \\
55 a 59 & 3797013 & 3,1 & 3947920 & 3,2 & 7744933 & 6,3 & 96,2 \\
60 a 64 & 3247563 & 2,6 & 3513925 & 2,8 & 6761488 & 5,5 & 92,4 \\
65 a 69 & 2202117 & 1,8 & 2913236 & 2,4 & 5115353 & 4,1 & 75,6 \\
70 a 74 & 1565121 & 1,3 & 2260998 & 1,8 & 3826119 & 3,1 & 69,2 \\
75 a 79 & 1201428 & 1,0 & 1823523 & 1,5 & 3024951 & 2,4 & 65,9 \\
80 a 84 & 680610 & 0,6 & 1156226 & 0,9 & 1836836 & 1,5 & 58,9 \\
85 e + & 358173 & 0,3 & 766504 & 0,6 & 1124677 & 0,9 & 46,7 \\
\hline Total & 60696724 & 49,1 & 62914443 & 50,9 & 123611167 & 100,0 & 96,5 \\
\hline
\end{tabular}

* por 100 mulheres

Fonte: Japan Vital Statistics (dados brutos)

SVANBORG e colaboradores (1985) relatam que, em 1977, a esperança de vida dos homens japoneses alcançou o mesmo nível (em torno de 72,7 anos) atingido pelos suecos do sexo masculino. Desde então sua vida média vem aumentando e foi relatado ser 74,2 anos, em 1982, enquanto que a Suécia, que por muito tempo foi considerada nação em que sua população tinha vida mais longa, permanece constante. Esta constância da esperança de vida na Suécia tem sido mantida por um aumento da mortalidade, principalmente por doenças cardiovasculares em homens de meia idade, balanceada pelo declínio da taxa de mortalidade nas idades mais jovens e também nas idades avançadas. 
Em mulheres, a vida média alcançou, em 1980, o mesmo nível (em torno de 79,1 anos) no Japão como na Suécia e, em 1982, a das mulheres japonesas foi superior à das suecas (79,7 anos, no Japão e 79,2 anos na Suécia). Isto significa que o aumento, que por três décadas vinha sendo mais acentuado no Japão, claramente continua. O mais rápido aumento no Japão ocorreu entre 1947 e 1952, sendo não menos do que 11,8 anos, em homens, e 11,5 anos, em mulheres.

Conforme ARAKI e MURATA (1987), por muitos anos, a vida média dos japoneses era muito menor do que a dos países ocidentais e, entre 1921-25, a esperança de vida ao nascer era somente 42,1 anos para homens e 43,2 anos para as mulheres. Contudo, alcançou, recentemente, um dos mais altos níveis do mundo. Para 1994, a Organização Mundial da Saúde faz referência a uma esperança de vida ao nascer dos japoneses de 76,6 anos para homens e 83,3 anos para as mulheres (WORLD HEALTH ORGANIZATION, 1996).

Diferentemente do Japão, a pirâmide etária do Estado do Paraná caracteriza uma sociedade com alta proporção de criança até 14 anos $(33,3 \%)$ e o número de idosos ainda é pequeno (4,4\% com 65 anos e mais). O número de mulheres passa a predominar a partir de 15 anos, todavia, diferentemente do Japão, observa-se uma distribuição quase que eqüitativa de homens e mulheres (tabela 8), com razão centesimal de sexo bastante próxima a $100 \mathrm{em}$ quase todas as faixas etárias. Pessoas com 85 anos e mais representam apenas $0,2 \%$ da população total. Caracteriza uma população experimentando declínio na fecundidade e a composição etária revelada é de uma população ainda jovem, porém, com tendência ao envelhecimento, como pode ser observado pelo deslocamento populacional das coortes intermediárias. A razão de dependência para o Estado foi de 60,4\% em 1991. 


\section{Tabela 8}

$\mathrm{N}^{\circ}$ e \% de habitantes segundo sexo, grupo etário e respectiva razão centesimal de sexo (RS)*. Estado do Paraná, 1991.

\begin{tabular}{cccccccr}
\hline \multirow{2}{*}{ Grupo etário } & \multicolumn{2}{c}{ Masculino } & \multicolumn{2}{c}{ Feminino } & \multicolumn{2}{c}{ Total } & \multirow{2}{*}{$\mathrm{RS}$} \\
& $\mathrm{N}^{\mathrm{o}}$ & $\%$ & $\mathrm{~N}^{\mathrm{o}}$ & $\%$ & $\mathrm{~N}^{\mathrm{0}}$ & \multicolumn{1}{c}{$\%$} & \\
\hline 0 a 4 & 469547 & 5,6 & 453760 & 5,4 & 923307 & 10,9 & 103,5 \\
5 a 9 & 480234 & 5,7 & 464230 & 5,5 & 944464 & 11,2 & 103,4 \\
10 a 14 & 479408 & 5,7 & 467030 & 5,5 & 946438 & 11,2 & 102,7 \\
15 a 19 & 437820 & 5,2 & 439870 & 5,2 & 877690 & 10,4 & 99,5 \\
20 a 24 & 405458 & 4,8 & 413356 & 4,9 & 818814 & 9,7 & 98,1 \\
25 a 29 & 371851 & 4,4 & 389322 & 4,6 & 761173 & 9,0 & 95,5 \\
30 a 34 & 318405 & 3,8 & 335183 & 4,0 & 653588 & 7,7 & 95,0 \\
35 a 39 & 274189 & 3,2 & 288791 & 3,4 & 562980 & 6,7 & 94,9 \\
40 a 44 & 228701 & 2,7 & 230340 & 2,7 & 459041 & 5,4 & 99,3 \\
45 a 49 & 183691 & 2,2 & 184549 & 2,2 & 368240 & 4,4 & 99,5 \\
50 a 54 & 153084 & 1,8 & 149531 & 1,8 & 302615 & 3,6 & 102,4 \\
55 a 59 & 124966 & 1,5 & 127974 & 1,5 & 252940 & 3,0 & 97,6 \\
60 a 64 & 103600 & 1,2 & 105635 & 1,3 & 209235 & 2,5 & 98,1 \\
65 a 69 & 74698 & 0,9 & 77109 & 0,9 & 151807 & 1,8 & 96,9 \\
70 a 74 & 48352 & 0,6 & 51444 & 0,6 & 99796 & 1,2 & 94,0 \\
75 a 79 & 30770 & 0,4 & 34213 & 0,4 & 64983 & 0,8 & 89,9 \\
80 a 84 & 15094 & 0,2 & 17555 & 0,2 & 32649 & 0,4 & 86,0 \\
85 e + & 7946 & 0,1 & 11007 & 0,1 & 18953 & 0,2 & 72,2 \\
\hline Total & 4207814 & 49,8 & 4240899 & 50,2 & 8448713 & 100,0 & 99,2 \\
\hline
\end{tabular}

* por 100 mulheres

Fonte: FIBGE (dados não publicados)

A explicação para a distribuição observada deve se reportar à história da ocupação do espaço paranaense, concernente ao período de maior incremento da população total. Os recenseamentos realizados no país desde 1940 mostram que entre 1950 e 1960 o Estado experimentou um incremento superior a $100 \%$ em sua população (FUNDAÇÃO IBGE, 1996). Este crescimento ocorreu primordialmente às expensas dos deslocamentos internos, principalmente de homens e famílias jovens inseridos no surto de colonização, especialmente do espaço norte paranaense, a partir de 1929 (BERNARDES, 1952). Tal fato pode explicar a presença de poucos idosos relativamente às demais faixas etárias nos anos 90 . O censo de 1991 revela que o Estado ocupava a sexta posição na ordenação 
nacional, por contingente populacional, concentrando $5,75 \%$ da população do país, porém registrou a menor taxa de crescimento anual do Brasil $(0,93 \%)$, com evidente perda na população rural. $O$ ritmo de crescimento populacional no Paraná vem se desacelerando, o que reflete a intensificação do declínio da fecundidade e inversão dos fluxos migratórios, observados desde a década de 70 . O rendimento médio do chefe de domicílio (3,3 salários mínimos) e a taxa de analfabetismo para pessoas de 10 anos e mais $(13,4 \%)$ apresentaramse ligeiramente abaixo da média do país (FUNDAÇÃO IBGE, 1995).

As questões relativas à estrutura demográfica, até aqui discutidas, revelam um cenário demográfico recente, historicamente determinado, com marcadas diferenças entre local de origem e de destino dos isseis residentes no Estado do Paraná, distinções estas que certamente permearam e definiram o modo de vida dos imigrantes, conferindo uma especificidade em seu perfil de saúde-doença.

\subsection{MORTALIDADE}

$\mathrm{Na}$ tabela 9 são apresentados coeficientes padronizados de mortalidade em indivíduos de 50 anos e mais e as razões entre os mesmos, nas populações estudadas. A comparação dos valores assumidos pelos indicadores revela taxas bem mais elevadas para os residentes no Estado do Paraná, em ambos os sexos. A razão de mortalidade padronizada e o respectivo intervalo de $95 \%$ de confiança para isseis, tendo Japão como população de referência mostra que, no sexo masculino, a diferença não é estatisticamente significante $(\mathrm{RMP}=0,97[0,92 ; 1,02])$. Porém, entre as mulheres, a mortalidade das isseis é $50 \%$ supẹior à das residentes no Japão $(\mathrm{RMP}=1,50[1,40 ; 1,61])$. Quando as taxas de mortalidade referentes aos isseis são comparadas com as da população geral do Estado do Paraná, apresentam-se mais favoráveis para isseis de ambos os sexos, isto é, menor mortalidade, sendo a diferença mais pronunciada nos homens do que nas mulheres (RMP de $0,65[0,62 ; 0,68]$ e de $0,81[0,77 ; 0,85]$, respectivamente). 


\section{Tabela 9}

Coeficientes de mortalidade geral padronizados ${ }^{1}$ (por 100.000 hab de 50 anos e mais), razão de mortalidade padronizada (RMP) e respectivo intervalo de $95 \%$ de confiança (IC 95\%) segundo sexo e população de estudo, 1991.

\begin{tabular}{cccccc}
\hline \multirow{2}{*}{ Sexo } & \multicolumn{3}{c}{ Coeficiente } & \multicolumn{2}{c}{ RMP IC $(95 \%)$} \\
& Japão & Isseis & Paraná & Isseis/Japão & Isseis/Paraná \\
\hline \multirow{2}{*}{$\begin{array}{c}\text { Masculino } \\
\text { Feminino }\end{array}$} & 2158,4 & 2086,3 & 3208,2 & $0,97[0,92 ; 1,02]$ & $0,65[0,62 ; 0,68]^{*}$ \\
& 1194,9 & 1796,4 & 2221,2 & $1,50[1,40 ; 1,61]^{*}$ & $0,81[0,77 ; 0,85]^{*}$ \\
\hline
\end{tabular}

* Estatisticamente significante em nível de 5\%

${ }^{1}$ Ajustados pela população mundial de 50 anos e mais

Taxas específicas de mortalidade, por grupos de idade, dos isseis, dos residentes no Japão e no Estado do Paraná são apresentadas na figura 7. Verifica-se que as taxas relativas aos isseis, em grande parte das faixas etárias, são intermediárias quando comparadas às dos residentes no Japão e no Estado do Paraná. Apesar da mortalidade dos isseis situar-se em posição intermediária, a análise da figura 7 permite evidenciar que a curva referente aos homens revela uma velocidade e intensidade de morrer dos isseis semelhante às dos japoneses, a partir dos 50 anos. Entre as mulheres isseis, notadamente, em algumas faixas etárias ( 75 a 79 anos e 85 anos e mais) as mulheres isseis apresentaram taxas de mortalidade maiores que Japão e Paraná. 


\section{Figura 7}

Coeficientes de mortalidade (por 100.000 hab) segundo sexo, grupo etário e população de estudo, 1991.
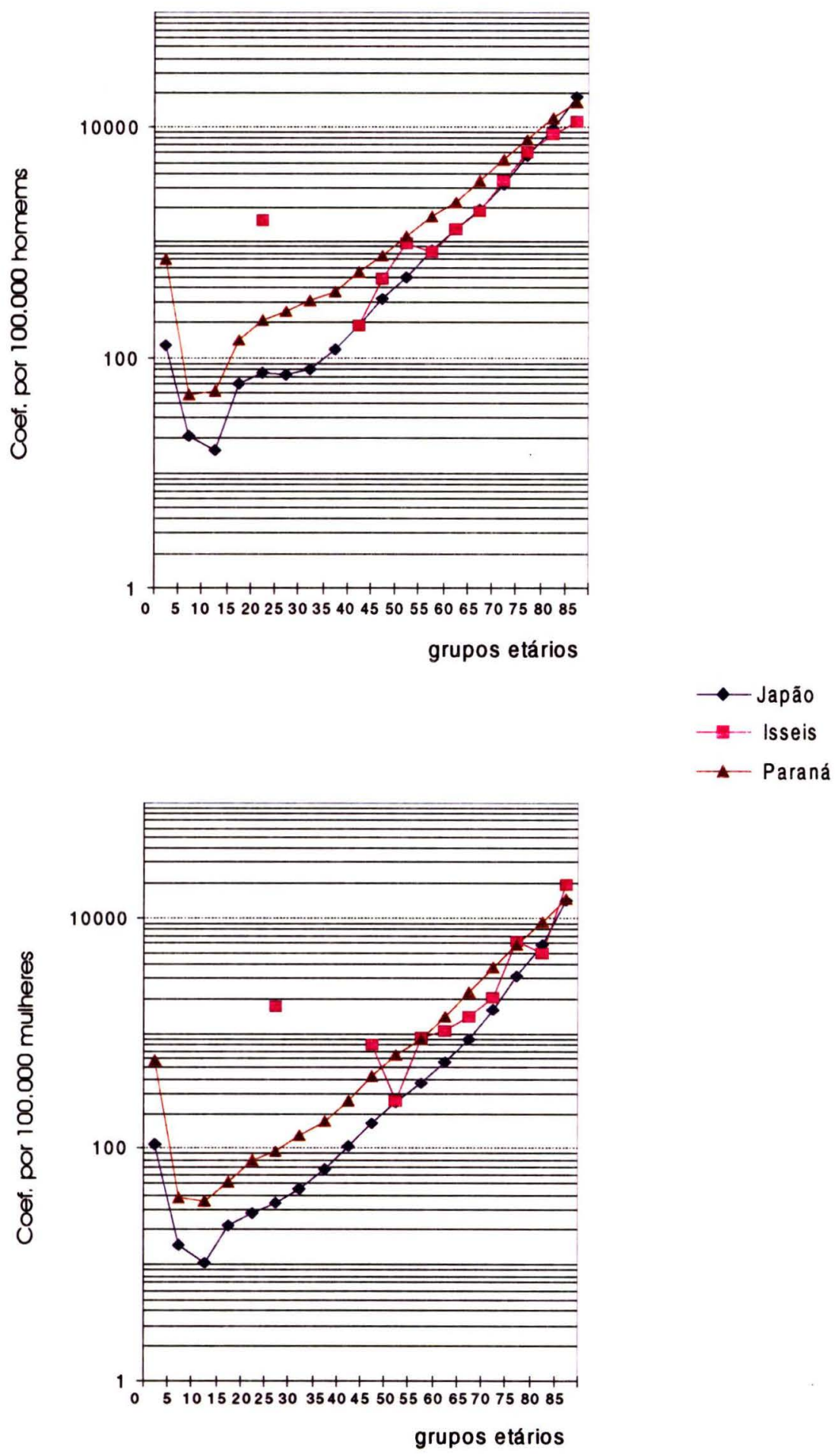
Ainda recorrendo aos dados apresentados na tabela 9, a comparação dos coeficientes de mortalidade entre sexos, em indivíuos de 50 anos e mais, permite apreciar que há taxas padronizadas mais baixas para as mulheres nas populações estudadas. Esta situação também se confirma nos coeficientes específicos apresentados na tabela 10.

\section{Tabela 10}

Coeficientes de mortalidade (por 100.000 habitantes) segundo sexo, grupo etário e população de estudo, 1991.

\begin{tabular}{rrrrrrr}
\hline \multirow{2}{*}{ Grupo etário } & \multicolumn{2}{c}{ Japão } & \multicolumn{2}{c}{ Isseis* } & \multicolumn{2}{c}{ Paraná } \\
& Masc & Fem & Masc & Fem & Masc & Fem \\
\hline 0 a 4 & 126,9 & 110,4 & - & - & 715,4 & 592,4 \\
5 a 9 & 21,4 & 15,0 & - & - & 48,4 & 38,0 \\
10 a 14 & 15,9 & 10,4 & - & - & 51,8 & 36,0 \\
15 a 19 & 60,5 & 21,6 & - & - & 142,1 & 52,1 \\
20 a 24 & 73,6 & 28,0 & 1587,3 & - & 207,2 & 78,3 \\
25 a 29 & 71,3 & 33,9 & - & 1754,4 & 247,8 & 95,7 \\
30 a 34 & 80,6 & 44,6 & - & - & 306,1 & 127,9 \\
35 a 39 & 116,4 & 66,1 & - & - & 375,5 & 172,4 \\
40 a 44 & 186,7 & 104,5 & 188,3 & - & 544,8 & 263,9 \\
45 a 49 & 320,4 & 166,2 & 480,8 & 806,5 & 774,8 & 427,6 \\
50 a 54 & 491,9 & 248,8 & 969,7 & 256,4 & 1122,0 & 656,4 \\
55 a 59 & 847,3 & 369,4 & 816,1 & 907,6 & 1655,8 & 902,4 \\
60 a 64 & 1314,7 & 555,7 & 1282,1 & 1056,2 & 2251,5 & 1405,1 \\
65 a 69 & 1927,2 & 901,4 & 1877,4 & 1401,9 & 3474,0 & 2247,0 \\
70 a 74 & 3250,3 & 1620,6 & 3408,1 & 2023,0 & 5282,0 & 3679,6 \\
75 a 79 & 5615,9 & 3076,5 & 6070,0 & 6405,2 & 7737,0 & 5971,9 \\
80 a 84 & 9834,2 & 5953,5 & 8757,1 & 4884,5 & 11930,4 & 9174,0 \\
85 e + & 18491,7 & 13910,1 & 11177,1 & 19382,7 & 16474,0 & 14504,1 \\
\hline
\end{tabular}

* Refere-se aos obitos ocorridos entre 01/03/90 e 28/02/93.

É notória, exceto as oscilações existentes em alguns grupos de idade da população issei, a sobremortalidade masculina. Tal fato sugere presença de fatores de risco atuando de forma diferenciada entre as populações e, dentro destas, entre os sexos. Frente às diferenças observadas e buscando uma melhor compreensão do quadro apresentado, 
procedeu-se, inicialmente, a discussão do diferencial de mortalidade segundo sexo e, posteriormente, a comparação do perfil de mortalidade das populações estudadas.

\subsubsection{Diferencial de mortalidade por sexo}

A diferença na mortalidade entre sexos revela maior velocidade e intensidade da morte entre os homens, sendo este diferencial consistentemente mais alto no Japão. Os dados da tabela 11 referem-se à Razão de Mortalidade Padronizada entre sexos, em indivíduos de 50 anos e mais. Os valores assumidos por este indicador foram da ordem de 1,81 e 1,44 para os residentes no Japão e no Estado do Paraná, respectivamente. Entre isseis esta diferença foi menor (RMP de 1,16 ), isto é, os homens têm força de mortalidade $16 \%$ maior.

\section{Tabela 11}

Razão de mortalidade padronizada (RMP) entre sexos (50 anos e mais) segundo população de estudo, 1991.

\begin{tabular}{cc}
\hline População de estudo & Razão de Mortalidade \\
\hline Japão & 1,81 \\
Isseis* & 1,16 \\
Paraná & 1,44 \\
\hline
\end{tabular}

*Refere-se aos óbitos ocorridos entre 01/03/90 e 28/02/93

Quando especificada em cada grupo etário, a razão entre taxas mostra-se bastante irregular entre isseis, mas, tanto para o Japão quanto para o Estado do Paraná, a estimativa permite inferir que a probabilidade de morrer dos homens é sempre mais elevada (tabela 12). 


\section{Tabela 12}

Razão de mortalidade (RM) entre sexos segundo grupo etário e população de estudo, 1991.

\begin{tabular}{cccc}
\hline Grupo etário & Japão & Isseis & Paraná \\
\hline 0 a 4 & 1,15 & - & 1,21 \\
5 a 9 & 1,43 & - & 1,27 \\
10 a 14 & 1,52 & - & 1,44 \\
15 a 19 & 2,80 & - & 2,72 \\
20 a 24 & 2,62 & $*$ & 2,65 \\
25 a 29 & 2,10 & $*$ & 2,59 \\
30 a 34 & 1,81 & - & 2,39 \\
35 a 39 & 1,76 & - & 2,18 \\
40 a 44 & 1,79 & $*$ & 2,06 \\
45 a 49 & 1,93 & 0,60 & 1,81 \\
50 a 54 & 1,98 & 3,78 & 1,71 \\
55 a 59 & 2,29 & 0,90 & 1,83 \\
60 a 64 & 2,37 & 1,21 & 1,60 \\
65 a 69 & 2,14 & 1,34 & 1,55 \\
70 a 74 & 2,01 & 1,68 & 1,44 \\
75 a 79 & 1,83 & 0,95 & 1,30 \\
80 a 84 & 1,65 & 1,79 & 1,30 \\
85 e + & 1,33 & 0,58 & 1,14 \\
\hline
\end{tabular}

* Ausência de óbitos em um dos sexos

Conforme BERQUÓ (1980), desde o nascimento, a mortalidade feminina é quase sempre menor que a masculina em todas as sociedades, independentemente do grau de desenvolvimento predominante. Esta superioridade masculina será ou não mantida em todas as idades dependendo do nível geral da mortalidade, ou seja, em países com altas esperanças de vida ao nascer, próximas de 70 anos, as mulheres apresentam menores taxas de mortalidade para todas as idades, contudo, as diferenças são menos pronunciadas quando a mulher está atravessando parte importante de seu período reprodutivo.

A situação descrita é observada no Japão, onde menores diferenciais por sexo, na faixa etária que vai de 15 a 74 anos, são verificados entre 35 e 44 anos. A partir de 45 anos observa-se elevação constante do diferencial, com pico entre 60 e 64 anos (razão de 2,4). 
Estes valores começam reduzir gradualmente e na idade avançada (maiores de 85 anos) a mortalidade feminina praticamente se iguala à masculina (tabela 12).

No Estado do Paraná, embora maior mortalidade também se observe entre os homens, a razão de mortalidade entre sexos mostra que até mesmo nas idades correspondentes ao período reprodutivo da mulher, a sobremortalidade masculina segue tendência ascendente, mostrando-se superior a $100 \%$ na faixa etária que vai de 15 a 44 anos, refletindo, de certa forma, o peso das causas externas entre os homens, desta faixa etária. A partir de 45 anos, progressivamente, o diferencial vai se reduzindo e a partir de 85 anos esta diferença praticamente desaparece (tabela 12).

No tocante aos isseis, os valores assumidos pelo indicador sugerem uma mortalidade feminina bastante próxima à masculina, quando se considera o conjunto da população. Todavia, a distribuição das razões nas distintas faixas etárias apresenta oscilações que podem ser função do número reduzido de eventos estudados ou podem sugerir presença de determinantes específicos e recomendam discussão do diferencial da mortalidade por causas específicas (tabela 12).

A sobremortalidade masculina observada nas três populações estudadas vai ao encontro dos resultados apresentados por ZHANG e colaboradores (1995) que, ao analisar a Razão de Mortalidade entre sexos, nas idades entre 45 e 74 anos em 30 países, identificaram mortalidade masculina $100 \%$ maior que a média das mulheres, exibindo China e Cuba os mais baixos valores para este indicador e França e Finlândia os mais altos. Concluem, os autores, que o fenômeno de sobremortalidade masculina variando com a idade e com os países resultam, provavelmente, da maneira diferente como certos agravos à saúde, como por exemplo, neoplasias, doenças do aparelho circulatório e causas externas, incidem sobre cada sexo, levando à morte. Os achados relativos às populações estudadas reforçam que determinantes da saúde da mulher podem diferir no Japão e em outras populações. 


\subsubsection{Mortalidade por causas}

Tomando por base a mortalidade proporcional masculina, em indivíduos de 50 anos e mais, frente às principais causas de óbito (em nível de capítulos da CID - 9), a situação dos isseis assemelha-se à dos residentes no Japão e no Paraná e foram representadas por doenças do aparelho circulatório, neoplasias e doenças do aparelho respiratório (tabela 13).

\section{Tabela 13}

$\mathrm{N}^{\circ}$ de óbitos e mortalidade proporcional (\%), em homens de 50 anos e mais, segundo principais causas básicas de morte (capítulos da CID-9) e população de estudo, 1991.

\begin{tabular}{|c|c|c|c|c|c|c|}
\hline \multirow[t]{2}{*}{ Causas de morte } & \multicolumn{2}{|c|}{ Japão } & \multicolumn{2}{|c|}{ Isseis* } & \multicolumn{2}{|c|}{ Paraná } \\
\hline & $\mathrm{N}^{0}$ & $\%$ & $N^{\circ}$ & $\%$ & $N^{\prime \prime}$ & $\%$ \\
\hline Infeciosas e parasitárias & 6559 & 1,6 & 10 & 1,9 & 464 & 2,8 \\
\hline Neoplasmas & 128005 & 31,8 & 88 & 17,1 & 2770 & 16,6 \\
\hline Endócrinas ${ }^{* *}$ & 5380 & 1,3 & 17 & 3,3 & 402 & 2,4 \\
\hline Aparelho circulatório & 137539 & 34,2 & 209 & 40,7 & 7205 & 43,1 \\
\hline Aparelho respiratório & 58391 & 14,5 & 71 & 13,8 & 1377 & 8,2 \\
\hline Aparelho digestivo & 19406 & 4,8 & 26 & 5,1 & 769 & 4,6 \\
\hline Externas & 20594 & 5,1 & 39 & 7,6 & 958 & 5,7 \\
\hline Subtotal & 375874 & 93,4 & 460 & 89,5 & 13945 & 83,3 \\
\hline Outras & 26618 & 6,6 & 54 & 10,5 & 2788 & 16,7 \\
\hline Total & 402492 & 100,0 & 514 & 100,0 & 16733 & 100,0 \\
\hline
\end{tabular}

* Refere-se aos óbitos ocorridos entre 01/03/90 e 28/02/93.

** Doenças das glândulas endócrinas, da nutrição e do metabolismo e transtornos imunitários

Em relação às doenças infecciosas, no sexo masculino, estas mostraram-se menos importante para os residentes no Japão $(1,6 \%)$ e isseis $(1,9 \%)$, enquanto que entre os residentes no Estado do Paraná, estas causas haviam sido responsáveis por 2,8\% das mortes. 
Os dados relativos à importância das causas entre as mulheres assemelham-se aos observados para os homens. Da mesma forma, doenças do aparelho circulatório e neoplasmas constituíram-se em principais causas de óbito nas populações femininas estudadas. Também se destaca a proporção de mortes por doenças infecciosas, entre mulheres isseis, que mostrou-se mais elevada do que as das residentes no Japão e no Paraná (tabela 14).

\section{Tabela 14}

$\mathrm{N}^{\mathrm{o}}$ de óbitos e mortalidade proporcional (\%), em mulheres de 50 anos e mais, segundo principais causas básicas de morte (capítulos da CID-9) e população de estudo, 1991.

\begin{tabular}{|c|c|c|c|c|c|c|}
\hline \multirow[t]{2}{*}{ Causas de morte } & \multicolumn{2}{|c|}{ Japão } & \multicolumn{2}{|c|}{ Isseis* } & \multicolumn{2}{|c|}{ Paraná } \\
\hline & $\mathrm{N}^{\mathrm{o}}$ & $\%$ & $N^{\circ}$ & $\%$ & $\mathrm{~N}^{\mathrm{o}}$ & $\%$ \\
\hline Infeciosas e parasitárias & 4686 & 1,3 & 13 & 2,9 & 283 & $\overline{2,3}$ \\
\hline Neoplasmas & 82625 & 23,4 & 74 & 16,6 & 1905 & 15,3 \\
\hline Endócrinas ${ }^{* *}$ & 6139 & 1,7 & 25 & 5,6 & 569 & 4,6 \\
\hline Aparelho circulatório & 153141 & 43,3 & 207 & 46,4 & 5877 & 47,1 \\
\hline Aparelho respiratório & 41291 & 11,7 & 40 & 9,0 & 1046 & 8,4 \\
\hline Aparelho digestivo & 15524 & 4,4 & 23 & 5,2 & 441 & 3,5 \\
\hline Externas & 13352 & 3,8 & 11 & 2,5 & 360 & 2,9 \\
\hline Subtotal & 316758 & 89,5 & 393 & 88,1 & 10481 & 84,0 \\
\hline Outras & 37046 & 10,5 & 53 & 11,9 & 1996 & 16,0 \\
\hline Total & 353804 & 100,0 & 446 & 100,0 & 12477 & 100,0 \\
\hline
\end{tabular}

* Refere-se aos óbitos ocorridos entre 01/03/90 e 28/02/93.

** Doenças das glândulas endocrinas, da nutrição e do metabolismo e transtornos imunitários

Dado que as proporções fornecem somente a importância de determinadas causas, no conjunto dos óbitos, serão analisados coeficientes por causas, buscando, com isso, uma estimativa do risco de morrer em cada população estudada e, posteriormente, em cada sexo.

Nas tabelas 15 e 16 são apresentados os coeficientes padronizados de mortalidade por causas e as respectivas razōes entre eles, para as populações de estudo. Observa-se, 
entre os homens, coeficiente de mortalidade por neoplasmas menor para isseis (418,9 por 100.000 homens de 50 anos e mais) (tabela 15) e mais elevado para residentes no Japão (696 por 100.000 homens de 50 anos e mais). Nas doenças do aparelho circulatório, isseis e residentes no Japão apresentam taxas bastante próximas $(766,7$ e 729,9 por 100.000 homens de 50 anos e mais, respectivamente), porém bem abaixo do valor correspondente aos residentes no Estado do Paraná (1388 por 100.000 homens de 50 anos e mais). No grupo das doenças endócrinas, nutricionais e metabólicas, a mortalidade dos isseis situa-se em posição intermediária e para as doenças do aparelho digestivo, a diferença não foi estatisticamente significante.

\section{Tabela 15}

Coeficientes de mortalidade padronizados ${ }^{1}$ (por 100.000 homens de 50 anos e mais), razão de mortalidade padronizada (RMP) e respectivo intervalo de $95 \%$ de confiança (IC $95 \%$ ) segundo população de estudo e principais causas básicas de morte ${ }^{2}$.

\begin{tabular}{|c|c|c|c|c|c|}
\hline \multirow[t]{2}{*}{ Causas de morte } & \multicolumn{3}{|c|}{ Coeficiente } & \multicolumn{2}{|c|}{ RMP IC $(95 \%)$} \\
\hline & Japão & Isseis & Paraná & Isseis/Japão & Isseis/Paraná \\
\hline Infecciosas e parasitárias & 35,0 & 90,0 & 86,8 & $2,57[1,32 ; 5,01]^{*}$ & $1,04[0,67 ; 1,61]$ \\
\hline Neoplasmas & 696,0 & 418,9 & 521,6 & $0,60[0,54 ; 0,67]^{*}$ & $0,80[0,71 ; 0,91]^{*}$ \\
\hline Endócrinas $^{3}$ & 28,9 & 53,1 & 79,0 & $1,84[1,37 ; 2,48]^{*}$ & $0,67[0,56 ; 0,81]^{*}$ \\
\hline Aparelho circulatório & 729,9 & 766,7 & 1388,0 & $1,05[0,97 ; 1,13]$ & $0,55[0,52 ; 0,58]^{*}$ \\
\hline Aparelho respiratório & 303,7 & 217,8 & 271,9 & $0,72[0,65 ; 0,79]^{*}$ & $0,80[0,72 ; 0,89]^{*}$ \\
\hline Aparelho digestivo & 106,2 & 123,4 & 143,3 & $1,16[0,87 ; 1,55]$ & $0,86[0,67 ; 1,11]$ \\
\hline Externas & 113,4 & 213,6 & 174,7 & $1,88[1,46 ; 2,44]^{*}$ & $1,22[0,99 ; 1,51]$ \\
\hline
\end{tabular}

Entre as mulheres, o coeficiente de mortalidade padronizado das isseis por neoplasias mostrou-se superior ao das residentes no Japão (respectivamente, 505,5 e 322,2 por 100.000 mulheres de 50 anos e mais) e, até mesmo, ao das residentes no Estado do Paraná (336 por 100.000 mulheres de 50 anos e mais); porém, esta superioridade não foi 
estatisticamente significante (RMP de 1,21 [1,00;1,46]). Para o grupo das doenças endócrinas, nutricionais e metabólicas, a mortalidade das isseis foi bem mais elevada do que a das residentes no Japão (RMP de $4,41[3,03 ; 6,39]$ ) e bastante próxima a das residentes no Estado do Paraná (RMP de $0,93[0,77 ; 1,12]$ ). No caso das doenças do aparelho digestivo, a taxa relativa às isseis assemelhou-se às das residentes no Japão e no Paraná. Entretanto, o coeficiente de mortalidade por doenças do aparelho circulatório das isseis $(786,1$ por 100.000 mulheres de 50 anos e mais) foi notadamente mais elevado do que o das residentes no Japão (485,2 por 100.000 mulheres de 50 anos e mais), contudo mais baixo do que o das residentes no Paraná (1047 por 100.000 mulheres de 50 anos e mais), isto é, as isseis apresentaram estimativa do risco de morrer $62 \%$ maior do que o das mulheres do seu país de origem e $75 \%$ do risco apresentado pelas mulheres do Paraná.

\section{Tabela 16}

Coeficientes de mortalidade padronizados ${ }^{\prime}$ (por 100.000 mulheres de 50 anos e mais), razão de mortalidade padronizada (RMP) e respectivo intervalo de $95 \%$ de confiança (IC 95\%) segundo população de estudo e principais causas básicas de morte ${ }^{2}$.

\begin{tabular}{|c|c|c|c|c|c|}
\hline \multirow[t]{2}{*}{ Causas de morte } & \multicolumn{3}{|c|}{ Coeficiente } & \multicolumn{2}{|c|}{ RMP IC $(95 \%)$} \\
\hline & Japão & Isseis & Paraná & Isseis/Japão & Isseis/Paraná \\
\hline Infecciosas e parasitárias & 16,7 & 68,0 & 50,3 & $4,07[2,33 ; 7,10]^{*}$ & $1,35[0,95 ; 1,92]$ \\
\hline Neoplasmas & 322,2 & 405,5 & 336,0 & $1,26[1,04 ; 1,53]^{*}$ & $1,21[1,00 ; 1,46]$ \\
\hline Endócrinas $^{3}$ & 21,2 & 93,5 & 100,6 & $4,41[3,04 ; 6,39]^{*}$ & $0,93[0,77 ; 1,12]$ \\
\hline Aparelho circulatório & 485,2 & 786,1 & 1047,0 & $1,62[1,48 ; 1,78]^{*}$ & $0,75[0,70 ; 0,80]^{*}$ \\
\hline Aparelho respiratório & 126,5 & 126,1 & 189,0 & $1,00[0,86 ; 1,15]$ & $0,67[0,59 ; 0,74]$ \\
\hline Aparelho digestivo & 54,1 & 73,3 & 78,1 & $1,36[1,08 ; 1,71]^{*}$ & $0,94[0,77 ; 1,14]$ \\
\hline Externas & 52.0 & 51,0 & 63,5 & $0,98[0,70 ; 1,38]$ & $0,80[0,59 ; 1,10]$ \\
\hline
\end{tabular}

As causas de óbito diferem substancialmente entre sexos. Embora representem as doenças do aparelho circulatório, as neoplasias e as doenças do aparelho respiratório as 
principais causas, para ambos os sexos, as taxas específicas por causas sugerem distintos níveis de exposição aos fatores de risco, entre os sexos, na mesma população. Os dados da tabela 17 referem-se às razões de mortalidade padronizada entre sexos, para as principais causas de óbito, nas populações de estudo. Nela, são merecedoras de atenção, entre os isseis, as semelhanças das taxas de mortalidade por neoplasias e doenças do aparelho circulatório em ambos sexos, diferentemente da situação verificada entre os residentes no Japão e no Paraná.

\section{Tabela 17}

Razão de mortalidade padronizada (RMP) ${ }^{1}$ entre sexos, em indivíduos de 50 anos e mais, segundo principais causas ${ }^{2}$ de morte e população de estudo, 1991.

\begin{tabular}{lccc}
\hline Causas de morte & Japão & Isseis $^{4}$ & Estado do Paraná \\
\hline Infeciosas e parasitárias & 2,10 & 1,32 & 1,73 \\
Neoplasmas & 2,16 & 1,03 & 1,55 \\
Endócrinas $^{3}$ & 1,36 & 0,57 & 0,79 \\
Aparelho circulatório & 1,50 & 0,98 & 1,33 \\
Aparelho respiratório & 2,40 & 1,73 & 1,44 \\
Aparelho digestivo & 1,96 & 1,68 & 1,83 \\
Externas & 2,18 & 4,19 & 2,75 \\
\hline Total & 1,81 & 1,16 & 1,44 \\
\hline
\end{tabular}

TCoficientes de mortalidade ajustados pela população mundial de 50 anos e mais

2 Segundo os Capítulos da CID - $9^{a}$ Revisão

${ }^{3}$ Doenças das glândulas endócrinas, da nutrição e do metabolismo e transtornos imunitários

${ }^{4}$ Refere-se aos óbitos ocorridos entre 01/03/90 e 28/02/93

Provavelmente a semelhança nas taxas de mortalidade, entre sexos, por doenças do aparelho circulatório e neoplasmas, esteja determinando uma razão de mortalidade por todas as causas mais próxima à unidade, na população issei (RMP de 1,16). ZHANG e colaboradores (1995) comentam que os níveis de mortalidade por doenças cardiovasculares e câncer determinam um maior ou menor diferencial entre sexos. Ilustram a situação 
analisando o indicador em três grupos etários (45-54, 55-64 e 65-74 anos), em vários países, nos quais encontraram, com exceção da China, maior taxa de mortalidade geral e por doenças cardiovasculares entre os homens, em todos os países estudados. Relativamente ao câncer, da mesma forma, maiores níveis de mortalidade foram observados em todos os países, no grupo etário de 55 a 74 anos. Entretanto, entre 45 e 54 anos, algumas nações apresentaram sobremortalidade feminina que, segundo os autores, deveu-se à maior participação da mortalidade por câncer de mama, colo uterino e útero, neste grupo etário. Além disso, em suas discussões, aventam também a participação dos fatores nutricionais, mais especificamente ingestão de gordura saturada, na mortalidade por doenças cardiovasculares e algumas localizações de câncer como mama, colo-retal e pulmão. Salientam que nas mulheres uma ingestão alta de gordura saturada é menos prejudicial do que em homens, por causa da proteção conferida contra doenças ateromatosas, pelos níveis mais altos da fração do colesterol de alta densidade (HDL). Concluem que as diferenças não podem ser explicadas pelos fatores genéticos e devem ser atribuídas ao estilo de vida, que é distinto em cada sexo e destacam o papel desempenhado por fatores sócio-econômicos para explicar a situação observada em países que diferiram dos demais, como, por exemplo, Cuba e China (ZHANG et al, 1995).

Assim sendo, é possível que os fatores sócio-econômicos estejam interferindo para as diferenças. A semelhança nas taxas de mortalidade entre sexos nos isseis, distintamente do observado para a maioria das populações, pode estar relacionada às exigências sociais feitas às mulheres, com manutenção dos antigos padrões observados entre os japoneses, como por exemplo, a postura discriminatório em relação às mulheres na sociedade japonesa, conforme ilustram KIYOTANI e YAMASHIRO (1992), ao descreverem que, quando da chegada ao Brasil, à mulher cabia, além de trabalhar no cafezal como os demais membros da família, a responsabilidade de preparo das refeições e dos afazeres domésticos. Esta situação caracteriza, de certa forma, jornada múltipla de trabalho. Assim, como no passado, pode ser que esta postura tenha persistido por muito tempo nesta sociedade. 
Todavia, é preciso lembrar a restrição na análise das causas de óbito segundo os capítulos da CID-9, por agruparem, dentro de cada um, grande variedade de patologias e não haver homogeneidade no eixo classificátorio. Segundo LAURENTI e colaboradores (1987), os agrupamentos (sub-divisões do capítulo), por reunirem um conjunto de categorias com características etiológicas semelhantes, podem possibilitar melhor discussão dos prováveis fatores que contribuem para o aparecimento das doenças.

Assim, a apreciação dos dados referentes à mortalidade proporcional segundo principais agrupamentos de causas permite verificar que, dentro de um mesmo capítulo, há diferenças na ordem de importância dos agrupamentos de causas, nas populações estudadas (tabela 18).

\section{Tabela 18}

$\mathrm{N}^{0}$ de óbitos e mortalidade proporcional (\%), em homens de 50 anos e mais, segundo principais causas básicas (agrupamentos da CID-9) e população de estudo, 1991.

\begin{tabular}{|c|c|c|c|c|c|c|}
\hline \multirow[t]{2}{*}{ Causa de morte } & \multicolumn{2}{|c|}{ Japão } & \multicolumn{2}{|c|}{ Isseis* } & \multicolumn{2}{|c|}{ Paraná } \\
\hline & $\mathrm{N}^{\mathrm{o}}$ & $\%$ & $\mathrm{~N}^{\circ}$ & $\%$ & $\mathrm{~N}^{\mathrm{o}}$ & $\%$ \\
\hline Todas causas & 402492 & 100,0 & 514 & 100,0 & 16733 & 100,0 \\
\hline \multicolumn{7}{|l|}{ Neoplasmas malignos } \\
\hline estômago & 28074 & 7,0 & 27 & 5,3 & 512 & 3,1 \\
\hline cólon & 7661 & 1,9 & 6 & 1,2 & 102 & 0,6 \\
\hline traquéia, brônquios e pulmão & 26764 & 6,6 & 17 & 3,3 & 408 & 2,4 \\
\hline próstata & 3815 & 0,9 & 2 & 0,4 & 236 & 1,4 \\
\hline Diabetes mellitus & 4276 & 1,1 & 14 & 2,7 & 306 & 1,8 \\
\hline \multicolumn{7}{|l|}{ Doenças do aparelho circulatório } \\
\hline Doenças isquêmicas do coração & 25969 & 6,5 & 57 & 11,1 & 2207 & 13,2 \\
\hline Doenças cerebrovasculares & 52431 & 13,0 & 88 & 17,1 & 2901 & 17,3 \\
\hline \multicolumn{7}{|l|}{ Causas externas } \\
\hline Suicídios & 6606 & 1,6 & 6 & 1,2 & 101 & 0,6 \\
\hline Homicídios & 137 & 0,0 & - & - & 147 & 0,9 \\
\hline
\end{tabular}

*Refere-se aos 6́bitos ocorridos entre 01/03/90 e 28/02/93. 
A observação dos dados, na tabela 18 , revela que, em nível dos agrupamentos, a mortalidade proporcional dos isseis de 50 anos e mais foi próxima à observada na população residente no Paraná, destacando-se as doenças cerebrovasculares $(17,1 \%$ e $17,3 \%)$, as doenças isquêmicas do coração $(11,1 \%$ e $13,2 \%)$, o câncer de estômago $(5,3 \%$ e $3,1 \%)$ e o câncer de pulmão $(3,3 \%$ e $2,4 \%)$. Na população masculina do Japão, ocuparam as quatro primeiras posições: doenças cerebrovasculares (13\%), câncer de estômago (7\%), câncer de pulmão $(6,6 \%)$ e as doenças isquêmicas do coração $(6,5 \%)$. Destaque para a proporção de diabetes mellitus em isseis, que se apresentou superior à dos residentes no Japão e até mesmo à dos residentes no Paraná $(2,7 \%, 1,1 \%$ e $1,8 \%$, respectivamente).

Entre as mulheres de 50 anos e mais, as principais causas de morte, nas três populações, foram representadas pelos agrupamentos contidos no capítulo das doenças do aparelho circulatórios (tabela 19). As doenças cerebrovasculares constituíram a principal causa de morte $(17,2 \%, 21,5 \%$ e $17,5 \%$, respectivamente, para as residentes no Japão, as isseis e as residentes no Paraná), seguidas pelas doenças isquêmicas do coração $(6,8 \%$, $11,4 \%$ e $12,6 \%$, respectivamente). Tanto entre as isseis quanto entre as residentes no Paraná, destacou-se como terceira causa o diabetes mellitus, diferindo da situação observada entre as residentes no Japão, para as quais, câncer de estômago $(4,4 \%)$, de pulmão $(2,7 \%)$ e de cólon $(2,1 \%)$, tiveram importância maior do que o diabetes mellitus $(1,4 \%)$.

Também merece destaque, a menor importância do câncer de estômago entre as residentes no Paraná $(1,6 \%)$, enquanto que entre as isseis, a proporção de mortes por esta causa $(3,4 \%)$ foi próxima a observada entre as residentes no Japão $(4,4 \%)$.

Além das causas descritas, no capítulo das causas externas, chama atenção a participação diferenciada do suicídio entre as residentes no Japão $(1,4 \%)$, cuja proporção está acima dos valores correspondentes às isseis $(0,4 \%)$ e às residentes no Estado do Paraná $(0,2 \%)$. Por outro lado, vale ressaltar que, entre as residentes no Estado do Paraná, suicídios e homicídios tiveram a mesma importância, enquanto que entre as residentes no 
Japão, homicídios assumem importância bem menor, à semelhança das isseis, em que os dados indicam ausência de registro de casos de morte por esta causa.

\section{Tabela 19}

$\mathrm{N}^{\circ}$ de óbitos e mortalidade proporcional (\%), em mulheres de 50 anos e mais, segundo principais causas básicas (agrupamentos da CID-9) e população de estudo, 1991.

\begin{tabular}{|c|c|c|c|c|c|c|}
\hline \multirow[t]{2}{*}{ Causas de morte } & \multicolumn{2}{|c|}{ Japão } & \multicolumn{2}{|c|}{ Isseis* } & \multicolumn{2}{|c|}{ Paraná } \\
\hline & $\mathrm{N}^{\circ}$ & $\%$ & $\mathrm{~N}^{\prime \prime}$ & $\%$ & $\mathrm{~N}^{\mathrm{o}}$ & $\%$ \\
\hline Todas causas & 353804 & 100,0 & 446 & 100,0 & 12477 & 00,0 \\
\hline \multicolumn{7}{|l|}{ Neoplasmas malignos } \\
\hline estômago & 15537 & 4,4 & 15 & 3,4 & 201 & 1,6 \\
\hline cólon & 7433 & 2,1 & 6 & 1,3 & 106 & 0,8 \\
\hline traquéia, brônquios e pulmão & 9621 & 2,7 & 3 & 0,7 & 182 & 1,5 \\
\hline mama feminina & 4568 & 1,3 & 5 & 1,1 & 217 & 1,7 \\
\hline útero - porção nāo especificada** & 1892 & 0,5 & 4 & 0,9 & 94 & 0,8 \\
\hline colo do útero & 1512 & 0,4 & 1 & 0,2 & 119 & 1,0 \\
\hline Diabetes mellitus & 4845 & 1,4 & 22 & 4,9 & 498 & 4,0 \\
\hline \multicolumn{7}{|l|}{ Doenças do aparelho circulatório } \\
\hline Doenças isquêmicas do coração & 23943 & 6,8 & 51 & 11,4 & 1570 & 12,6 \\
\hline Doenças cerebrovasculares & 60927 & 17,2 & 96 & 21,5 & 2189 & 17,5 \\
\hline \multicolumn{7}{|l|}{ Causas externas } \\
\hline Suicídios & 4899 & 1,4 & 2 & 0,4 & 30 & 0,2 \\
\hline Homicídios & 117 & 0,0 & - & - & 21 & 0,2 \\
\hline
\end{tabular}

* Refere-se aos óbitos ocorridos entre 01/03/90 e 28/02/93.

** CID 179

A comparação dos dados das tabelas 18 e 19 permite verificar que a participação dos agrupamentos de causas, em cada sexo, apresenta-se de forma distinta. Maiores diferenças são notadas para o conjunto das neoplasias, principalmente câncer de estômago e pulmão, cuja importância é bem maior entre os homens. Porém, dado que a mortalidade 
proporcional, conforme mencionado anteriormente, apenas indica a importância de determinadas causas no conjunto das causas que levaram à morte, a discussão das diferenças descritas, bem como, dos possíveis determinantes da situação observada será realizada a partir do exame dos coeficientes mortalidade das principais causas.

Tendo em vista tais questões, as discussões que se seguem foram baseadas na análise de dados por agrupamentos da CID. Foram destacadas apenas algumas doenças que a literatura vem registrando como de interesse no estudo envolvendo populações japonesas migrantes (GORDON, 1957 e 1967; GOTLIEB, 1988; TSUGANE et al, 1994; CARDOSO et al, 1997). São, portanto, especificamente, aquelas relativas a alguns agrupamentos do capítulo das doenças do aparelho circulatório (doenças cerebrovasculares e doenças isquêmicas do coração), dos neoplasmas (estômago, cólon, pulmão, mama feminina e próstata), das doenças das glândulas endócrinas, nutricionais e metabólicas (com destaque para diabetes mellitus) e das causas externas (especificamente suicídio). Vale a pena, ainda, ressaltar que algumas causas de óbito merecedoras de discussão, de acordo com as justificativas do presente estudo, não constituíram objeto de análise. Conforme já mencionado nos procedimentos metodológicos, um exemplo seria o câncer de colo uterino que, apesar da sua importância, o reduzido número de eventos registrados entre as isseis recomenda cautela quanto às conclusões.

\subsubsection{Mortalidade por doenças do aparelho circulatório}

De acordo com o apreciado nas tabelas 13 e 14, as doenças do aparelho circulatório constituíram as principais causas de óbito, nas três populações estudadas. A importância deste grupo de causa na mortalidade não se restringe apenas às populações estudadas, mas constitui um fenômeno mundialmente observado na atualidade (WORLD HEALTH ORGANIZATION, 1996). Os primeiros estudos envolvendo populações japonesas migrantes (GORDON, 1957 e 1967) já haviam sido desenvolvidos com a finalidade de 
identificar fatores associados à ocorrência destas doenças, mais especificamente, das doenças isquêmicas do coração (CID 410-414) e das doenças cerebrovasculares (CID 430438). No caso do presente estudo, estas causas responderam por uma expressiva parcela de mortes (tabelas 18 e 19) e apresentaram marcantes diferenças em suas taxas, conforme permitem verificar as discussões que se seguem.

\section{- Doenças isquêmicas do coração}

As taxas padronizadas de mortalidade por doenças isquêmicas do coração em isseis de 50 anos e mais, situaram-se em posição intermediária em ambos os sexos (233,3 e 191,3 por 100.000 hab de 50 anos e mais, respectivamente, para homens e mulheres).

\section{Tabela 20}

Coeficientes de mortalidade padronizados' por doenças isquêmicas do coração (por 100.000 hab de 50 anos e mais), razão de mortalidade padronizada (RMP) e respectivo intervalo de 95\% de confiança (IC 95\%) segundo sexo e população de estudo, 1991.

\begin{tabular}{cccccc}
\hline \multirow{2}{*}{ Sexo } & \multicolumn{3}{c}{ Coeficiente } & \multicolumn{2}{c}{ RMP IC(95\%) } \\
& Japão & Isseis & Paraná & Isseis/Japão & Isseis/Paraná \\
\hline \multirow{2}{*}{ Masculino } & 137,8 & 233,3 & 421,0 & $1,69[1,54 ; 1,86]^{*}$ & $0,55[0,52 ; 0,59]^{*}$ \\
Feminino & 75,6 & 191,3 & 280,4 & $2,53[2,29 ; 2,80]^{*}$ & $0,68[0,65 ; 0,72]^{*}$
\end{tabular}

* Estatisticamente significante em nível de $5 \%$

1 Ajustados pela população mundial de 50 anos e mais

Os valores apresentados na tabela 20 permitem evidenciar menores taxas de morte entre os residentes no Japão, principalmente entre as mulheres (respectivamente, 137,8 e 75,6 por 100.000 hab de 50 anos e mais). Relativamente aos isseis, a mortalidade dos homens correspondeu a pouco mais da metade da taxa da população masculina do estado 
(RMP de 0,55 [0,52;0,59]); contudo, entre as mulheres o diferencial foi menos acentuado (RMP de $0,68[0,65 ; 0,72]$ ), sugerindo que o padrão de mortalidade das isseis mais se aproxima do apresentado pelas paranaenses, principalmente, ao se levar em consideração a mortalidade das isseis por esta causa, que foi 2,53 vezes a das residentes no Japão. Essas diferenças foram estatisticamente significantes. Também, na tabela 20 , observa-se uma sobremortalidade masculina por doenças isquêmicas do coração nas três populações, sendo as diferenças mais pronunciadas nos residentes no Japão (RMP de 1,82); entre as populações isseis, o diferencial homem/mulher é bem menos acentuado (RMP de 1,21)

Os dados da tabela 21 referem-se à mortalidade por doenças isquêmicas do coração nas distintas faixas etárias e fornecem uma idéia do diferencial de risco de acordo com a idade. No tocante às populaçōes masculinas, observa-se que as taxas de mortalidade dos isseis situam-se em posição intermediária, em todos os grupos etários específicos.

Chama atenção, ainda na tabela 21, a alta mortalidade dos paranaenses em comparação aos residentes no Japão, principalmente na faixa etária de 35 a 59 anos, insinuando uma possível exposição precoce dos residentes no Paraná aos fatores de risco para doenças isquêmicas do coração. Quanto às populaçōes femininas, as diferenças entre as residentes no Paraná e no Japão são observadas em todos os grupos de idade.

As diferentes taxas de mortalidade, entre países, por doenças isquêmicas do coração constitui fenômeno que vem sendo referido com frequência. Para MARMOT (1985), existe evidência que a mortalidade e a morbidade por doenças isquêmicas do coração variam entre diferentes países e, dentro do país, entre várias regiões geográficas. Contudo, a mortalidade e, provavelmente, a incidência da doença cardíaca coronariana (CHD) têm declinado em vários países (como Estados Unidos, Finlândia e Austrália), mas a Suécia vem apresentando um aumento na mortalidade que não é facilmente explicado. Especificamente em relação ao Japão, tem-se observado um contínuo declínio nos coeficientes de mortalidade padronizados por idade. Mudanças nas taxas de mortalidade comprovam que CHD não é atributo fixo da população, nem conseqüência inevitável da 
idade e argumentam a favor das possibilidades de prevenção e tratamento da doença de forma bem sucedida (MARMOT, 1985).

\section{Tabela 21}

Coeficientes de mortalidade por doenças isquêmicas do coração (por 100.000 habitantes) segundo sexo, grupo etário e população de estudo, 1991.

\begin{tabular}{crrrrrr}
\hline & \multicolumn{2}{c}{ Japão } & \multicolumn{2}{c}{ Isseis* } & \multicolumn{2}{c}{ Paraná } \\
Grupo etário & Masc & Fem & Masc & Fem & Masc & Fem \\
\hline 0 a 4 & - & 0,1 & - & - & - & - \\
5 a 9 & - & 0,0 & - & - & - & - \\
10 a 14 & - & 0,0 & - & - & - & - \\
15 a 19 & 0,1 & 0,1 & - & - & 0,9 & 0,2 \\
20 a 24 & 0,3 & 0,2 & - & - & 1,0 & 0,5 \\
25 a 29 & 1,1 & 0,3 & - & - & 5,1 & 1,0 \\
30 a 34 & 1,8 & 0,4 & - & - & 6,9 & 3,0 \\
35 a 39 & 3,2 & 0,8 & - & - & 23,7 & 11,4 \\
40 a 44 & 6,7 & 1,4 & - & - & 42,9 & 23,0 \\
45 a 49 & 13,5 & 3,5 & - & - & 79,1 & 32,6 \\
50 a 54 & 23,4 & 5,6 & 121,2 & - & 138,0 & 59,6 \\
55 a 59 & 46,3 & 11,9 & 62,8 & 82,5 & 225,2 & 95,5 \\
60 a 64 & 77,8 & 24,4 & 226,2 & 169,0 & 306,5 & 158,3 \\
65 a 69 & 123,1 & 50,9 & 177,1 & 155,8 & 513,5 & 314,3 \\
70 a 74 & 222,0 & 113,0 & 249,4 & 137,9 & 737,4 & 459,5 \\
75 a 79 & 402,0 & 246,1 & 668,7 & 784,3 & 901,6 & 793,3 \\
80 a 84 & 679,0 & 475,6 & 1224,1 & 858,1 & 1605,8 & 1266,6 \\
85 e + & 1173,7 & 951,5 & 1186,9 & 1728,4 & 1764,6 & 2010,9 \\
\hline Refere-se aos 6bitos ocorridos entre $01 / 03 / 90$ e $28 / 02 / 93$. & & &
\end{tabular}

LILIENFELD e STOLLEY (1994) destacam que as diferentes taxas entre os países são difíceis de serem completamente explicadas por causa da variação na prática diagnóstica e na confiabilidade das declarações de óbito por locais geográficos. Todavia, segundo STAMLER (1989), as comparações das variações geográficas, desde que sejam consideradas as limitações e analisadas em conjunto com resultados obtidos através de diferentes procedimentos metodológicos, podem contribuir na elucidação de fatores 
etiológicos, particularmente o papel dos fatores de risco relacionados ao estilo de vida favoráveis e desfavoráveis.

Para MARTINS e colaboradores (1995), atividades no trabalho, tipo de nutrição e outros hábitos legitimados culturalmente criam estilos de vida. No organismo humano, apesar da busca de adaptação e balanço vital, a homeostase nem sempre é compatível com a sua longevidade e incluem-se, aí, estilo de vida que pode relacionar-se à morbidade, levando à morte prematura, como é o caso da doença cardiovascular aterosclerótica.

ABU-ZEID e colaboradores (1978), também, defendem que principalmente fatores ambientais, particularmente dieta, são responsáveis por estas diferenças. Apesar disso, reconhecem o papel dos fatores genéticos na origem da doença isquêmica do coração, apoiados pela evidência que certos padrões anatômicos das artérias coronarianas são herdados e podem reduzir ou elevar o desenvolvimento da doença isquêmica do coração ou trombose e ateroma.

MARTINS e colaboradores (1996), em revisão, relatam que os fatores de risco da doença cardiovascular aterosclerótica são representados por um conjunto de doenças crônico-degenerativas de evolução prolongada como as dislipidemias, a hipertensão arterial, a obesidade e o diabetes mellitus. Estas doenças guardam entre si complexa relação, tendo em comum suas etiologias. Entre as frações do colesterol total, a de baixa densidade tem sido apontada como uma das mais importantes constituintes da composição do ateroma. Por outro lado, a de alta densidade atuaria no transporte reverso do colesterol, diminuindo ou estagnando a formação da placa.

Para SOLBERG e colaboradores (1987), a relação entre severidade e extensão da aterosclerose coronariana e o desenvolvimento da doença cardíaca coronariana é, na atualidade, quase que universalmente aceita e sugerem que o processo de aterosclerose é o resultado da interação dos fatores genéticos e ambientais. llustram o efeito dos fatores ambientais com base nas diferenças geográficas na aterosclerose que não podem ser 
explicadas pelas diferenças genéticas ou raciais. Mencionam a baixa frequência de doença cardíaca coronariana não como uma especificidade determinada geneticamente, mas reflexo do grau de aterosclerose coronariana e níveis de certos fatores de risco. Apoiam-se nas evidências fornecidas pelos estudos sobre a população de japoneses que migraram para os Estados Unidos e Havaí, nos quais observou-se que a posição ocupada pelos japoneses de Havaí, quanto à mortalidade por doenças isquêmicas do coração, era intermediária quando comparada com Estados Unidos e Japão. Para SVANBORG e colaboradores (1985) a baixa frequência de morte por infarto de miocárdio no Japão pode ser atribuída parcialmente às diferenças nutricionais.

No estudo realizado por TSUGANE e colaboradores (1994), identificou-se nível de colesterol sérico total muito mais alto entre japoneses do Brasil do que de cada um dos cinco grupos do Japão. Relacionam, então, as mais altas taxas de mortalidade por doenças isquêmicas do coração, observadas por ocasião de estudo anterior, na primeira geração de japoneses residentes em São Paulo (GOTLIEB, 1988), ao aumento do nível de colesterol. Explicam este aumento a partir da alta ingestão de carne, especialmente bovina, cujo consumo diário foi observado em $40 \%$ dos homens de 40 a 49 anos em São Paulo, ao passo que a proporção no Japão variava de $0 \%$ a $7 \%$. Além disso, atribuem, também, o aumento do risco de doença isquêmica do coração à elevação dos níveis de pressão sangüínea e no índice de massa corporal, e ao mais baixo valor de colesterol de alta densidade observado entre japoneses de São Paulo. Todavia, a despeito de mais altas taxas de mortalidade por doença isquêmica do coração, entre isseis, verificaram menor frequência de fumantes entre japoneses de São Paulo, relativamente aos do Japão.

MORAES e SOUZA (1996), em discussão das condições associadas às doenças isquêmicas do coração, destacam, como mais potentes fatores de risco, a hipertensão arterial, a hipercolesterolemia e o hábito de fumar. No estudo, avaliando a existência de um efeito dose-resposta entre níveis de exposição a estes fatores de risco e as doenças isquêmicas do coração, além de confirmarem a relevância destes fatores de risco, destacam 
o efeito deletério do tempo de exposição à hipertensão arterial e à quantidade de cigarros consumidos por dia.

Frente às considerações e as taxas de mortalidade apresentadas pelos isseis residentes no Estado do Paraná, é possível que os migrantes estejam reproduzindo as mudanças em seu estilo de vida, a exemplo do que ocorreu com os que migraram para São Paulo e, até mesmo, para os Estados Unidos.

Em relação ao diferencial entre sexos, a menor mortalidade feminina observada nas três populações estudadas pode ser explicada com base em ZHANG e colaboradores (1995) que destacam um efeito danoso, provavelmente, menor do consumo de gordura saturada em mulheres. Comentam que tal fato pode estar associado a níveis mais altos de hormônios sexuais e, consequientemente, níveis aumentados de colesterol de alta densidade, que protege contra doenças ateromatosas. WALDRON (1983) destaca, também, a ampla pressão social contra fumo sobre às mulheres, que pode contribuir para um mais baixo risco de doenças isquêmicas do coração. Todavia, ressalta que as mais importantes evidências sobre a influência ambiental são fornecidas pelos achados que demonstram que a magnitude da mortalidade por doenças isquêmicas do coração nos distintos sexos apresenta variação histórica e cultural.

TSUGANE e colaboradores (1994) mencionam que a prevalência de fumantes entre mulheres japonesas de São Paulo é marcadamente mais baixa do que entre homens. É provável que mulheres isseis do Paraná, à semelhança de São Paulo, fumem menos, tenham níveis mais altos de colesterol protetor e níveis mais baixos de pressão arterial diastólica, fatos explicativos para os diferenciais observados.

Relativamente à maior mortalidade observada para a população geral do Estado do Paraná, é bastante provável que esta situação seja conseqüente à influência dos fatores de risco discutidos. Embora não dispondo de dados específicos sobre o Estado, uma aproximação poderia ser feita, baseando no estudo realizado por MARTINS e 
colaboradores (1995), relativamente à uma população residente em uma área metropolitana da região Sudeste do Brasil (Cotia - SP). Dentre os resultados, identificaram, em todos os agrupamentos sociais, hábitos componentes do estilo de vida que se constituem em fatores de risco de morbidades determinantes das doenças cardiovasculares ateroscleróticas. Constataram uma prevalência média de tabagismo de $45 \%$ entre os homens, uniformemente distribuída entre as classes sociais, e de $22,5 \%$ entre as mulheres; alta prevalência de sedentarismo (entre $40 \%$ e $50 \%$ ), sem diferenças entre os sexos e classes sociais; e o etilismo como um hábito bastante difundido entre os homens.

Os resultados do presente estudo relativos às doenças isquêmicas do coração mostram-se de acordo com apresentados em outros estudos e permitem confirmar a importância da participação dos fatores de risco, principalmente, aqueles inerentes ao modo de viver, sugerindo a possibilidade de alteração tanto nos níveis de incidência quanto de mortalidade por esta doença.

\section{- Doenças cerebrovasculares}

As doenças cerebrovasculares mostraram-se mais importantes do que as doenças isquêmicas do coração, nas três populações estudadas (figura 8). A mortalidade por doenças cerebrovasculares, em ambos os sexos, foi mais alta nos isseis do que nos habitantes do Japão; porém, enquanto que, entre os homens, o coeficiente padronizado de mortalidade referente aos isseis foi apenas $18 \%$ maior (RMP de $1,18[1,12 ; 1,24])$ do que o dos residentes no Japão, entre as mulheres, o valor assumido pela RMP indicou que a mortalidade das isseis foi praticamente o dobro da observada para as mulheres no Japão. Observa-se que o risco estimado entre os isseis é $60 \%$ do valor apresentado pelos homens paranaenses, enquanto que não há diferença estatisticamente significante entre as mulheres residentes no Estado do Paraná. Somente entre os isseis foi detectado maior risco de morrer entre as mulheres (tabela 22). 
Figura 8

Coeficientes de mortalidade padronizados* por doenças isquêmicas do coração (DIC) e por doenças cerebrovasculares (DCV) segundo sexo e população de estudo (por 100.000 hab de 50 anos e mais), 1991.
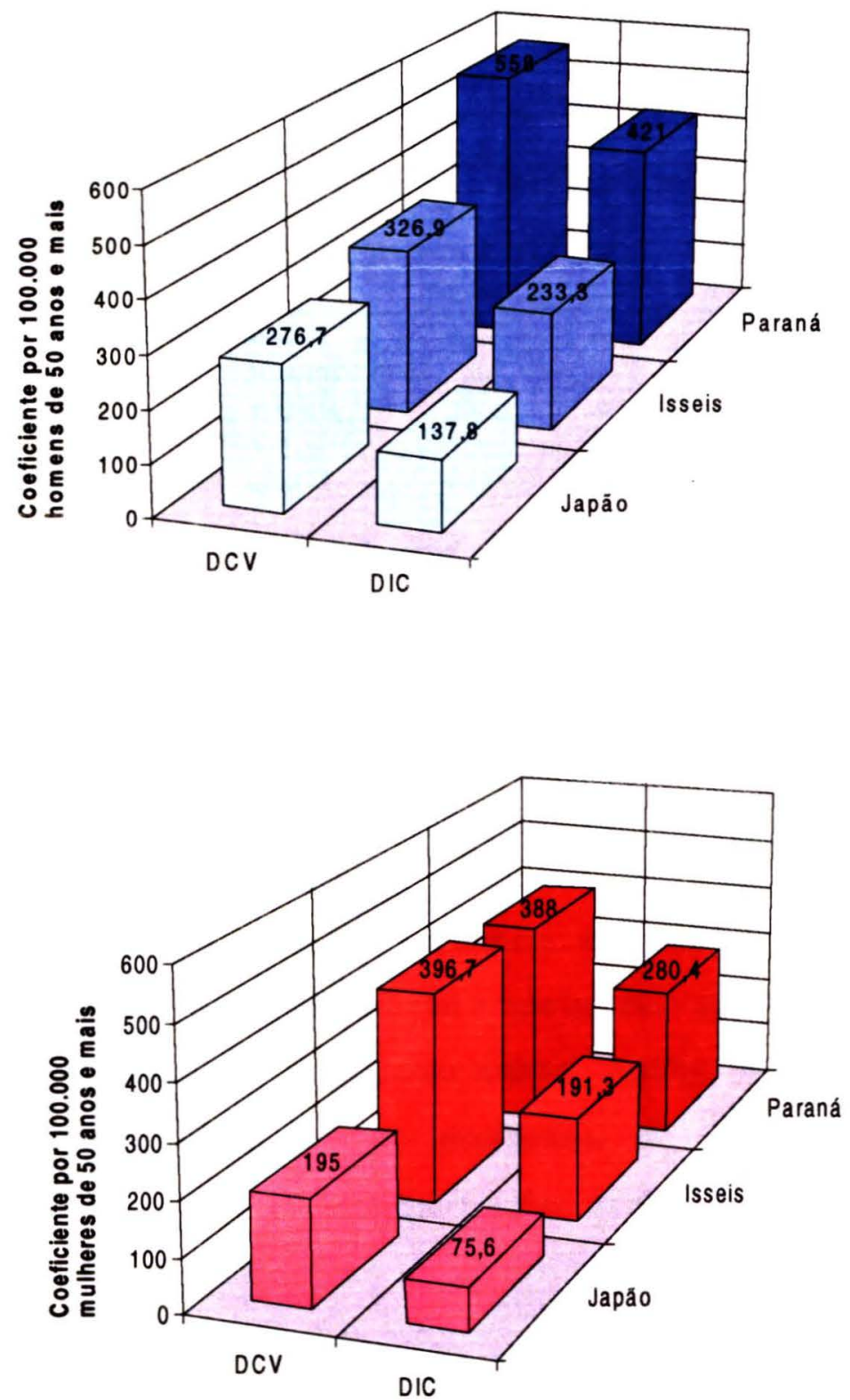

*Ajustados pela população mundial de 50 anos e mais 


\section{Tabela 22}

Coeficientes de mortalidade padronizados ${ }^{1}$ por doenças cerebrovasculares (por 100.000 hab de 50 anos e mais), razão de mortalidade padronizada (RMP) e respectivo intervalo de 95\% de confiança (IC 95\%) segundo sexo e população de estudo, 1991.

\begin{tabular}{cccccc}
\hline \multirow{2}{*}{ Sexo } & \multicolumn{3}{c}{ Coeficiente } & \multicolumn{2}{c}{ RMP IC $(95 \%)$} \\
& Japão & Isseis & Paraná & Isseis/Japão & Isseis/Paraná \\
\hline \multirow{2}{*}{ Masculino } & 276,7 & 326,9 & 558,0 & $1,18[1,12 ; 1,24]^{*}$ & $0,59[0,56 ; 0,61]^{*}$ \\
Feminino & 195,0 & 396,7 & 388,0 & $2,03[1,90 ; 2,18]^{*}$ & $1,02[0,97 ; 1,08]$
\end{tabular}

* Estatisticamente significante em nível de $5 \%$

${ }^{1}$ Ajustados pela população mundial de 50 anos e mais

Segundo MARMOT (1985), a mortalidade por doenças cerebrovasculares apresentou tendência declinante em muitos países ocidentais; este declínio começou bem antes daquele observado para doenças isquêmicas do coração, insinuando presença de determinantes distintos para cada doença, senão ambas seguiriam a mesma curva no tempo.

Tem sido estabelecido que a ocorrência de doença cerebrovascular está estreitamente relacionada à hipertensão arterial e que excesso de sal na dieta, por sua vez, associa-se ao desenvolvimento da hipertensão arterial. Análise realizada por OMURA e colaboradores (1987) demonstra que o decréscimo da mortalidade por doenças cerebrovasculares no Japão foi consequiência das mudanças nos padrões dietéticos tradicionais.

$\mathrm{Na}$ maioria dos países ocidentais, hábitos nutricionais têm-se modificado, desde 1950, mas as mudanças têm sido limitadas quando comparadas ao Japão, onde ocorreu marcada alteração qualitativa. Historicamente, a dieta japonesa caracteriza-se pela pequena quantidade de gordura e de proteínas, rica em carbohidrato e pela alta ingestão de sal. No entanto, nos últimos anos, hábitos nutricionais correntes, com predomínio de vegetais, vêm 
se alterando e observa-se diminuição do uso de sal e gradual aumento da ingestão de proteína e gordura; entretanto, a quantidade de carne ingerida ainda é baixa quando comparada à da maioria dos países europeus industrializados. Não se conhece em que extensão tais mudanças explicam o marcado declínio nas mortes por doenças cerebrovasculares no país, principalmente, ao se considerar que o tratamento com drogas antihipertensivas se tornou bastante comum entre japoneses (SVANBORG et al, 1985).

Talvez, as questões relativas ao tratamento da hipertensão arterial expliquem o porquê da maior importância das doenças cerebrovasculares em relação às doenças isquêmicas do coração no Estado do Paraná, diferindo da situação observada para muitas localidades do país (SICHIERI et al, 1992). Tal situação pode estar relacionada à deficiência dos programas de controle da hipertensão arterial, principalmente, em nível básico. Segundo LESSA (1993), a maior participação de doenças cerebrovasculares, em relação às doenças isquêmicas do coração, pode estar sugerindo altas prevalências de hipertensão arterial não tratada e não controlada.

SALA e colaboradores (1996) salientam que as proposições relativas à redução da morbimortalidade por doenças cerebrovasculares passam pela diminuição dos níveis pressóricos (sistólico e diastólico), através de estratégias dirigidas aos grupos considerados de risco. Relatam que ao mensurarem efetividade do programa de hipertensão arterial, segundo a redução em seus níveis, em indivíduos hipertensos submetidos a ações programáticas, constataram que 78,7\% dos portadores de hipertensão arterial, considerados para avaliação, apresentaram média de redução de pressão arterial diastólica de $8,8 \mathrm{mmHg}$ e de $17,7 \mathrm{mmHg}$ da sistólica. Além disso, em 44,4\% dos indivíduos ocorreu normalização da pressão aos níveis preconizados pelo programa.

TSUGANE e colaboradores (1994), frente a menores taxas de mortalidade por acidente vascular cerebral em isses residentes em São Paulo, relativamente ao Japão, na presença de pressão arterial sangüínea diastólica e sistólica muito mais alta, atribuem tais diferenças, a um provável aumento na ingestão de calorias total e de gordura. Salientam 
que, apesar de mais altos níveis de colesterol sérico, ácido úrico e peso corporal nos japoneses do Brasil, observou-se diminuição da mortalidade por acidente vascular cerebral.

Provavelmente, diferentemente do que ocorreu no Japão, a manutenção dos antigos hábitos alimentares e maior dificuldade de acesso aos serviços de saúde determinaram níveis mais elevados de mortalidade entre japoneses do Paraná, em relação à do Japão, pois conforme coloca MARMOT (1985), o declínio da mortalidade por acidente vascular cerebral e doença isquêmica do coração no Japão deveu-se, em grande parte, ao tratamento intenso da pressão sangưínea e à modificação dos padrões dietéticos.

\subsubsection{Mortalidade por neoplasias malignas}

A apreciação dos coeficientes de mortalidade padronizados por neoplasias, apresentados na tabela 23, segundo localização anatômica revela que entre os homens as taxas de mortalidade por câncer de estômago, cólon, pulmão e próstata foram menores para os isseis (respectivamente, 99,8;24,6;87,1 e 12,9 por 100.000 homens de 50 anos e mais) relativamente aos residentes no Japão $(152,4 ; 41,6 ; 143,8$ e 19,6 por 100.000 homens de 50 anos e mais, respectivamente). Em relação aos residentes no Estado do Paraná, com exceção de câncer de próstata, as demais localizações mostraram taxas ligeiramente inferiores às observadas para isseis $(97,5 ; 19,2 ; 76,2$ e 47,2 por 100.000 homens de 50 anos e mais, respectivamente).

Nas populações femininas, os valores assumidos pelos coeficientes de mortalidade padronizados por neoplasias malignas revelam, para mulheres isseis, valores próximos para câncer de estômago, cólon e mama e baixos para pulmão $(56,6 ; 31 ; 24,1$ e 8,2 por 100.000 mulheres de 50 anos e mais, respectivamente), quando comparados aos das residentes no Japão (respectivamente, 58,$9 ; 28,6 ; 21,9$ e 36,3 por 100.000 mulheres de 50 anos e mais). 
Quando se estabelece comparação entre as isseis e as paranaenses, verifica-se que a mortalidade das residentes no Paraná foi mais elevada para câncer de pulmão e mama e mais baixa para câncer de estômago e cólon (tabela 23)

\section{Tabela 23}

Coeficientes de mortalidade padronizados* por neoplasias malignas (por 100.000 hab de 50 anos e mais) segundo localização anatômica, sexo e população de estudo, 1991.

\begin{tabular}{lrrrrrr}
\hline \multirow{2}{*}{ Localização anatômica } & \multicolumn{3}{c}{ Masculino } & \multicolumn{3}{c}{ Feminino } \\
& Japão & Isseis** & Paraná & Japão & Isseis** & Paraná \\
\hline Estômago & 152,4 & 99,8 & 97,5 & 58,9 & 56,6 & 35,7 \\
Cólon & 41,6 & 24,6 & 19,2 & 28,6 & 31,0 & 18,9 \\
Traquéia, brônquios e pulmão & 143,8 & 87,1 & 76,2 & 36,3 & 8,2 & 32,0 \\
Mama & - & - & - & 21,8 & 24,1 & 37,6 \\
Próstata & 19,6 & 12,9 & 47,2 & - & - & - \\
\hline
\end{tabular}

* Ajustados pela população mundial de 50 e mais anos.

** Refere-se aos óbitos ocorridos entre 01/03/90 e 28/02/93.

As taxas de mortalidade por câncer de estômago, cólon e pulmão mostram-se mais altas para os homens do que para as mulheres entre os residentes no Japão e no Estado do Paraná. Situação semelhante é observada entre isseis, para os quais apenas a mortalidade por câncer de cólon foi superior nas mulheres. Porém, dada a participação de fatores carcinogênicos distintos de acordo com a localização anatômica da doença, será realizada análise específica dos dados. 


\section{- Câncer de estômago}

Conforme verificado na tabela 23 , entre as principais localizações de neoplasias malignas, câncer de estômago é a mais freqüente causa de morte nas três populações estudadas. Todavia, taxas mais elevadas são observadas entre os residentes no Japão, em ambos sexos. Especificamente na população masculina, isseis apresentaram taxa bem menor do que a dos residentes no Japão (RMP de $0,65[0,56 ; 0,76])$ e bastante próxima à da população geral do Estado Paraná (RMP de $1,02[0,94 ; 1,12]$ ) (tabela 24).

\section{Tabela 24}

Coeficientes de mortalidade padronizados ${ }^{1}$ por neoplasma maligno de estômago ${ }^{2}$ (por 100.000 hab de 50 anos e mais), razão de mortalidade padronizada (RMP) e respectivo intervalo de 95\% de confiança (IC 95\%) segundo sexo e população de estudo, 1991.

\begin{tabular}{lccccc}
\hline \multirow{2}{*}{ Sexo } & \multicolumn{3}{c}{ Coeficiente } & \multicolumn{2}{c}{ RMP IC(95\%) } \\
& Japão & Isseis & Paraná & Isseis/Japão & Isseis/Paraná \\
\hline Masculino & 152,4 & 99,8 & 97,5 & $0,65[0,56 ; 0,76]^{*}$ & $1,02[0,94 ; 1,12]$ \\
Feminino & 58,9 & 56,6 & 35,7 & $0,96[0,75 ; 1,22]$ & $1,58[1,38 ; 1,82]^{*}$ \\
\hline * Estatisticamente significante em nível de 5\%. & & \\
Ajustados pela população mundial de 50 anos e mais. \\
CID 151
\end{tabular}

A razão de mortalidade padronizada, para mulheres isseis, foi de $0,96[0,75 ; 1,22] \mathrm{e}$ $1,58[1,38 ; 1,82]$ tendo, respectivamente, as residentes no Japão e no Estado do Paraná como população de referência, estimando um risco de morte por esta causa $58 \%$ maior do que o das paranaenses (tabela 24). 
Os resultados referentes às populações femininas assemelham-se aos encontrados por TSUGANE e colaboradores (1990b) relativos aos isseis, de ambos os sexos, do Município de São Paulo, no qual a mortalidade em isseis não diferiu da observada nos residentes no Japão e foi 1,5 vezes a da população geral do Município de São Paulo e vão ao encontro dos referidos na literatura.

Taxas elevadas de mortalidade por câncer de estômago entre os japoneses foram objeto de discussão em vários estudos. Conforme destacam HOWSON e colaboradores (1986), o Japão era referenciado como o país, em que sua população apresentava as mais altas taxas de mortalidade por esta doença. COGGON e ACHESON (1984) comentaram que a taxa de morte por esta causa situava-se em posição intermediária em japoneses que migraram para os Estados Unidos (mais baixas que a dos residentes no Japão e mais altas do que a dos americanos). Ressaltavam, contudo, que particularmente entre grupos etários mais velhos, a taxa era mais próxima a do local de nascimento do que a de destino, o que podia estar indicando que migrantes são seletivamente menos propensos a desenvolver câncer gástrico ou que risco de câncer gástrico pode ser modificado, em alguma extensão, mais tardiamente.

O fato da incidência da doença ser menor nas populações migrantes do que em seu país de origem indica influência mais importante dos fatores ambientais, embora seja inegável o papel desempenhado pela suscetibilidade genética. Além disso, a redução na incidência é menos observada entre a primeira geração do que em seus descendentes, sugerindo também que estes fatores ambientais operam precocemente na vida ou, alternativamente, que eles são fenômenos culturais que perdem seu impacto, assim que gerações sucessivas adotam os modos de seu local de moradia (COGGON e ACHESON, 1984).

Segundo HOWSON e colaboradores (1986), embora nenhum fator isoladamente possa explicar todas as variações internacionais observadas no risco de câncer gástrico, são os fatores dietéticos que oferecem as melhores explicações para as diferenças geográficas, 
temporais e indivıduais no risco de câncer gástrico. Os autores apresentam uma discussão concernente aos possíveis fatores associados à incidência e à mortalidade por câncer de estômago, à luz das evidências, e destacam:

a) ingestão de alta quantidade de sal com nitrato - embora considerado fator de risco para câncer de estômago, pouco se conhece sobre possível interação. A relação da mortalidade por câncer de estômago com sódio sempre foi mais forte do que com "nitrato". Existe boa evidência ligando ingestão de sal à prevalência de atrofia gástrica, bem conhecido como precursor da mortalidade por câncer gástrico. Para países, especialmente asiáticos, com alta ingestão de sódio a origem do nitrato é principalmente em pickles, alimentos curados e molhos fermentados. Estes alimentos salgados e molhos são também de alto teor em nitrato, seja porque foram adicionados aos alimentos ou por causa de síntese de aminoácidos durante a fermentação.

b) lesões precursoras - atrofia gástrica crônica e sua lesão associada, metaplasia intestinal, são as precursoras mais intimamente ligadas ao aumento do risco de câncer tipo intestinal. O papel da úlcera gástrica benigna como uma precursora de câncer gástrico näo está claro, mas evidências correntes sugerem independência. Embora úlceras gástricas sejam freqüentemente encontradas em conjunto com câncer gástrico, muitos investigadores acreditam que sejam secundárias ao carcinoma em situ.

c) nitrato/nitrito - uma provável origem de contaminação da água é o excessivo uso de fertilizante com nitratos. Altas concentraçōes de nitratos no solo, resultando de super uso de fertilizantes à base de nitrato e drenagem deficiente, têm sido positivamente correlacionadas com mortalidade por câncer gástrico em várias populações.

d) carbohidrato - a evidência para uma precoce idade crítica para a migração apoia a hipótese que a alta ingestão de carbohidrato é mais injuriosa no processo pré-canceroso, mais provavelmente ao tempo de seu início. Achados experimentais apoiam este argumento pela demonstração que dieta alta em amido, incluindo predominantemente 
cereais em grão como um todo, podem esfoliar mecanicamente a mucosa estomacal, promovendo assim absorção de um carcinogênico. Além disso, alto consumo de carbohidrato tem sido mostrado ser inversamente associado com ingestão de gordura e proteína. Dieta com baixa quantidade de proteína tem mostrado inibir reparação de lesões gástricas pela reduzida produção de muco gástrico, com isso, facilitando a absorção de substâncias carcinogênicas gástricas. A dieta com alta quantidade de amido e baixa de proteína pode reduzir a concentração de agentes no suco gástrico que ativamente decomporiam os nitritos.

e) vegetais e frutas frescas - comparação entre países tem também demonstrado uma associação inversa entre consumo de frutas e vegetais frescos e mortalidade por câncer gástrico. A relativamente alta mortalidade por câncer gástrico no Japão e Chile, a despeito de sua elevada ingestão de vegetais, pode também refletir uma maior prevalência de fatores de risco interrelacionados, por exemplo, elevada ingestão de nitrato de outras origens, sal e/ou carbohidrato ou diferentes métodos de preparo de vegetais. Um exemplo seria o hábito entre japoneses de ferver vegetais antes de servir, com isso, reduzindo seu valor nutritivo.

f) vitaminas C, E e A - consumo de frutas e vegetais está associado com um aumento da ingestão dietética de vitaminas $\mathrm{C}, \mathrm{E}$ e $\mathrm{A}$. Experimentalmente, todas três vitaminas têm demonstrado a capacidade de inibir processos químicos possivelmente associados com carcinogênese gástrica. As evidências epidemiológicas favorecendo o papel protetor da vitamina $\mathrm{A}$ é mais forte do que para vitamina $\mathrm{C}$ e $\mathrm{E}$, mas permanece inconsistente.

A hipótese que o sal poderia estar envolvido na etiologia de câncer baseia-se na observação de que as taxas de mortalidade por câncer de estômago e por acidentes vasculares cerebrais estavam fortemente correlacionadas. Embora agindo por diferentes mecanismos, sugerem que o sal possa ser o fator causal destas duas doenças. Mais evidência desta teoria vem dos estudos desenvolvidos no Japão onde correlações entre 
mortalidade por câncer de estômago e a concentração de sal (usada na pasta de soja e na ingestão de alimentos salgados) têm sido demonstradas. O declínio da incidência do câncer gástrico em alguns países desenvolvidos parece ser resultado do impacto da rápida e ampla expansão de geladeiras, desde 1900. Com a existência de maior número de geladeiras, ocorreu redução acentuada no consumo de sal que era utilizado para a preservação dos alimentos; com isto, denotou-se uma tendência declinante, no mundo, na mortalidade por câncer de estômago. A proporção de domicílios japoneses com geladeiras elétricas aumentou rapidamente depois de 1960, aproximadamente à época em que as taxas de mortalidade por câncer gástrico começaram a cair. Estes dados sugerem que o refrigerador doméstico, através de sua preservação de produtos frescos e congelados ou de seu efeito indireto sobre práticas dietéticas tais como salgar e fazer conservas tipo "pickles", pode ser associado com o declínio no câncer gástrico no Japão. Em concordância, tanto a mortalidade por câncer de estômago como a mortalidade por doenças cerebrovasculares começaram a declinar na década de 60 (HOWSON et al, 1986; JOOSSENS et al, 1996).

Os dados relativos às populações estudadas, concernentes à associação entre câncer de estômago e doença cerebrovascular indicam presença de fatores específicos para a mortalidade para cada doença. Verifica-se, na figura 9, que as taxas relativas aos residentes no Japão e no Paraná apresentam sentidos opostos. A população do Japão com as maiores taxas de mortalidade por câncer de estômago apresentam menores valores para doenças cerebrovasculares, sendo o inverso observado entre os residentes no Paraná. 
Figura 9

Coeficientes de mortalidade padronizados* por doenças cerebrovasculares (DCV) e por câncer de estômago (por 100.000 hab de 50 anos e mais) segundo sexo e população de estudo, 1991.
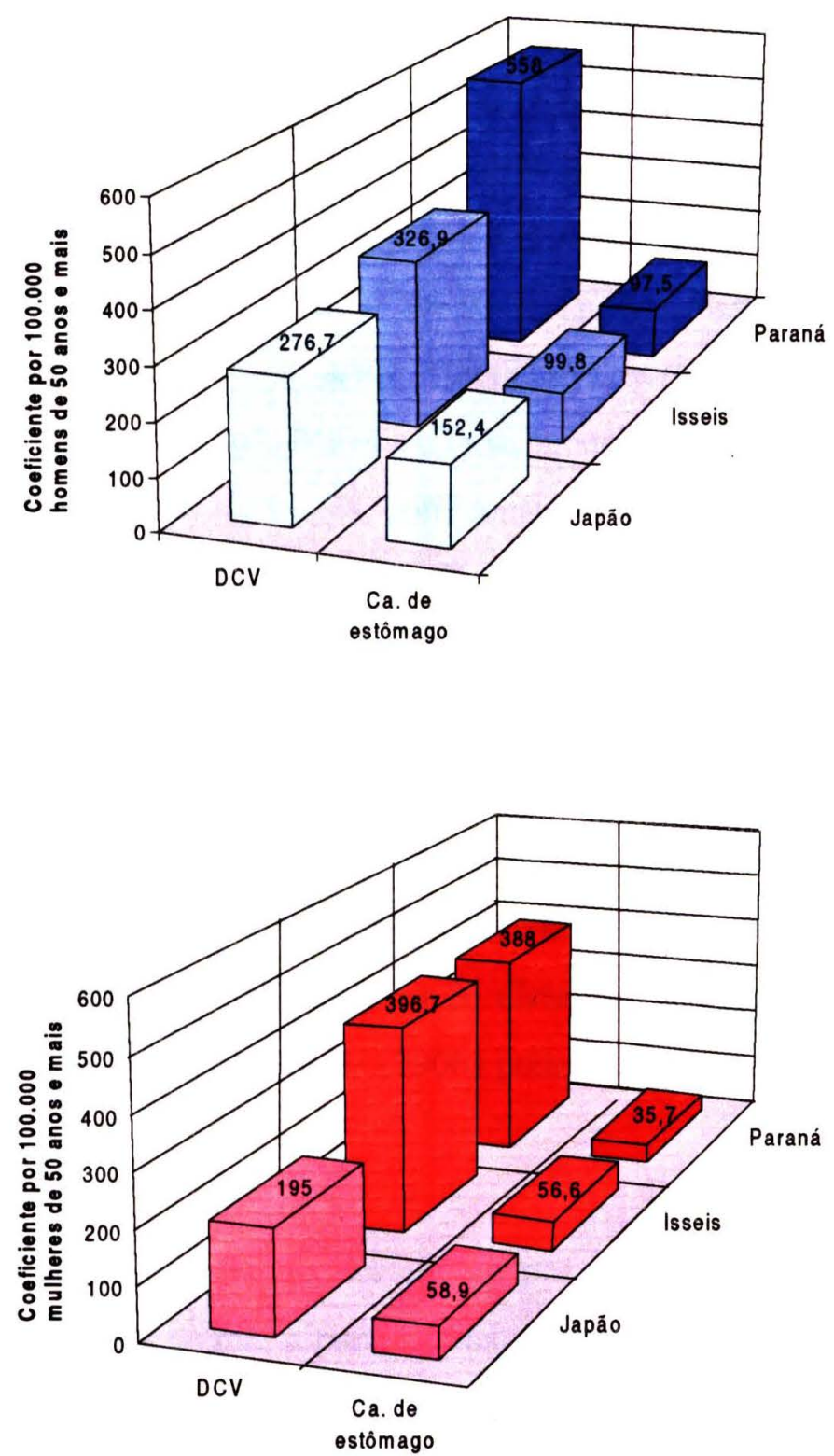

*Ajustados pela população mundial de 50 anos e mais 
No presente estudo, o entendimento do fato da mortalidade das mulheres isseis situar-se bastante próxima das residentes no Japão poderia ser buscado nas questões apresentadas por ISHII (1980 e 1986) que, destacando o aspecto cultural como um dos fatores determinantes das práticas dietéticas, compara hábitos alimentares de uma população de isseis e seus descendentes, residentes em localidades do Estado de São Paulo. Evidencia um enfraquecimento do fator cultural concernente à alimentação, nas gerações nascidas no Brasil. Em seus estudos, constata que os japoneses, apesar de radicados há mais de 35 anos no Brasil, ainda mantinham muitos hábitos nativos, seja na escolha dos alimentos como no seu preparo. Relata que os isseis, embora residindo em localidades distintas, apresentaram semelhança quanto aos tipos de alimentos, considerados orientais, mais consumidos, destacando-se o arroz (preparado somente com água), "shoyu", "ajinomoto", "missô", "tuquemono". Por outro lado, menciona, também, a incorporação do grupo de alimentos tipicamente nacionais, com consumo quase que diário de alho, cebola, café, pão, feijão, e, entre 50 a $80 \%$ dos dias do ano, pimenta-do-reino, leite e margarina. Em suas conclusões destaca a mudança dos hábitos alimentares que vem ocorrendo entre a segunda geração.

Todas as questōes aqui colocadas sugerem que as isseis residentes no Paraná, provavelmente, tendem a reter mais os hábitos alimentares nativos do que os homens e que fatores de risco mais comuns como ingestão de dieta rica em nitrato/nitrito e alimentos salgados presentes no Japão (TSUGANE, 1990b) podem estar presentes, também, entre as isseis.

Relativamente ao diferencial de mortalidade por sexo, os resultados encontrados são concordantes aos observados na maior parte do mundo, sendo de 1,5 a 3 vezes superior nos homens e a despeito da grande diferença na incidência e mortalidade por câncer gástrico, entre os países, a razão entre sexos mostra pouca variação geográfica, sugerindo que qualquer que seja a questão que é responsável pela variação internacional na incidência de câncer de estômago afeta homens e mulheres de maneira similar através do mundo (HOWSON et al 1986). 


\section{- Câncer de cólon}

Comparando-se as taxas de mortalidade por câncer de cólon nas populações masculinas estudadas de 50 anos e mais, observa-se que a mortalidade dos isseis foi intermediária, ou seja, mais baixa do que a dos residentes no Japão (RMP isseis/Japão de $0,59[0,52 ; 0,68])$ e mais elevada do que a verificada entre os residentes no Estado do Paraná (RMP isseis/Paraná de $1,28[1,05 ; 1,57]$ ) (tabela 25)

No tocante às mulheres isseis, os valores assumidos pela razão de mortalidade padronizada mostram que a diferença entre as taxas de mortalidade por câncer de cólon não foi estatisticamente significante quando comparada à das residentes no Japão (RMP de $1,08[0,86 ; 1,37])$, porém, foi superior em $64 \%$ à taxa observada entre as paranaenses (RMP de $1,64[1,23 ; 2,19]$ ) (tabela 25).

\section{Tabela 25}

Coeficientes de mortalidade padronizados ${ }^{1}$ por neoplasma maligno de cólon ${ }^{2}$ (por 100.000 hab de 50 anos e mais), razão de mortalidade padronizada (RMP) e respectivo intervalo de 95\% de confiança (IC 95\%) segundo sexo e população de estudo, 1991.

\begin{tabular}{|c|c|c|c|c|c|}
\hline \multirow[t]{2}{*}{ Sexo } & \multicolumn{3}{|c|}{ Coeficiente } & \multicolumn{2}{|c|}{ RMP IC $(95 \%)$} \\
\hline & Japão & Isseis & Paraná & Isseis/Japão & Isseis/Paraná \\
\hline Masculino & 41,6 & 24,6 & 19,2 & $0,59[0,52 ; 0,68]^{*}$ & $1,28[1,05 ; 1,57]^{*}$ \\
\hline Feminino & 28,6 & 31,0 & 18,9 & $1,08[0,86 ; 1,37]$ & $1,64[1,23 ; 2,19]^{*}$ \\
\hline
\end{tabular}

KAMPMAM e colaboradores (1995), ao examinarem a relação entre câncer de cólon e padrões dietéticos, enfatizam a contribuição dos alimentos na etiologia de câncer, 
com destaque para o consumo de fibras como fator de proteção (conferida pelo efeito primário dos vegetais ou frutas, com uma variedade de nutrientes e substâncias bioativas) e ingestão de gordura aumentando o risco da doença (principalmente consumo de carne vermelha uma das maiores origens de gordura saturada na dieta ocidental). Ressaltam que os resultados das pesquisas, quanto a esses fatores, nem sempre são coincidentes.

Dentro desta linha, TSUGANE e colaboradores (1990b), identificando taxas de mortalidade por câncer de cólon similar, em ambos os sexos, nos japoneses residentes no Japão e no Município de São Paulo, à luz das considerações correntes que sugerem presença de fatores etiológicos comuns para mortalidade por câncer coloretal e por doenças cardíacas ateroscleróticas e entre o grau de aterosclerose e a prevalência de pólipo no cólon, constataram também que as taxas de mortalidade por doenças isquêmicas do coração entre imigrantes japoneses aumentam em direção a altas taxas encontradas na população geral de São Paulo, apesar das conclusões relativas ao câncer coloretal. Salientam que a maior ingestão de gorduras, entre japoneses de São Paulo, parece ser a causa da alta mortalidade por doenças isquêmicas do coração, mas não parece estar relacionada ao câncer de cólon. Outros fatores tais como ingestão de fibras e vegetais podem explicar a diferença.

Relativamente às populações do presente estudo, a análise conjunta dos dados de mortalidade por câncer de cólon e doenças isquêmicas do coração (figura 10) revelam que, a exemplo do observado para isseis em São Paulo, em ambos os sexos, as taxas apresentam sentidos opostos, ou seja, as maiores taxas de mortalidade por doenças isquêmicas do coração observadas na população do Paraná são acompanhadas por estimativa menor do risco de morrer por câncer de cólon. Por outro lado, os residentes no Japão, com maiores taxas de mortalidade por câncer de cólon (homens), apresentam menor risco de morte por doenças isquêmicas do coração. Estes resultados sugerem, a exemplo do observado para câncer de estômago e doenças cerebrovasculares, presença de alguns fatores de risco específicos na etiologia das doenças. 


\section{Figura 10}

Coeficientes de mortalidade padronizados* por doenças isquêmicas do coração (DIC) e por câncer de cólon (por 100.000 hab de 50 anos e mais) segundo sexo e população de estudo, 1991.
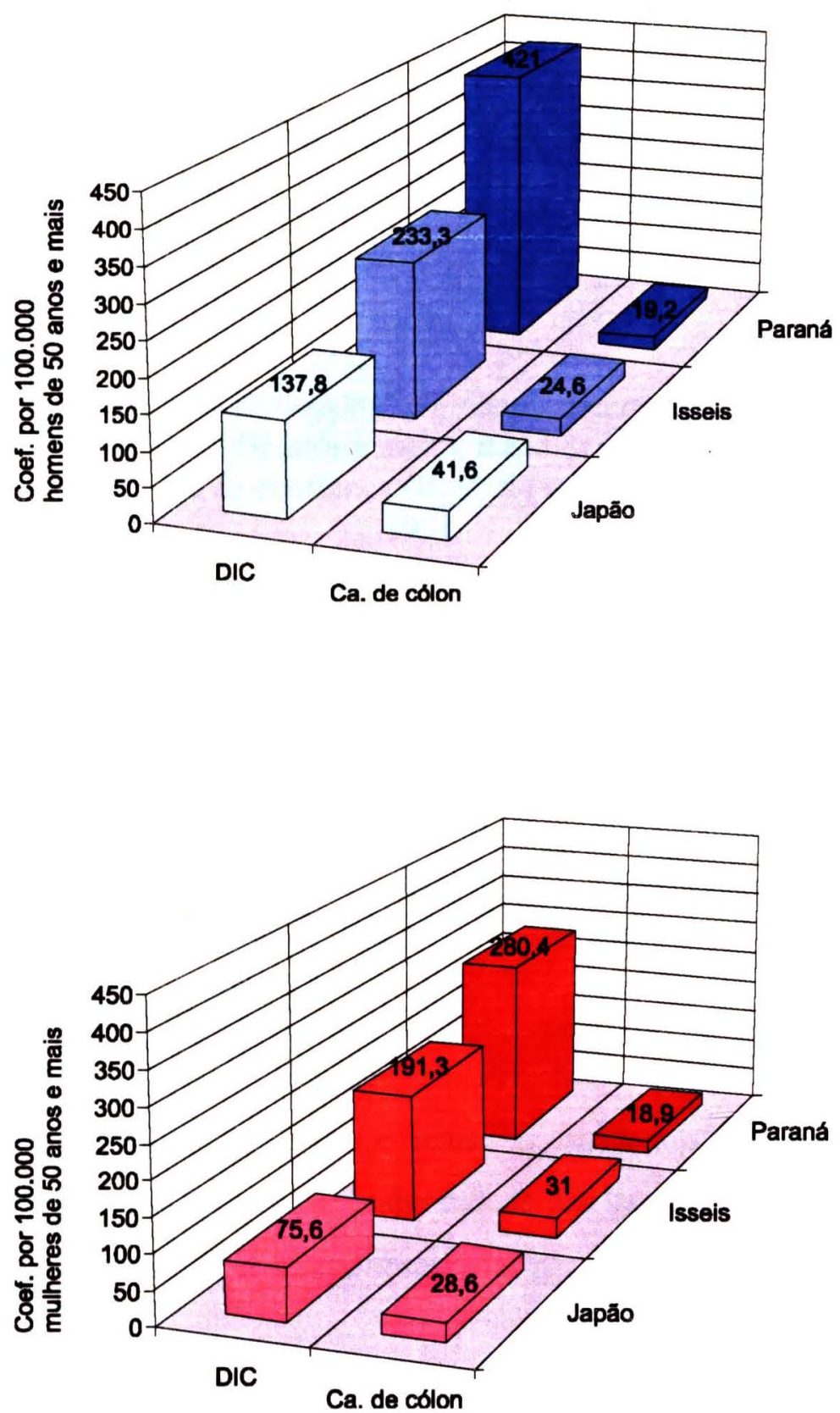

*Ajustados pela população mundial de 50 anos e mais 


\section{- Câncer de pulmão}

Câncer de pulmão é a segunda localização mais importante na mortalidade por neoplasias malignas das populações masculinas de 50 anos e mais. Esta mortalidade mostrou-se similar, não havendo diferença estatisticamente significante entre isseis $\mathrm{e}$ habitantes do Estado do Paraná (RMP de $1,14[0,97 ; 1,35]$ ), mas os residentes no Japão apresentaram taxas mais altas (RMP entre isseis/Japão de $0,61[0,54 ; 0,68]$ ) (tabela 26).

\section{Tabela 26}

Coeficientes de mortalidade padronizados' por neoplasma maligno da traquéia, brônquios e pulmão ${ }^{2}$ (por 100.000 hab de 50 anos e mais), razão de mortalidade padronizada (RMP) e respectivo intervalo de $95 \%$ de confiança (IC $95 \%$ ) segundo sexo e população de estudo, 1991.

\begin{tabular}{lrrrrr}
\hline \multirow{2}{*}{ Sexo } & \multicolumn{3}{c}{ Coeficiente } & \multicolumn{2}{c}{ RMP IC(95\%) } \\
& Japão & Isseis & Paraná & Isseis/Japão & Isseis/Paraná \\
\hline Masculino & 143,8 & 87,1 & 76,2 & $0,61[0,54 ; 0,68]^{*}$ & $1,14[0,97 ; 1,35]$ \\
Feminino & 36,3 & 8,2 & 32,0 & $0,23[0,20 ; 0,25]^{*}$ & $0,26[0,23 ; 0,29]^{*}$ \\
\hline $\begin{array}{l}\text { * Estatisticamente significante em nível de 5\% } \\
\text { Ajustados pela população mundial de 50 anos e mais } \\
\text { CID 162 }\end{array}$ & & & \\
\end{tabular}

Entre as mulheres de 50 anos e mais, as residentes no Japão e no Paraná apresentaram taxas bastante próximas; a mortalidade das isseis por esta causa representou apenas $23 \%$ e $26 \%$, respectivamente, das observadas para essas populações (tabela 26).

Chama atenção, nos dados apresentados na tabela 26 , a sobremortalidade masculina por esta causa nas três populações estudadas. Os coeficientes apresentados permitem estimar uma razão entre taxas (masculino/feminino) da ordem de 3,96; 10,62 e 2,38, respectivamente, para residentes no Japão, isseis e população total do Paraná. Estes 
resultados permitem verificar, por exemplo, que, entre isseis de 50 anos e mais, a mortalidade masculina por câncer de pulmão foi mais de dez vezes à observada entre as mulheres.

O resultado obtido nas três populações, quanto à sobremortalidade masculina, é concordante ao registrado na literatura. Para WALDRON (1983), as diferenças entre sexos na mortalidade por câncer de pulmão, em países industrializados, devem-se às grandes distinções no hábito de fumar, entre os sexos, e à maior exposição do homem a carcinógenos ocupacionais. Ressalte-se que, conforme já mencionado, o hábito de fumar, fator de risco mais comumente relacionado ao câncer de pulmão, é pouco freqüente entre as mulheres japonesas.

TSUGANE e colaboradores (1990b), ao identificarem um valor mais baixo, para coeficientes de mortalidade por câncer de pulmão, entre os imigrantes residentes na cidade de São Paulo, especialmente em mulheres, aventavam como explicação a possibilidade das isseis residentes em São Paulo terem fumado menos do que residentes no Japão, no processo de adaptação. Em estudo posteriormente desenvolvido por estes autores sobre estilo de vida, na mesma população, constataram que, de fato, o hábito de fumar era pouco freqüente entre as isseis. Relatam que enquanto $90 \%$ das mulheres referiam nunca ter fumado, este percentual era de 30,2\%, entre os homens (TSUGANE et al, 1994).

É possível, também, que entre as isseis do Paraná o hábito de fumar seja pouco frequente e explique uma taxa de mortalidade por esta causa tendo um valor igual a $10 \%$ a dos homens. 
- Câncer de mama e de próstata

Quanto à mortalidade por câncer de mama, foi possível verificar que as isseis de 50 anos e mais apresentaram taxa semelhante à das residentes no Japão e mais baixa do que a da população geral do Estado do Paraná (figura 11).

\section{Figura 11}

Coeficientes de mortalidade padronizados* por câncer de mama (por 100.000 mulheres de 50 anos e mais) segundo população de estudo, 1991.

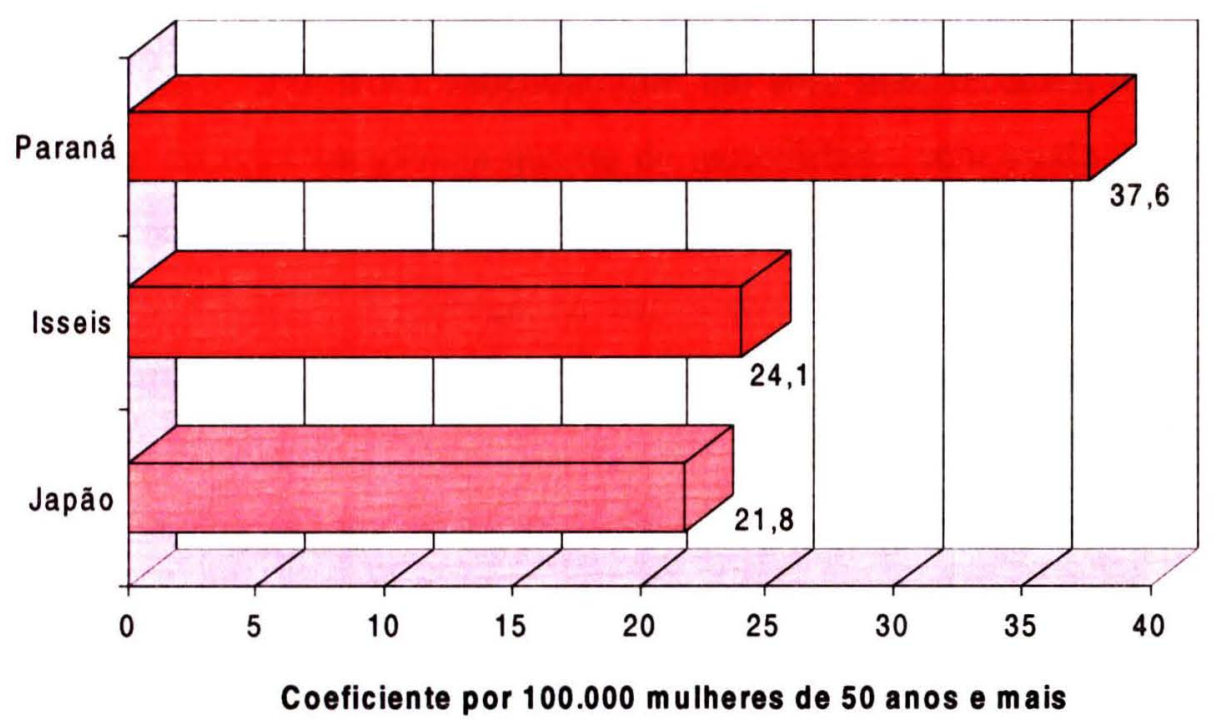

*Ajustados pela população mundial de 50 anos mais 
O valor estimado para a razão de mortalidade padronizada por idade não revela diferença estatisticamente significante entre a mortalidade feminina por câncer de mama no Japão e entre as isseis (RMP de 1,11[091;1,35]). Entretanto, ao comparar as taxas referentes às isseis e às paranaenses, verifica-se que a mortalidade das isseis representou apenas $64 \%$ da mortalidade das residentes no Paraná (RMP de $0,64[0,55 ; 0,75]$ ), portanto houve diferença estatisticamente significante.

A taxa apresentada para as residentes no Paraná $(37,6$ por 100.000 mulheres de 50 anos e mais) bem mais alta do que a das isseis e das residentes no Japão seria esperada, tendo em vista as questões comentadas quanto a ocorrência de câncer de mama em japonesas. KELSEY e HORN-ROSS (1993), estabelecendo uma comparação entre as taxas de incidência entre várias regiões do mundo, relatam que, por muitos anos, as taxas de incidência e de mortalidade por câncer de mama têm sido mais altas na América do Norte e região Norte da Europa, intermediárias no Sul da Europa e na América Latina, e mais baixas na Ásia e África. Entretanto, salientam que, em anos mais recentes, um importante aumento, tanto das taxas de incidência quanto de mortalidade, vem sendo observado nos países asiáticos, como, por exemplo, no Japão. Atribuem as alterações observadas na distribuição temporal das taxas de doença, em países como Japão, a uma possível mudança na exposição aos fatores de risco associados à ocorrência de câncer de mama.

WAKAI e colaboradores (1995), também, comentando as menores taxas de mortalidade por câncer de mama entre japonesas, comparativamente às de países ocidentais, destacam a tendência ao aumento, tanto na incidência como na mortalidade, por esta causa, e atribuem o fato às mudanças no estilo de vida (menor paridade, menarca precoce, menopausa tardia, obesidade pós-menopausa). Relatam que no Japão a idade média para menarca tem diminuído gradualmente, desde a década de 20 . Porém, durante a Segunda Guerra Mundial, o crescimento das crianças foi afetado, resultando em atraso na idade para menarca. Além disso, destacam aumento gradual na idade para menopausa, postergação do primeiro nascimento, passando a idade média de 24,4 para 27,1 anos entre 1950 e 1991, declínio rápido da fecundidade de 1947 a 1960 de 4,5 para 2 filhos e 
aumento da média do índice de massa corporal em mulheres com mais de 40 anos desde 1950, sendo que, em mulheres em torno de 60 anos, este índice passou de 21,4, em 1950, para 23,5 , em 1990.

Taxas semelhantes, observadas entre as isseis e as residentes no Japão, podem ser conferidas à manutenção dos antigos padrões da população que migrou para o Brasil. Dados relativos à mortalidade das isseis residentes no Município de São Paulo, para o mesmo período, revelam valores muito próximos (23,9 por 100.000 mulheres de 50 anos e mais, em 1991) ao observado para as isseis residentes no Estado do Paraná (GOTLIEB, dados não publicados). A situação descrita, talvez, guarde alguma relação com as inúmeras privações a que se expuseram as imigrantes que chegaram ao Brasil ainda criança, o que pode ter resultado em um possível atraso na idade da menarca. Conforme relatam KIYOTANI e YAMASHIRO (1992), à época da chegada ao Brasil, os imigrantes se submetiam às péssimas condições de moradia e alimentação, que além de insuficiente, do ponto de vista qualitativo, diferia substancialmente do padrão japonês. Também, é muito provável que os casamentos ocorressem logo após adolescência em obediência à tradição, bastante arraigada na primeira geração de imigrantes, denominada "Miai" (casamentos arranjados) com consequiente início da prole e multiparidade.

TSUGANE e colaboradores (1990b) relatam que mudanças hormonais, influenciadas pela dieta e outras mudanças no estilo de vida, parecem estar relacionadas à mortalidade por câncer de mama. Em estudo realizado no Município de São Paulo, os autores verificaram aumento da mortalidade por câncer de mama somente na geração nascida no Brasil, insinuando que mudanças na dieta e no estilo de vida influenciam risco de câncer de mama quando estas ocorrem durante a infância. Dentre as mudanças dietéticas destacam a alta ingestão de gordura entre as descendentes de japoneses como fator que pode estar associado à mais alta mortalidade e, provavelmente, incidência de câncer de mama. 
Por outro lado, relativamente ao câncer de próstata, estes mesmos autores (TSUGANE et al, 1990b), observando para os isseis coeficientes com valores intermediários daqueles referentes aos residentes no Japão e na cidade de São Paulo, destacam também as mudanças dietéticas, especificamente alta ingestão de gordura, entre japoneses brasileiros, como fator que pode estar associado à maior mortalidade por câncer de próstata, em relação a dos residentes no Japão. Todavia, o resultado encontrado no presente estudo difere da situação descrita e observa-se que os isseis residentes no Estado do Paraná apresentaram a menor taxa (figura 12), sendo que a sua mortalidade correspondeu a $66 \%$ da verificada para os residentes no Japão (RMP de 0,66 [0,52;0,82]) e apenas $27 \%$ da observada para os residentes no Paraná (RMP de 0,27 [0,24; 0,33].

\section{Figura 12}

Coeficientes de mortalidade padronizados* por câncer de próstata (por 100.000 homens de 50 anos e mais) segundo população de estudo, 1991.

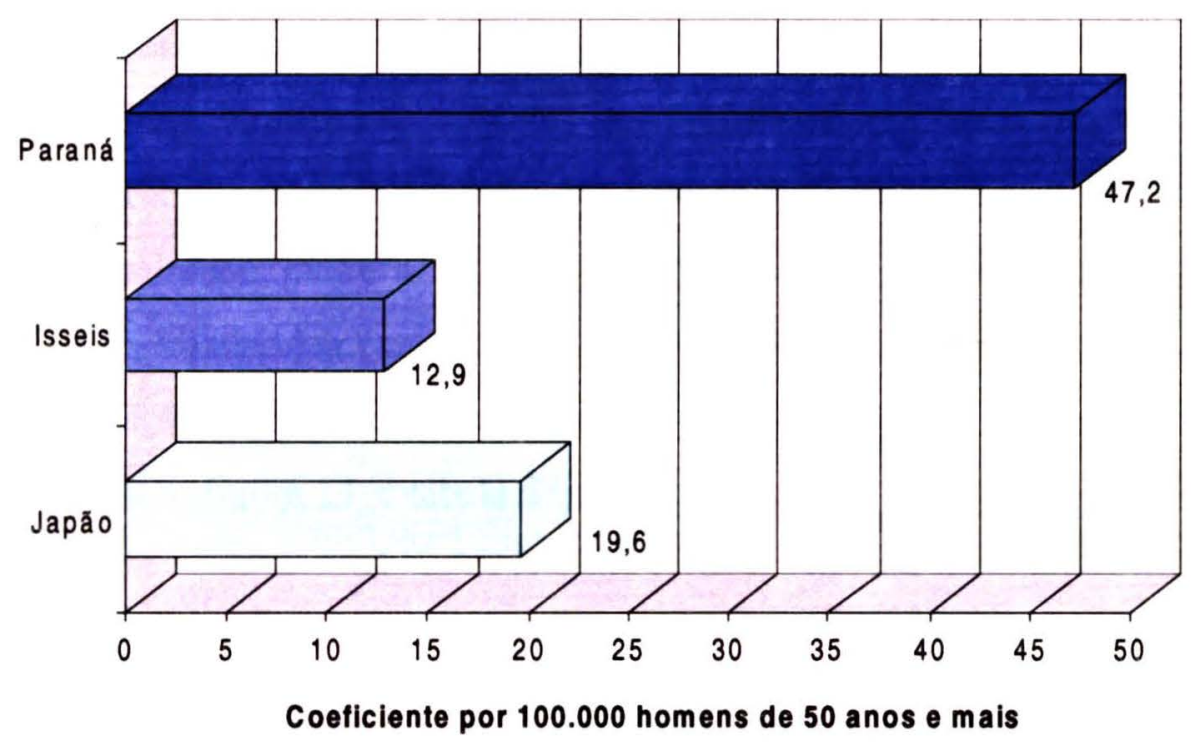

*Ajustados pela população mundial de 50 anos e mais 
Os distintos resultados encontrados nestes estudos sugerem que vários fatores associarn-se à ocorrência desta doença e reforçam questões colocadas por NOMURA e KOLONEL (1993), quais sejam, do conhecimento ainda restrito sobre a etiologia desta doença, apesar da sua importância crescente no contexto mundial. Em suas recomendações destacam a necessidade de trabalhos que tenham como proposta melhor esclarecer, entre outras questões, a participação da suscetibilidade genética (no caso de pacientes jovens), das práticas dietéticas (especialmente o papel das gorduras e vitaminas), dos fatores hormonais (no caso dos adenocarcinomas), da influência da vasectomia e da hipertrofia benigna da próstata sobre risco de câncer.

\subsubsection{Mortalidade por doenças das glândulas endócrinas, nutricionais e metabólicas}

\section{- Diabetes mellitus}

Relativamente à mortalidade por diabetes, isseis apresentam valores intermediários em ambos os sexos. Entretanto, enquanto que no Japão a velocidade e intensidade de morte por esta causa mostram-se menores em mulheres, entre as isseis, a taxa é $87 \%$ superior a dos homens, assemelhando-se à situação encontrada no Estado do Paraná, onde a razão de mortalidade padronizada entre sexos, tendo população masculina como referência, é de aproximadamente 1,52. Maiores diferenciais entre as populaçōes são observadas na relação entre as isseis e mulheres japonesas em todas as faixas etárias (RMP de $5,08[4,22 ; 6,12]$ ) (figura 13 e tabela 27 ). 


\section{Figura 13}

Coeficientes de mortalidade padronizados* por diabetes mellitus (por 100.000 hab de 50 anos e mais) segundo sexo e população de estudo, 1991.

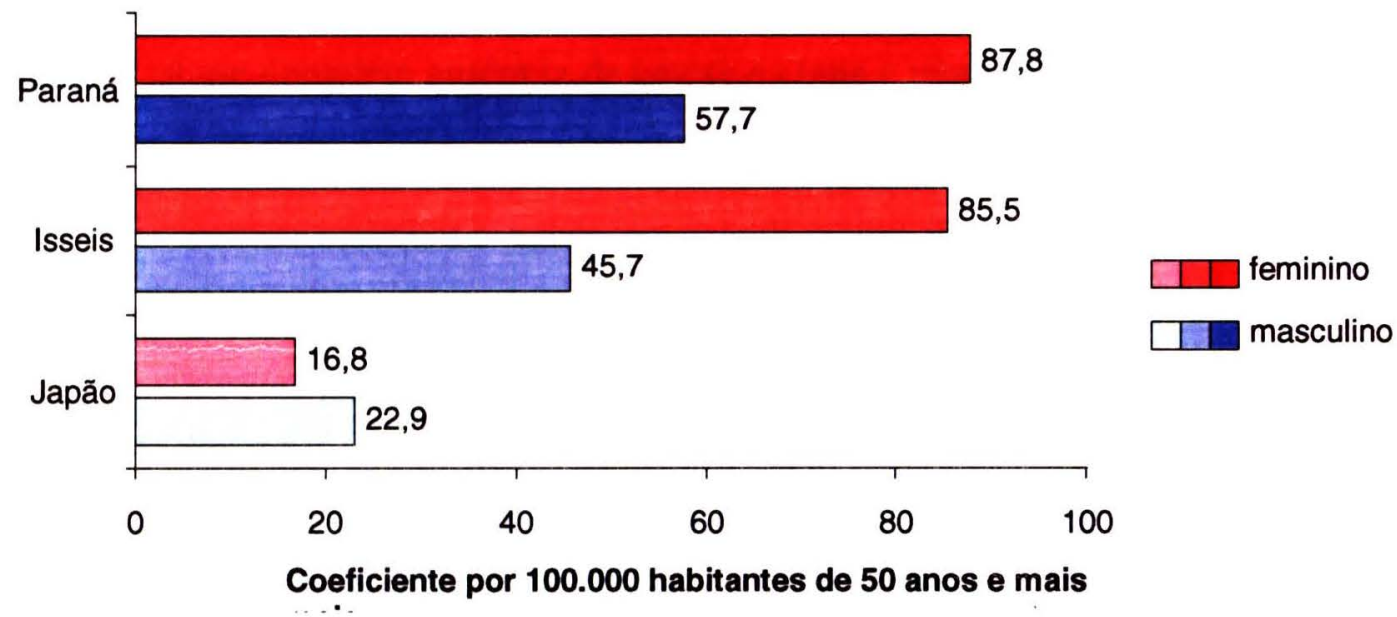

*Ajustados pela população mundial de 50 anos e mais

\section{Tabela 27}

Coeficientes de mortalidade padronizados ${ }^{1}$ por diabetes mellitus ${ }^{2}$ (por 100.000 hab de 50 anos e mais) razão de mortalidade padronizada (RMP) e respectivo intervalo de $95 \%$ de confiança (IC95\%) segundo sexo e população de estudo, 1991.

\begin{tabular}{cccccc}
\hline \multirow{2}{*}{ Sexo } & \multicolumn{3}{c}{ Coeficiente } & \multicolumn{2}{c}{ RMP IC(95\%) } \\
& Japão & Isseis & Paraná & Isseis/Japão & Isseis/Paraná \\
\hline \multirow{2}{*}{ Masculino } & 22,9 & 45,7 & 57,7 & $2,00[1,72 ; 2,32]^{*}$ & $0,79[0,72 ; 0,88]^{*}$ \\
Feminino & 16,8 & 85,5 & 87,8 & $5,08[4,22 ; 6,12]^{*}$ & $0,97[0,89 ; 1,07]$
\end{tabular}

* Estatisticamente significante em nível de 5\%

${ }^{1}$ Ajustados pela população mundial de 50 anos e mais

${ }^{2}$ CID 250 
Segundo SASAKI e colaboradores (1978), japoneses diabéticos mostravam características inteiramente diferentes daquelas apresentadas pelos habitantes de países ocidentais, como baixas taxas de mortalidade e prevalência, relativa falta de aterosclerose severa, menor frequêencia das complicações diabéticas (retinopatia diabética, nefropatia e neuropatia), quase completa ausência de cetose e coma e relativamente baixa freqüência de diabetes tipo 1. Contudo, por causa das mudanças graduais no modo de vida nos anos recentes, aspectos dos diabéticos japoneses vêm sendo bastante alterados, com notório aumento da taxa de mortalidade, que tem triplicado nos últimos 20 anos.

No estudo relativo ao Município de São Paulo taxas de mortalidade por diabetes mellitus mais altas foram identificadas em imigrantes japoneses comparativamente à população do Japão. Destacam os autores que tal fato relaciona-se à provável mudança nos hábitos dietéticos, em direção ao estilo brasileiro, caracterizados por uma maior ingestão de gordura e, conseqüente, obesidade (TSUGANE et al, 1989). Os resultados referentes à sobremortalidade feminina (que apenas não se verificou entre residentes no Japão) também são comentados naquele trabalho. GOTLIEB (1988) explica a situação observada em São Paulo como provável consequiência da adoção de hábitos correntes, entre paulistanos, pelos isseis

Estes resultados indicam que os isseis do Estado do Paraná, também, tenderam a modificar gradualmente seus hábitos nativos e, embora o papel da hereditariedade na etiologia da doença esteja bem estabelecida (MORRIS et al, 1989), fornecem mais evidências sobre a importância dos fatores ambientais. Além disso, é preciso considerar as limitações da fonte da dados consultada; sabe-se que estimativas a partir de registros de mortalidade subestimam a real magnitude da prevalência da doença em coletividades, por considerar apenas os casos que tiveram diabetes mellitus como causa básica de morte (LESSA et al, 1996). LLANOS e LIBMAN (1995) referem que, além da grande variabilidade temporal e geográfica existente nas práticas de codificação, em mais de $30 \%$ das declarações de morte de pessoas portadoras da doença, o termo diabetes, sequer, é mencionado. 
Tais questões indicam que a análise da mortalidade tendo diabetes como causa básica de morte reflete apenas uma parcela das mortes devidas a esta doença, e que as diferenças entre os residentes no Estado do Paraná (aí incluindo os isseis) e residentes no Japão, provavelmente, são mais acentuadas. Permitem, assim, de certo modo, concluir que muitas mortes ocorridas em 1991, no Estado do Paraná, poderiam ser evitadas, principalmente ao se levar em consideração a estrutura ainda precária dos serviços de saúde voltados para o atendimento aos portadores da diabetes mellitus. É bastante provável que os grandes diferenciais observados na mortalidade entre residentes no Japão e no Estado do Paraná devam-se a tais aspectos.

\subsubsection{Mortalidade por causas externas}

\section{- Suicídios}

No tocante às causas externas, suicídios entre isseis merecem atenção porque apresentam-se de forma diferenciada quando comparados às sociedades com traços culturais distintos. Conforme permitem apreciar os dados da tabelas 28, taxas de mortalidade por suicídio diferem marcadamente entre homens isseis e do Estado do Paraná; a razão de mortalidade padronizada e respectivo intervalo de $95 \%$ de confiança, tendo Paraná como referência é igual a $1,73[1,34 ; 2,23]$. Quando os dados são comparados com Japão, este valor passa a ser de $0,84[0,70 ; 1,00]$, porém esta diferença não é estatisticamente significante. Comportamento semelhante observou-se entre as mulheres isseis (RMP de 0,95 [0,68; 1,31] e 3,68 [2,02;6,68] tendo, respectivamente, Japão e Paraná como referência). 


\section{Tabela 28}

Coeficientes de mortalidade padronizados ${ }^{1}$ por suicídios e por lesões auto-infligidas ${ }^{2}$ (por 100.000 hab de 50 anos e mais), razão de mortalidade padronizada (RMP) e, respectivo, intervalo de $95 \%$ de confiança (IC 95\%) segundo sexo e população de estudo, 1991.

\begin{tabular}{|c|c|c|c|c|c|}
\hline \multirow[t]{2}{*}{ Sexo } & \multicolumn{3}{|c|}{ Coeficiente } & \multicolumn{2}{|c|}{ RMP IC $(95 \%)$} \\
\hline & Japão & Isseis & Paraná & Isseis/Japão & Isseis/Paraná \\
\hline Masculino & 36,9 & 30,8 & 17,8 & $0,84[0,70 ; 1,00]$ & $1,73[1,34 ; 2,23]^{*}$ \\
\hline Feminino & 20,9 & 19,8 & 5,4 & $0,95[0,68 ; 1,31]$ & $3,68[2,02 ; 6,68]^{*}$ \\
\hline
\end{tabular}

Muitos estudos abordam a influência dos fatores culturais e religiosos como determinantes da mortalidade por suicídio. SHATENSTEIN e KARK (1995), ao analisar taxas de suicídio entre judeus residentes em Israel e Montreal, comparativamente à população canadense total, observam marcantes diferenças entre estas três populações, identificando mais baixas taxas entre judeus, principalmente de Montreal. Relacionam, então, tais diferenças a uma possível proteção conferida por certas religiões, como a judaica, em que a importância atribuída à família e o senso de comunidade e solidariedade contribuem para atenuar os efeitos do "stress" da vida cotidiana. Quanto à diferença na taxa de mortalidade por suicídio entre as duas comunidades judaicas, aventa a possibilidade de resultar dos distintos graus de coesão e de aderência à cultura. Contudo, ressaltam que não se observam diferenças nas taxas entre as mulheres, o que poderia ser explicado como reflexo da menor importância atribuída pela mulher à coesão comunitária.

Pode ser que mulheres isseis e do Japão, à exemplo das judaicas, encontrem modos específicos de superar os problemas da vida cotidiana, explicando menores taxas em relação aos homens. Vale a pena ressaltar que, em termos absolutos, entre isseis, ocorreram apenas 2 casos de mortes por suicídio em mulheres e 6 em homens, correspondendo, 
respectivamente, a $0,2 \%$ e $1,2 \%$, em relação ao total de óbitos em cada sexo (tabelas 18 e 19).

HUCHCROFT e TANNEY (1988) destacam que taxas masculinas de mortalidade mais altas por suicídio constituem fenômeno quase que universalmente observado, embora razões para este diferencial não estejam claras, ainda. GRANIZO e colaboradores (1996), por sua vez, relatam que parte expressiva dos casos de suicídio, em países industrializados, acometem pessoas idosas. Dentro desta linha, estudo desenvolvido por ROCKETT e SMITH (1989), estabelecendo comparação nas taxas de mortalidade por suicídio entre cinco países industrializados (Estados Unidos, França, Inglaterra, Alemanha Ocidental e Japão), segundo sexo e grupos etários, identificou, nas mulheres japonesas idosas, as mais altas taxas. Como possível fator explicativo para o observado, aventam a influência da aceitação da prática de suicídio, como parte do legado cultural, no Japão.

Tradicionalmente, Japão vem apresentando altas taxas de suicídio quando comparados com vários países. ARAKI e MURATA (1986) relatam que, depois da II Guerra Mundial, a mortalidade por suicídio no Japão aumentou subitamente para um nível extremamente alto em ambos os sexos. A mortalidade nos homens começou a aumentar novamente desde o final da década de 60 , contudo a mortalidade em mulheres declinou após alcançar o maior pico em 1973-4. Esta tendência contrasta com a taxa constante nos Estados Unidos, durante 1950-80, e com o marcado declínio, na Grã Bretanha. De acordo com o estudo, baixa renda foi positivamente relacionada à mortalidade por suicídio, em homens de meia idade, tanto em 1970 quanto em 1975 e sugere que o aumento nas taxas de morte por suicídio nos homens de meia idade, durante 1975-82, resultou do declínio na economia seguindo a crise do petróleo.

Todavia, a título de ilustração, os dados da tabela 29, que se referem às taxas de mortalidade nas faixas etárias, permitem apreciar que estas taxas no Japão aumentam com a idade, em ambos os sexos, porém a tendência é mais acentuada nas mulheres, nas quais o diferencial quase triplica quando se comparam coeficientes relativos às pessoas de 50 a 54 
anos e 85 anos e mais. Embora dados disponíveis não permitam conclusões sobre a situação da prática de suicídio entre isseis do Paraná, é bastante provável que, a exemplo de residentes no Município de São Paulo, para os quais o suicídio, no mesmo período, representou menos de $0,8 \%$ das causas de morte em ambos os sexos (GOTLIEB, dados não publicados), gradualmente tenderam a abandonar alguns valores culturais de seu país de origem. Reforçam tais questões o fato de apenas um dos 8 óbitos por esta causa, entre isseis do Paraná, ter incidido em pessoas com 85 anos e mais.

\section{Tabela 29}

Coeficientes de mortalidade por suicídios e lesões auto-inflingidas (por 100.000 hab) segundo sexo, grupo etário e população de estudo, 1991.

\begin{tabular}{ccccccc}
\hline & \multicolumn{2}{c}{ Japão } & \multicolumn{2}{c}{ Isseis* } & \multicolumn{2}{c}{ Paraná } \\
Grupo etário & Masc & Fem & Masc & Fem & Masc & Fem \\
\hline 0 a 4 & - & - & - & - & - & - \\
5 a 9 & - & - & - & - & - & - \\
10 a 14 & 0,5 & 0,3 & - & - & 0,8 & 0,9 \\
15 a 19 & 4,9 & 2,6 & - & - & 4,6 & 5,0 \\
20 a 24 & 13,5 & 6,9 & - & - & 12,4 & 4,8 \\
25 a 29 & 17,9 & 8,5 & - & - & 9,7 & 3,6 \\
30 a 34 & 17,8 & 7,9 & - & - & 11,3 & 3,9 \\
35 a 39 & 20,3 & 8,2 & - & - & 11,0 & 3,1 \\
40 a 44 & 22,4 & 9,4 & - & - & 9,6 & 4,8 \\
45 a 49 & 30,7 & 11,9 & - & - & 20,7 & 3,8 \\
50 a 54 & 36,0 & 15,6 & - & - & 11,8 & 6,0 \\
55 a 59 & 37,0 & 15,8 & 62,8 & 82,5 & 23,2 & 1,6 \\
60 a 64 & 32,2 & 17,9 & - & - & 22,2 & 8,5 \\
65 a 69 & 31,1 & 20,8 & 70,9 & - & 13,4 & 6,5 \\
70 a 74 & 33,9 & 28,1 & - & - & 16,6 & 5,8 \\
75 a 79 & 48,0 & 36,0 & 102,9 & 65,4 & 32,5 & 5,9 \\
80 a 84 & 67,1 & 45,4 & - & - & 19,9 & - \\
85 e + & 76,2 & 55,7 & 98,9 & - & - & - \\
\hline
\end{tabular}

* Refere-se aos óbitos ocorridos entre 01/03/90 e 28/02/93. 
5. CONSIDERAÇÕES FINAIS 
Os resultados do estudo relativo aos isseis de 50 anos e mais residentes no Estado do Paraná confirmam a pressuposição norteadora do estudo, permitindo, mais uma vez, evidenciar que o padrão de mortalidade dos imigrantes tende a se afastar daquele existente no seu país de origem. Foi observado que as taxas de mortalidade para a maioria das causas, em ambos os sexos, situaram-se entre as dos residentes no Japão e no Estado do Paraná, mas não se verificou diferença significante entre o coeficiente padronizado de mortalidade geral dos homens isseis e o da população masculina do Japão. Todavia, o valor referente às mulheres isseis situou-se em posição intermediária quando comparado ao das residentes no Japão e no Paraná. Este aspecto está a sugerir que a intensidade das mudanças ocorridas na vida dos migrantes japoneses processou-se de forma distinta em cada sexo, fato que se torna mais evidente ao focalizar algumas causas específicas estudadas.

Considerando-se a mortalidade masculina, são destacáveis nos isseis, de 50 anos e mais, comparativamente aos habitantes no Japão, os coeficientes significativamente mais baixos para câncer de estômago, cólon, pulmão e próstata, porém, mais altos para diabetes, doenças isquêmicas do coração e doenças cerebrovasculares.

Em contrapartida, apreciou-se que as mulheres isseis, de 50 anos e mais, apresentaram taxas de mortalidade por câncer de estômago, cólon e mama bastante próxima das observadas para as habitantes no Japão. Entretanto, no caso das doenças isquêmicas do coração e doenças cerebrovasculares, a mortalidade das isseis foi mais que o dobro da observada nas mulheres do seu país de origem. Outra causa destacável na população feminina é a mortalidade por diabetes mellitus, cuja taxa padronizada referente às isseis foi quatro vezes maior do que a das residentes no Japão.

De outra parte, a comparação entre o padrão de mortalidade dos isseis e dos residentes no Paraná sugere que o nível de saúde dos isseis é mais favorável. Com exceção de câncer de estômago (mulheres), câncer de cólon e suicídio, para a maioria das outras causas estudadas foram verificados coeficientes de mortalidade entre isseis (de ambos os 
sexos) comparativamente mais baixos do que da população total do Paraná; esta diferença foi estatisticamente significante, mas, especificamente entre as mulheres, a mortalidade por diabetes mellitus e doenças cerebrovasculares mostrou-se similar nas duas populações.

A literatura postula que as populações migrantes apresentam um padrão de mortalidade compatível ao grau de aculturação atingido. Assim sendo, ao constatar que o padrão de mortalidade de isseis residentes no Estado do Paraná afasta do Japão, aproximando-se do Paraná, hipóteses podem ser levantadas no sentido de adaptação ao local de destino com atenuação de traços culturais do local de origem. Mas, o estudo está a indicar que, entre as possíveis questões explicativas, os determinantes gerais das condições de vida que acabam conferindo um modo de viver nas populações, indubitavelmente, guardam estreita relação com o modo de adoecer e de morrer por doenças prevalentes na sociedade contemporânea. No entanto, por serem muitos os mecanismos que definem este processo e as limitações conseqüentes ao delineamento adotado neste estudo, os resultados obtidos são indicativos de tópicos merecedores de atenções futuras.

Reafirmam, assim, o potencial científico de estudos de migrantes japoneses na contribuição para a elucidação da complexa trama de determinação das doenças crônicodegenerativas, especialmente algumas localizações de neoplasmas malignos (como estômago, mama e próstata), doenças isquêmicas do coração, doenças cerebrovasculares e diabetes mellitus. Desvelar tais questões, por meio de outras opções metodológicas, somadas às evidências atuais, certamente, contribuirá para melhor compreensão de como e quando tais doenças iniciam, o que no contexto da saúde coletiva pode significar maiores possibilidades de atuação e aprimoramento da qualidade e extensão da vida. 
6. REFERÊNCIAS BIBLIOGRÁFICAS 
ABU-ZEID, H.A et al. Ethnic differences in mortality from ischemic heart disease: a study of migrant and native populations. J. Chron. Dis, 31:137-46, 1978.

ALMEIDA FILHO, N. Epidemiologia sem números: uma introdução crítica à ciência epidemiológica. Rio de Janeiro, Campus, 1989.

ARAKI, S \& MURATA, K. Suicide mortality in Japan: analysis of the unusual secular trends. Tohoku J. exp. Med., 149:205-11, 1986.

ARAKI, S \& MURATA, K. Factors affecting the longevity of total Japanese population. Tohoku J. exp. Med., 151:15-24, 1987.

ARAÚJO, J.D. Polarização epidemiológica no Brasil. Inf. Epidemiol. SUS, 1(2):5-16, 1992.

BARRETO, M.L \& CARMO, E.H. Situação de saúde da população brasileira: tendências históricas, determinantes e implicações para as políticas de saúde. Inf. Epidemiol. SUS, 3(3/4): 7-34, 1994.

BEAGUEHOLE, R. International trends in coronary heart disease mortality, morbidity and risk factors. Epidemiol. Rev., 12:1-15, 1990.

BERnARDES, N. Expansão do povoamento no Estado do Paraná. Rev. Bras. Geogr., 427-51, out-dez, 1952.

BERQUÓ, E.S. Fatores estáticos e dinâmicos - mortalidade e fecundidade. In: Santos, J.LF et al, org. Dinâmica da população: teoria, métodos e técnicas de análise. São Paulo, T.A. Queiroz, 1980. p.21-85.

CARDOSO, M.A. et al. Dietary patterns in Japanese migrants to southeastern Brazil and their descendants. J. Epidemiol., 1997 (impress)

CASTRO PAULA, A. M. et al. Avaliação dos dados de mortalidade, Brasil - 1979 a 1989. Inf. Epidemiol. SUS, 3(1):21-41, 1994.

CENTRO DE ESTUDOS NIPO-BRASILEIROS. Pesquisa da população de descendentes de japoneses residentes no Brasil: 1987-1988. São Paulo, 1990.

COGGON, D \& ACHESON, E.D. The geography of cancer of the stomach. Med. Bull., 40:335-41, 1984.

DOUSTDAR, N.M. \& PEREIRA, V.V.V.R. Indicadores de saúde: mortalidade no Paraná. Curitiba, IPARDES, 1991. 
DUNCAN, B.B. et al. Fatores de risco para doenças não transmissíveis em área metropolitana na região Sul do Brasil. Prevalência e simultaneidade. Rev. Saúde Pública, 27:143-8, 1993.

FANG, J. et al. Cancer mortality of Chinese in New York City 1988-1992. Int. J. Epidemiol., 25: 907-12, 1996.

FLETCHER, R.H et al. Epidemiologia clínica. Porto Alegre, Artes Médicas, 1989.

FRANCO, L.J. Diabetes in Japanese-Brazilians - influence of the acculturation process. Diabetes Res. Clin. Pract., 34 (Suppl.) S51-S57, 1996.

FUNDAÇÃO IBGE. Situação demográfica, social e econômica: primeiras considerações Estado do Paraná. Rio de Janeiro, IBGE, 1995.

FUNDAÇÃO IBGE. Tendências demográficas: uma análise a partir dos resultados do censo demográfico de 1991. Rio de Janeiro, IBGE, 1996.

GEORGE, P. As migrações internacionais. Lisboa, Publicações Dom Quixote, 1977.

GORDON, T. Mortality experience among the Japanese in the United States, Hawaii, and Japan. Public Health Rep., 72:543-53, 1957.

GORDON, T. Further mortality experience among Japanese Americans. Public Health Rep., 82:973-84, 1967.

GOTLIEB, S. L. D. Alguns aspectos da mortalidade entre japoneses e seus descendentes residentes no Município de São Paulo, Brasil. Rev. Saúde Pública, 1:911-20, 1974.

GOTLIEB, S.L.D. Mortalidade em migrantes: japoneses residentes no Município de São Paulo. São Paulo, 1988. [Tese de Livre-Docência - Faculdade de Saúde Pública da USP].

GOTLIEB, S.L.D. Mortalidade em migrantes japoneses residentes no Município de São Paulo, Brasil, 1980. Rev. Saúde Pública, 24:453-67, 1990

GRANIZO, J.J. et al. Age-period-cohort analysis of suicide mortality rates in Spain, 1959 1991. Int. J. Epidemiol, 25:814-20, 1996.

GUIMARÃES, R. Novas perspectivas temáticas para a epidemiologia. In: Congresso Brasileiro de Epidemiologia, 1", Campinas, 1990, Anais. Rio de Janeiro, ABRASCO, s.d. p.241-7. 
HANDA, T. O imigrante japonês: história de sua vida no Brasil. São Paulo, T.A. Queiroz/Centro de Estudos Nipo-Brasileiros, 1987.

HATANO, S. Changing CHD mortality and its causes in Japan during 1955-1985. Int. J. Epidemiol., 18 (suppl.1): S149-58, 1989.

HOWSON, C.P et al. The decline in gastric cancer: epidemiology of an unplanned triumph. Epidemiol. Rev., 8:1-27, 1986.

HUCHCROFT, S.A \& TANNEY, B.L. Sex-specific suicide trends in Canada, 1971-1985. Int. J. Epidemiol., 17:839-43, 1988

ISHII, M. Estudo de uma população de origem japonesa e de seus hábitos alimentares quando integrada no sistema ecológico de duas localidades da expansão cafeeira paulista. São Paulo, 1980. [Dissertação de Mestrado - Faculdade de Saúde Pública da USP].

ISHII, M. Hábitos alimentares de segmentos populacionais japoneses: histórico da natureza e direção da mudança. São Paulo, 1986. [Tese de Doutorado - Faculdade de Saúde Pública da USP].

JAPAN MINISTRY OF HEALTH AND WELFARE. Vital Statistics: 1991. Tokyo, 1992.

JOOSSENS, J.V et al. Dietary salt, nitrate and stomach cancer mortality in 24 countries. European Cancer Prevention (ECP) and the INTERSALT Cooperative Research Group. Int. J. Epidemiol., 25:494-504, 1996.

KAMPMAN, E et al. Vegetable and animal products as determinants of colon cancer risk in Dutch men and women. Cancer Causes Control, 6:225-234, 1995.

KELSEY, J.L. \& HORN-ROSS, P.L. Breast cancer: magnitude of the problem and descriptive epidemiology. Epidemiol. Rev., 15: 7-16, 1993.

KIYOTANI, M. \& YAMASHIRO, J. Do Kasato-Maru até a década de 20. In: Sociedade Brasileira de Cultura Japonesa. Uma epopéia moderna: 80 anos da imigração japonesa no Brasil. São Paulo, HUCITEC, 1992. p.63-135.

LANDS, W.M. et al. Changing dietary patterns. Am. J. Clin. Nutr., 51: 991-3, 1992.

L.ARAIA, R.B. Cultura: um conceito antropológico. Rio de Janeiro, Jorge Zahar Editor, 1993.

LAURENTI, R. et al. Estatísticas de saúde. São Paulo, EPU, 1987. 
LESSA, I. Doenças não transmissíveis. In: Rouquayrol, M.Z. Epidemiologia e saúde. 4 ed. Rio de Janeiro, MEDSI, 1993. p.269-79.

LESSA, I. et al. Doenças crônicas não-transmissíveis no Brasil: dos fatores de risco ao impacto social. Bol. Oficina Sanit. Panam., 120:389-413, 1996.

LILIENFELD, D. \& STOLLEY, P. D. Foundations of epidemiology. New York, Oxford University Press, 1994.

LLANOS, G. \& LIBMAN, I. La diabetes en las Américas. Bol. Oficina Sanit. Panam., 118:1-17, 1995.

MARMOT, M.G. \& SYME, S.L. Acculturation and coronary heart disease in JapaneseAmericans. Am. J. Epidemiol., 104:225-47, 1976.

MARMOT, M.G. Interpretation of trends on coronary heart disease mortality. Acta Med. Scand. (Suppl) 701:58-65, 1985.

MARTINS, I.S et al. Smoking, consumption of alcohol and sedentary life style in population grouping and their relationships with lipemic disorders. Rev. Saúde Pública, 29:38-45, 1995.

MARTINS, I,S. et al. Doenças cardiovasculares ateroscleróticas, dislipidemias, hipertensão, obesidade e diabetes melito em população da área metropolitana da região Sudeste do Brasil. II - Dislipidemias. Rev. Saúde Pública, 30:75-84, 1996.

MICHAMAN, M.Z.H.B. et al. Epidemiologic studies of coronary heart disease and stroke in Japanese men living in Japan, Hawaii and California: distribuition of biochemical risk factors. Am. J. Epidemiol., 102:491-501, 1975.

MINISTÉRIO DA SAÚDE. Fundação Nacional de Saúde. Centro Nacional de Epidemiologia, Coordenação de Informações e Análise da Situação de Saúde. Estatística de Mortalidade: Brasil, 1990. Brasília, CENEPI, 1996.

MINISTÉRIO DOS NEGÓCIOS ESTRANGEIROS DO JAPÃO. O Japão de hoje. s.l., 1972.

MORAEŚ, S.A. de S. \& SOUZA, J. M. P. de. Efeito dose-resposta de fatores de risco para doença isquêmica do coração. Rev. Saúde Pública, 30: 471-8, 1996.

MORRIS, R.D. et al. Obesity and heredity in the etiology of non-insulin-dependent diabetes mellitus in 32,662 adult white women. Am. J. Epidemiol., 130:112-21, 1989. 
NOMURA, A.M.Y \& KOLONEL, L. Prostate cancer: a current perspective. Am. J. Epidemiol., 13:200-27, 1991.

NOGUEIRA, A. R. Antecedentes da imigração japonesa no Brasil. In: Sociedade Brasileira de Cultura Japonesa. Uma epopéia moderna: 80 anos da imigração japonesa no Brasil. São Paulo, HUCITEC, 1992. p.35-58.

OGUIDO, H. De imigrantes a pioneiros: a saga dos japoneses no Paraná. $2^{\mathrm{a}}$ ed. Curitiba, s.e., 1988.

OMURA, T et al. Geographical distribution of cerebrovascular disease mortality and food intakes in Japan. Soc. Sci. Med., 24:401-7, 1987.

ORGANIZAÇÃO MUNDIAL DA SAÚDE. Manual da classificação internacional de doenças, lesões e causas de óbito; $9^{a}$ revisão, 1975. São Paulo, Centro Brasileiro para a Classificação de Doenças, 1978.

PEREIRA, M.G. Epidemiologia: teoria e prática. Rio de Janeiro, Guanabara-Koogan, 1995.

REED, D.M. et al. Acculturation and coronary heart disease among Japanese men in Hawaii. Am. J. Epidemiol., 115: 894-905, 1982.

RENNER, C.H \& PATARRA, N.L. Migrações. In: Santos, J.L.F. et al, org. Dinâmica da população: teoria, métodos e técnicas de análise. São Paulo, T.A. Queiroz, 1980. p.236-260.

REZENDE, T. H. Ryu Mizuno: saga japonesa em terras brasileiras. Curitiba, SEEC/INL, 1991.

ROCKETT, I.R.H \& SMITH, G.S. Homicide, suicide, motor vehicle crash, and fall mortality: United States' experience in comparative perspective. Am. J. Public Health, 79:1396-400, 1989

RODRIGUES DA SILVA, G. Avaliação e perspectivas da epidemiologia no Brasil. In: Congresso Brasileiro de Epidemiologia, $1^{\circ}$, Campinas, 1990, Anais. Rio de Janeiro, ABRASCO, s.d. p.108-39.

ROUQUAYROL, M.Z. Epidemiologia e saúde. $3^{\text {a }}$ ed. Rio de Janeiro, MEDSI, 1988.

ROUQUAYROL, M.Z. et al. Principais causas de morte no Brasil, 1978-88. Inf. Epidemiol. SUS, 2:28-37, 1993. 
RUMEL, D. Razões de mortalidade frente ao efeito desigualdade em estudos de mortalidade associada a categorias ocupacionais e níveis sociais. Rev. Saúde Pública, 22:335-40, 1988 .

SABROZA, P.C. \& LEAL, M.C. Saúde, ambiente e desenvolvimento: alguns conceitos fundamentais. In: Leal, M.C. et al., org. Saúde, ambiente e desenvolvimento. São Paulo, HUCITEC/ABRASCO, 1992.

SALA, A et al. Avaliação da efetividade do controle da hipertensão arterial em unidade básica de saúde. Rev. Saúde Pública. 30:161-7, 1996.

SASAKI, A et al. A changing pattern of causes of death in Japanese diabetics. Observations over fifteen years. J. Chron Dis., 31:433-44, 1978.

SHATENSTEIN, B. \& KARK, J. Mortality in two Jewish populations - Montreal and Israel: environmental determinants of differences. Int. J. Epidemiol., 24: 730-9, 1995.

SICHIERI, R et al. Geographical patterns of proportionate mortality for the most common causes of death in Brazil. Rev. Saúde Pública, 26:242-30, 1992.

SINGER, P. Economia política da urbanização. $8^{\text {a }}$ ed. São Paulo, Brasiliense, 1981.

SOLBERG, L. A et al. Comparison of coronary atherosclerosis in middle-aged Norwegian and Japanese men: an autopsy study. Lab. Invest., 56:451-6, 1987.

SMITH, P.G. Comparison between registries: age-standardized ratios. In: WORLD HEALTH ORGANIZATION. Cancer incidence in five continents. United Kingdom, International for Research on Cancer, 1992.

SOUZA, I. Migrações internas no Brasil. Rio de Janeiro, Vozes, 1980.

SOUZA, J.M.P. de et al. Proportional cancer incidence according to selected sites comparison between residents in the City of S. Paulo, Brazil: Japanese and Brazilian/Portuguese descent. Rev. Saúde Pública, 25:188-92, 1991.

STAMLER, J. Opportunities and pitfalls in international comparisons related to patterns, trends and determinants of CHD mortality. Int. J. Epidemiol., 18 (suppl 1): S3-18, 1989.

SVANBORG, A et al. Comparison of ecology, ageing and state of health in Japan and Sweden, the present and previous leaders in longevity. Acta Med. Scand., 218:5-17, 1985. 
SYME, S.L. et al. Epidemiologic studies of coronary heart disease and stroke in Japanese men living in Japan, Hawaii and California: introduction. Am. J. Epidemiol., 102:477-80, 1975 .

TAJIRI, T. \& YAMASHIRO, J. As grandes migrações da Europa nos séculos XIX e XX. In: Sociedade Brasileira de Cultura Japonesa. Uma epopéia moderna: 80 anos da imigração japonesa no Brasil. São Paulo, HUCITEC, 1992. p.15-20.

TELAROLLI Jr, R et al. Perfil demográfico e condições sanitárias dos idosos em área urbana do Sudeste do Brasil. Rev. Saúde Pública, 30: 485-98, 1996.

TERRIS, M. Desegregating health statistics. Am. J. Public Health, 63: 477-80, 1973.

TSUGANE, S. et al. Mortality and cause of death among first-generation Japanese in São Paulo, Brazil. Int. J. Epidemiol., 18:647-51, 1989.

TSUGANE, S. et al. Cancer incidence rates among Japanese immigrants in the city of São Paulo, 1969-78. Cancer Causes and Control, 1:189-93, 1990a.

TSUGANE, S. et al. Lifestyle and health related factors among randomly selected Japanese residents in the city of São Paulo, Brazil, and their comparisons with Japanese in Japan. J. Epidemiol., 4:37-46, 1994.

UCHIYAMA, K et al. Emigração como política de Estado. In: Sociedade Brasileira de Cultura Japonesa. Uma epopéia moderna: 80 anos da imigração japonesa no Brasil. São Paulo, HUCITEC, 1992. p.137-246.

VIEIRA, F.I.S. O japonês na frente de expansão paulista. São Paulo, Pioneira/EDUSP, 1973.

WAKAI, K et al. Epidemiology of breast cancer in Japan. Int. J. Epidemiol., 24: 285-91, 1995.

WALDRON, I. Sex differences in human mortality: the role of genetic factors. Soc. Sci. Med., 17: 321-33, 1983.

WORLD HEALTH ORGANIZATION. World health statistics annual - 1995. Geneva, 1996.

WORTH, R.M. et al. Epidemiologic studies of coronary heart disease and stroke in Japanese men living in Japan, Hawaii and California: mortality. Am. J. Epidemiol., 102:481-90, 1975 . 
YAMOCHI, Y. Imigração japonesa: ontem e hoje - o exemplo dos japoneses da comunidade nikkei de Uraí (PR-Brasil). São Paulo, 1991. [Dissertação de Mestrado Faculdade de Filosofia, Letras e Ciências Humanas da USP].

ZHANG, X. H. et al. The sex ratio of mortality and its secular trends. Int. J. Epidemiol., 24: $720-29,1995$. 
7. ANEXOS 


\begin{abstract}
ANEXO 1
População estimada* para primeiro de julho de 1991 segundo sexo e grupo etário. Japão e Estado do Paraná
\end{abstract}

\begin{tabular}{ccccc}
\hline \multirow{2}{*}{ Grupo etário } & \multicolumn{2}{c}{ Japão } & \multicolumn{2}{c}{ Estado do Paraná } \\
& Masculino & Feminino & Masculino & Feminino \\
\hline 0 a 4 & 3248167 & 3086259 & 468822 & 453059 \\
5 a 9 & 3751728 & 3570829 & 479492 & 463513 \\
10 a 14 & 4220319 & 4008440 & 478668 & 466309 \\
15 a 19 & 5072575 & 4816722 & 437144 & 439191 \\
20 a 24 & 4778832 & 4604910 & 404832 & 412718 \\
25 a 29 & 4036479 & 3940501 & 371277 & 388721 \\
30 a 34 & 3910589 & 3832596 & 317913 & 334665 \\
35 a 39 & 4330223 & 4271207 & 273766 & 288345 \\
40 a 44 & 5651071 & 5596030 & 228348 & 229984 \\
45 a 49 & 4280267 & 4314169 & 183407 & 184264 \\
50 a 54 & 4087435 & 4172295 & 152848 & 149300 \\
55 a 59 & 3859633 & 4010438 & 124773 & 127776 \\
60 a 64 & 3333093 & 3582818 & 103440 & 105472 \\
65 a 69 & 2394911 & 3029310 & 74583 & 76990 \\
70 a 74 & 1579622 & 2326933 & 48277 & 51365 \\
75 a 79 & 1226930 & 1873336 & 30722 & 34160 \\
80 a 84 & 717374 & 1238900 & 15071 & 17528 \\
85 e + & 372675 & 807283 & 7934 & 10990 \\
\hline Total & 60851923 & 63082976 & 4201316 & 4234350 \\
\hline
\end{tabular}

*Estimativa pelo método geométrico (LAURENTI et al, 1987) 


\section{ANEXO 2}

População padrão* segundo grupos etários

\begin{tabular}{cr}
\hline Grupo etário & $\mathrm{N}^{\mathrm{O}}$ \\
\hline 0 a 4 & 12000 \\
5 a 9 & 10000 \\
10 a 14 & 9000 \\
15 a 19 & 9000 \\
20 a 24 & 8000 \\
25 a 29 & 8000 \\
30 a 34 & 6000 \\
35 a 39 & 6000 \\
40 a 44 & 6000 \\
45 a 49 & 6000 \\
50 a 54 & 5000 \\
55 a 59 & 4000 \\
60 a 64 & 4000 \\
65 a 69 & 3000 \\
70 a 74 & 2000 \\
75 a 79 & 1000 \\
80 a 84 & 500 \\
85 e + & 500 \\
\hline Total* & 100000 \\
\hline
\end{tabular}

*população mundial

Fonte: SMITH, 1992. 


\section{ANEXO 3}

$\mathrm{N}^{\circ}$ de óbitos no sexo masculino segundo principais causas básicas de morte e grupos etários. Isseis do Estado do Paraná, 1991

\begin{tabular}{|c|c|c|c|c|c|c|c|c|}
\hline \multirow[b]{2}{*}{ Grupo etário } & \multicolumn{7}{|c|}{ Causa de morte** } & \multirow[b]{2}{*}{ XVII } \\
\hline & I & II & III & VII & VIII & IX & XVI & \\
\hline $0 \mathrm{a} 4$ & - & - & - & - & - & - & - & - \\
\hline 5 a 9 & - & - & - & - & - & - & - & - \\
\hline 10 a 14 & - & - & - & - & - & - & - & - \\
\hline 15 a 19 & - & - & - & - & - & - & - & - \\
\hline 20 a 24 & - & - & - & - & - & - & - & 1 \\
\hline 25 a 29 & - & - & - & - & - & - & - & - \\
\hline 30 a 34 & - & - & - & - & - & - & - & - \\
\hline 35 a 39 & - & - & - & - & - & - & - & - \\
\hline 40 a 44 & - & - & - & - & - & - & - & 1 \\
\hline 45 a 49 & - & 1 & - & - & - & 1 & 1 & - \\
\hline 50 a 54 & 2 & 3 & - & 1 & - & 1 & - & 1 \\
\hline 55 a 59 & - & 2 & - & 3 & 1 & 1 & 1 & 4 \\
\hline 60 a 64 & 1 & 7 & - & 17 & 1 & 3 & 1 & 3 \\
\hline 65 a 69 & 1 & 13 & 1 & 16 & 6 & 1 & 4 & 8 \\
\hline 70 a 74 & 1 & 15 & 5 & 35 & 6 & 2 & 8 & 6 \\
\hline 75 a 79 & 1 & 19 & 4 & 55 & 16 & 7 & 4 & 11 \\
\hline 80 a 84 & 1 & 16 & 5 & 35 & 14 & 8 & 11 & 1 \\
\hline $85 \mathrm{e}+$ & 3 & 13 & 2 & 47 & 27 & 3 & 7 & 5 \\
\hline Total* & 10 & 89 & 17 & 209 & 71 & 27 & 37 & 41 \\
\hline
\end{tabular}

* Excluídos os casos cuja idade e/ou sexo são desconhecidos

** I - Doenças infecciosas e parasitárias (001-139)

II - Neoplamas (140-239)

III - Doenças das glândulas endócrinas, da nutrição e do metabolismo e transtornos imunitários (240-279)

VII - Doenças do aparelho circulatório (320-389)

VIII - Doenças do aparelho respiratório (460-519)

IX - Doenças do aparelho digestivo (520-579)

XVI - Sintomas, sinais e afeç̧ões mal-definidas (780-799)

XVII - Causas externas (E899-E999) 
$\mathrm{N}^{0}$ de óbitos no sexo feminino segundo principais causas básicas de morte e grupos etários, Isseis do Estado do Paraná, 1991.

\begin{tabular}{lcccccccc}
\hline & \multicolumn{7}{c}{ Causa de morte** } \\
\cline { 2 - 8 } Grupo etário & I & II & III & VII & VIII & IX & XVI & XVII \\
\hline 0 a 4 & - & - & - & - & - & - & - & - \\
5 a 9 & - & - & - & - & - & - & - & - \\
10 a 14 & - & - & - & - & - & - & - & - \\
15 a 19 & - & - & - & - & - & - & - & - \\
20 a 24 & - & - & - & - & - & - & - & - \\
25 a 29 & - & - & - & - & - & - & 1 & - \\
30 a 34 & - & - & - & - & - & - & - & - \\
35 a 39 & - & - & - & - & - & - & - & - \\
40 a 44 & - & - & - & - & - & - & - & - \\
45 a 49 & 1 & 2 & - & - & - & - & - & - \\
50 a 54 & - & 1 & - & - & - & - & - & - \\
55 a 59 & 1 & 3 & - & 5 & - & - & - & 1 \\
60 a 64 & 2 & 9 & 1 & 10 & - & - & 1 & - \\
65 a 69 & - & 9 & 5 & 15 & 1 & 3 & 1 & 1 \\
70 a 74 & 2 & 10 & 3 & 19 & 3 & 2 & 2 & $2-$ \\
75 a 79 & 4 & 19 & 7 & 45 & 6 & 6 & 3 & 4 \\
80 a 84 & - & 11 & 6 & 36 & 4 & 7 & 8 & 2 \\
85 e + & 4 & 12 & 3 & 77 & 26 & 5 & 25 & 1 \\
\hline Total* & 14 & 76 & 25 & 207 & 40 & 23 & 41 & 11 \\
\hline
\end{tabular}

* Excluídos os casos cuja idade e/ou sexo são desconhecidos

** I - Doenças infecciosas e parasitárias (001-139)

II - Neoplamas (140-239)

III - Doenças das glândulas endócrinas, da nutrição e do metabolismo e transtornos imunitários (240-279)

VII - Doenças do aparelho circulatório (320-389)

VIII - Doenças do aparelho respiratório (460-519)

IX - Doenças do aparelho digestivo (520-579)

XVI - Sintomas, sinais e afecções mal-definidas (780-799)

XVII - Causas externas (E899-E999) 
$\mathrm{N}^{\circ}$ de óbitos no sexo masculino segundo principais causas básicas de morte e grupos etários, Japão, 1991.

\begin{tabular}{|c|c|c|c|c|c|c|c|c|}
\hline \multirow[b]{2}{*}{ Grupo etário } & \multicolumn{8}{|c|}{ Causa de morte** } \\
\hline & I & II & III & VII & VIII & IX & XVI & XVII \\
\hline 0 a 4 & 141 & 116 & 59 & 212 & 221 & 43 & 310 & 679 \\
\hline 5 a 9 & 14 & 142 & 10 & 52 & 49 & 8 & 6 & 382 \\
\hline 10 a 14 & 20 & 166 & 14 & 69 & 50 & 9 & 6 & 206 \\
\hline 15 a 19 & 29 & 270 & 16 & 195 & 107 & 14 & 21 & 2230 \\
\hline 20 a 24 & 31 & 298 & 21 & 313 & 125 & 41 & 20 & 2501 \\
\hline 25 a 29 & 39 & 334 & 25 & 450 & 131 & 46 & 25 & 1701 \\
\hline 30 a 34 & 46 & 498 & 35 & 684 & 102 & 103 & 38 & 1519 \\
\hline 35 a 39 & 79 & 1132 & 59 & 1181 & 179 & 313 & 50 & $18+2$ \\
\hline 40 a 44 & 163 & 3003 & 152 & 2814 & 290 & 8.58 & 64 & 2827 \\
\hline 45 a 49 & 228 & 4314 & 212 & 3757 & 432 & 1387 & 84 & 2864 \\
\hline 50 a 54 & 356 & 7376 & 338 & 5449 & 753 & 1905 & 102 & 3205 \\
\hline 55 a 59 & 557 & 14134 & 532 & 8518 & 1451 & 2898 & 162 & 3475 \\
\hline 60 a 64 & 732 & 20117 & 717 & 11621 & 2812 & 3044 & 253 & 3103 \\
\hline 65 a 69 & 904 & 20385 & 618 & 13019 & 4390 & 2284 & 331 & 2493 \\
\hline 70 a 74 & 975 & 19620 & 698 & 16325 & 6964 & 2071 & 524 & 2132 \\
\hline 75 a 79 & 1222 & 20697 & 968 & 24891 & 12019 & 2562 & 1190 & 2453 \\
\hline 80 a 84 & 1056 & 15991 & 814 & 28171 & 14629 & 2397 & 2359 & 2169 \\
\hline $85 \mathrm{e}+$ & 757 & 9685 & 695 & 29545 & 15373 & 2245 & 6004 & 1564 \\
\hline Total* & 7349 & 138278 & 5983 & 147266 & 60077 & 22228 & 11549 & 37345 \\
\hline
\end{tabular}

* Excluídos os casos cuja idade e/ou sexo são desconhecidos

** I - Doenças infecciosas e parasitárias (001-139)

II - Neoplamas (140-239)

III - Doenças das glândulas endócrinas, da nutrição e do metabolismo e transtornos imunitários (240-279)

VII - Doenças do aparelho circulatório (320-389)

VIII - Doenças do aparelho respiratório (460-519)

IX - Doenças do aparelho digestivo (520-579)

XVI - Sintomas, sinais e afeç̧ōes mal-definidas (780-799)

XVII - Causas externas (E899-E999) 
$\mathrm{N}^{0}$ de óbitos no sexo feminino segundo principais causas básicas de morte e grupos etários, Japão, 1991.

\begin{tabular}{|c|c|c|c|c|c|c|c|c|}
\hline \multirow[b]{2}{*}{ Grupo etário } & \multicolumn{8}{|c|}{ Causa de morte** } \\
\hline & I & II & III & VII & VIII & IX & XVI & XVII \\
\hline $0 \mathrm{a} 4$ & 100 & 101 & 48 & 169 & 188 & 32 & 243 & 482 \\
\hline 5 a 9 & 19 & 123 & 12 & 45 & 36 & 3 & 7 & 174 \\
\hline 10 a 14 & 16 & 127 & 3 & 37 & 46 & 7 & 3 & 106 \\
\hline 15 a 19 & 23 & 188 & 9 & 94 & 55 & 5 & 13 & 539 \\
\hline 20 a 24 & 26 & 186 & 11 & 132 & 70 & 15 & 14 & 728 \\
\hline 25 a 29 & 21 & 305 & 26 & 188 & 83 & 27 & 14 & 537 \\
\hline 30 a 34 & 20 & 618 & 17 & 278 & 94 & 40 & 13 & 469 \\
\hline 35 a 39 & 41 & 1333 & 32 & 434 & 122 & 73 & 9 & 575 \\
\hline 40 a 44 & 68 & 3049 & 66 & 1079 & 166 & 204 & 30 & 889 \\
\hline 45 a 49 & 107 & 3612 & 94 & 1602 & 240 & 253 & 25 & 931 \\
\hline 50 a 54 & 146 & 5173 & 164 & 2424 & 333 & 462 & 53 & 1162 \\
\hline 55 a 59 & 223 & 7164 & 274 & 3614 & 603 & 846 & 66 & 1242 \\
\hline 60 a 64 & 413 & 9099 & 382 & 5396 & 1067 & 1089 & 109 & 1316 \\
\hline 65 a 69 & 503 & 11037 & 628 & 8755 & 1819 & 1414 & 181 & 1503 \\
\hline 70 a 74 & 625 & 12357 & 876 & 14275 & 3514 & 1832 & 416 & 1716 \\
\hline 75 a 79 & 869 & 14222 & 1158 & 25567 & 6785 & 2553 & 1165 & 2136 \\
\hline 80 a 84 & 919 & 13025 & 1368 & 35878 & 10003 & 3150 & 3171 & 2063 \\
\hline $85 \mathrm{e}+$ & 988 & 10548 & 1289 & 572.32 & 17167 & 4178 & 13033 & 2214 \\
\hline Total ${ }^{*}$ & 5127 & 92267 & 6457 & 157199 & 42391 & 16183 & 18565 & 18782 \\
\hline $\begin{array}{r}* \text { Excluídos o } \\
* * \text { I - Doenças } \\
\text { II - Neoplam } \\
\text { III - Doenças } \\
\text { VII - Doenças } \\
\text { VIII - Doenças } \\
\text { IX - Doenças } \\
\text { XVI - Sintomas } \\
\text { XVII - Causas e }\end{array}$ & $\begin{array}{l}\text { a idade } \\
\text { s e par: } \\
\text { 39) } \\
\text { ulas en } \\
\text { to circu } \\
\text { ho resp } \\
\text { ho dige } \\
\text { afecçõe } \\
800\end{array}$ & $\begin{array}{l}\text { e/ou sex } \\
\text { sitárias ( } \\
\text { 6crinas, } \\
\text { atório (3 } \\
\text { atório (4 } \\
\text { tivo }(520 \\
\text { mal-def }\end{array}$ & $\begin{array}{l}\text { ão desc } \\
1-139) \\
\text { nutriçã } \\
-459) \\
-519) \\
79) \\
\text { idas (78 }\end{array}$ & do $\mathrm{m}$ & ism & storn & Iunitár & 40-279) \\
\hline
\end{tabular}


$\mathrm{N}^{0}$ de óbitos no sexo masculino segundo principais causas básicas de morte e grupos etários, Estado do Paraná, 1991.

\begin{tabular}{|c|c|c|c|c|c|c|c|c|}
\hline \multirow[b]{2}{*}{ Grupo etário } & \multicolumn{8}{|c|}{ Causa de morte** } \\
\hline & I & II & III & VII & VIII & IX & XVI & XVII \\
\hline $0 \mathrm{a} 4$ & 473 & $\overline{28}$ & 117 & 19 & 362 & - & 353 & 198 \\
\hline 5 a 9 & 15 & 34 & 4 & 4 & 12 & 9 & 13 & 120 \\
\hline 10 a 14 & 7 & 24 & 5 & 1 & 10 & 3 & 16 & 140 \\
\hline 15 a 19 & 13 & 34 & 7 & 29 & 16 & 6 & 35 & 445 \\
\hline 20 a 24 & 19 & 30 & 18 & 33 & 12 & 12 & 48 & 633 \\
\hline 25 a 29 & 34 & 41 & 42 & 52 & 19 & 35 & 64 & 597 \\
\hline 30 a 34 & 30 & 63 & 33 & 95 & 28 & 59 & 85 & 507 \\
\hline 35 a 39 & 41 & 86 & 33 & 169 & 25 & 91 & 105 & 408 \\
\hline 40 a 44 & 50 & 107 & 28 & 282 & 46 & 126 & 141 & 389 \\
\hline 45 a 49 & 79 & 190 & 32 & 395 & 59 & 149 & 162 & 295 \\
\hline 50 a 54 & 69 & 321 & 33 & 600 & 59 & 135 & 217 & 224 \\
\hline 55 a 59 & 75 & 374 & 38 & 821 & 103 & 119 & 256 & 213 \\
\hline 60 a 64 & 75 & 488 & 69 & 930 & 154 & 119 & 275 & 160 \\
\hline 65 a 69 & 79 & 508 & 75 & 1104 & 195 & 117 & 332 & 114 \\
\hline 70 a 74 & 55 & 430 & 63 & 1156 & 232 & 108 & 369 & 85 \\
\hline 75 a 79 & 44 & 340 & 54 & 1112 & 254 & 82 & 360 & 78 \\
\hline 80 a 84 & 44 & 195 & 32 & 878 & 217 & 55 & 288 & 45 \\
\hline $85 e+$ & 23 & 114 & 38 & 604 & 163 & 34 & 257 & 39 \\
\hline Total* & 1225 & 3407 & 721 & 8284 & 1966 & 1259 & 3376 & 4690 \\
\hline
\end{tabular}

* Excluídos os casos cuja idade e/ou sexo são desconhecidos

** I - Doenças infecciosas e parasitárias (001-139)

II - Neoplamas (140-239)

III - Doenças das glândulas endócrinas, da nutrição e do metabolismo e transtornos imunitários (240-279)

VII - Doenças do aparelho circulatório (390-459)

VIII - Doenças do aparelho respiratório (460-519)

IX - Doenças do aparelho digestivo (520-579)

XVI - Sintomas, sinais e afecções mal-definidas (780-799)

XVII - Causas externas (E899-E999) 
$\mathrm{N}^{\mathrm{o}}$ de óbitos no sexo feminino segundo principais causas básicas de morte e grupos etários, Estado do Paraná, 1991.

\begin{tabular}{crrrrrrrr}
\hline & \multicolumn{7}{c}{ Causa de morte** } \\
\cline { 2 - 9 } Grupo etário & I & II & III & VII & VIII & IX & XVI & XVII \\
\hline 0 a 4 & 450 & 23 & 114 & 8 & 306 & - & 294 & 122 \\
5 a 9 & 19 & 27 & 3 & 8 & 6 & 11 & 16 & 63 \\
10 a 14 & 6 & 14 & 6 & 12 & 13 & 5 & 13 & 76 \\
15 a 19 & 5 & 26 & 4 & 7 & 10 & 6 & 16 & 103 \\
20 a 24 & 11 & 25 & 19 & 26 & 10 & 13 & 31 & 120 \\
25 a 29 & 15 & 40 & 16 & 38 & 15 & 17 & 36 & 108 \\
30 a 34 & 20 & 68 & 18 & 76 & 21 & 21 & 30 & 94 \\
35 a 39 & 20 & 111 & 13 & 141 & 16 & 28 & 36 & 68 \\
40 a 44 & 21 & 120 & 25 & 195 & 25 & 35 & 79 & 56 \\
45 a 49 & 32 & 200 & 29 & 282 & 36 & 35 & 85 & 57 \\
50 a 54 & 27 & 223 & 35 & 378 & 57 & 49 & 119 & 56 \\
55 a 59 & 40 & 257 & 59 & 472 & 73 & 37 & 132 & 47 \\
60 a 64 & 49 & 324 & 66 & 630 & 96 & 62 & 170 & 45 \\
65 a 69 & 24 & 301 & 86 & 817 & 149 & 65 & 211 & 38 \\
70 a 74 & 43 & 294 & 111 & 895 & 167 & 70 & 241 & 37 \\
75 a 79 & 42 & 255 & 97 & 1032 & 180 & 71 & 266 & 51 \\
80 a 84 & 26 & 157 & 68 & 827 & 139 & 49 & 267 & 40 \\
85 e + & 32 & 94 & 47 & 826 & 185 & 38 & 295 & 46 \\
\hline Total* & 882 & 2559 & 816 & 6670 & 1504 & 612 & 2337 & 1227 \\
\hline
\end{tabular}

* Excluídos os casos cuja idade e/ou sexo são desconhecidos

** I - Doenças infecciosas e parasitárias (001-139)

II - Neoplamas (140-239)

III - Doenças das glândulas endócrinas, da nutrição e do metabolismo e transtornos imunitários (240-279)

VII - Doenças do aparelho circulatório (390-459)

VIII - Doenças do aparelho respiratório (460-519)

IX - Doenças do aparelho digestivo (520-579)

XVI - Sintomas, sinais e afecçōes mal-definidas (780-799)

XVII - Causas externas (E899-E999) 
$\mathrm{N}^{0}$ de óbitos no sexo masculino segundo principais causas básicas de morte e grupos etários, Isseis do Estado do Paraná, 1991.

\begin{tabular}{ccccccccc}
\hline & \multicolumn{7}{c}{ Causa de morte (CID)** } \\
\cline { 2 - 8 } Grupo etário & 151 & 153 & 162 & 185 & 250 & $410-414$ & $430-438$ E950-E959 \\
\hline 0 a 4 & - & - & - & - & - & - & - & - \\
5 a 9 & - & - & - & - & - & - & - & - \\
10 a 14 & - & - & - & - & - & - & - & - \\
15 a 19 & - & - & - & - & - & - & - & - \\
20 a 24 & - & - & - & - & - & - & - & - \\
25 a 29 & - & - & - & - & - & - & - & - \\
30 a 34 & - & - & - & - & - & - & - & - \\
35 a 39 & - & - & - & - & - & - & - & - \\
40 a 44 & - & - & - & - & - & - & - & 1 \\
45 a 49 & - & - & - & - & - & - & - & - \\
50 a 54 & - & - & 1 & - & - & 1 & - & - \\
55 a 59 & - & - & - & - & - & 1 & 1 & 1 \\
60 a 64 & 3 & 1 & 1 & - & - & 6 & 10 & - \\
65 a 69 & 4 & 1 & 3 & - & 1 & 5 & 6 & 2 \\
70 a 74 & 4 & 1 & 2 & 1 & 5 & 6 & 18 & - \\
75 a 79 & 4 & 2 & 6 & - & 3 & 13 & 26 & 2 \\
80 a 84 & 6 & 0 & 3 & 1 & 4 & 13 & 12 & 1 \\
85 e + & 6 & 1 & 1 & - & 1 & 12 & 15 & 1 \\
\hline Total* & 27 & 6 & 17 & 2 & 14 & 57 & 88 & 7 \\
\hline
\end{tabular}

* Excluídos os casos cuja idade e/ou sexo são desconhecidos

**CID 151 - Neoplasma maligno do estômago

CID 153 - Neoplasma maligno do colo

CID 162 - Neoplasma maligno da traquéia, brônquios e pulmão

CID 185 - Neoplasma maligno da próstata

CID 250 - Diabetes mellitus

CID 410-414 Doença isquêmica do coração

CID 430-438 Doença cerebrovascular

E950-E959 Suicidios e lesōes auto-infligidas 
$\mathrm{N}^{0}$ de óbitos no sexo feminino segundo principais causas básicas de morte e grupos etários, Isseis do Estado do Paraná, 1991.

\begin{tabular}{cccccccccc}
\hline & \multicolumn{7}{c}{ Causa de morte (CID)** } \\
\cline { 2 - 9 } Grupo etário & 151 & 153 & 162 & 174 & 180 & 250 & $410-414$ & $430-438$ E950-E959 \\
\hline 0 a 4 & - & - & - & - & - & - & - & - & - \\
5 a 9 & - & - & - & - & - & - & - & - & - \\
10 a 14 & - & - & - & - & - & - & - & - & - \\
15 a 19 & - & - & - & - & - & - & - & - & - \\
20 a 24 & - & - & - & - & - & - & - & - & - \\
25 a 29 & - & - & - & - & - & - & - & - & - \\
30 a 34 & - & - & - & - & - & - & - & - & - \\
35 a 39 & - & - & - & - & - & - & - & - & - \\
40 a 44 & - & - & - & - & - & - & - & - & - \\
45 a 49 & 1 & & 1 & - & - & - & - & - & - \\
50 a 54 & - & - & - & - & - & - & - & - & - \\
55 a 59 & - & 1 & - & - & - & - & 1 & 4 & 1 \\
60 a 64 & 1 & - & - & 1 & - & 1 & 4 & 5 & - \\
65 a 69 & 1 & - & - & 1 & - & 5 & 4 & 6 & - \\
70 a 74 & 3 & - & - & - & - & 3 & 3 & 9 & - \\
75 a 79 & 3 & 3 & 2 & 3 & - & 6 & 12 & 23 & 1 \\
80 a 84 & 2 & 1 & 1 & - & - & 5 & 13 & 10 & - \\
85 e & 5 & 1 & 0 & - & - & 2 & 14 & 39 & - \\
\hline Total* & 16 & 6 & 4 & 5 & 1 & 22 & 51 & 96 & 2 \\
\hline
\end{tabular}

\footnotetext{
* Excluídos os casos cuja idade e/ou sexo são desconhecidos

* CID 151 - Neoplasma maligno do estômago

CID 153 - Neoplasma maligno do colo

CID 162 - Neoplasma maligno da traquéia, brônquios e pulmão

CID 174 - Neoplasma maligno da mama feminina

CID 180 - Neoplasma maligno do colo do útero

CID 250 - Diabetes mellitus

CID 410-414 Doença isquêmica do coração

CID 430-438 Doença cerebrovascular

E950-E959 Suicídios e lesōes auto-infligidas
} 
$\mathrm{N}^{\circ}$ de óbitos no sexo masculino segundo principais causas básicas de morte e grupos etários, Japão, 1991.

\begin{tabular}{crrrrrrrrr}
\hline & \multicolumn{7}{c}{ Causa de morte (CID)** } \\
\cline { 2 - 9 } Grupo etário & 151 & 153 & 162 & 185 & 250 & $410-414$ & $430-438$ & E950-E959 & E960-E969 \\
\hline 0 a 4 & - & - & - & - & 2 & - & 25 & - & 32 \\
5 a 9 & - & - & - & - & 0 & - & 8 & - & 20 \\
10 a 14 & - & 1 & 1 & - & 3 & 1 & 8 & 22 & 12 \\
15 a 19 & 2 & 2 & 1 & 2 & 8 & 6 & 21 & 247 & 19 \\
20 a 24 & 18 & 11 & 5 & 1 & 10 & 13 & 43 & 644 & 25 \\
25 a 29 & 39 & 17 & 14 & - & 12 & 45 & 75 & 723 & 21 \\
30 a 34 & 97 & 33 & 52 & 3 & 24 & 72 & 169 & 696 & 18 \\
35 a 39 & 279 & 65 & 134 & 2 & 36 & 140 & 346 & 879 & 21 \\
40 a 44 & 738 & 180 & 420 & 1 & 100 & 379 & 1052 & 1267 & 47 \\
45 a 49 & 1048 & 265 & 576 & 12 & 162 & 577 & 1539 & 1316 & 41 \\
50 a 54 & 1702 & 464 & 962 & 27 & 279 & 956 & 2213 & 1473 & 42 \\
55 a 59 & 2962 & 811 & 1959 & 113 & 445 & 1788 & 3349 & 1428 & 26 \\
60 a 64 & 4181 & 1154 & 3703 & 230 & 593 & 2593 & 4345 & 1072 & 27 \\
65 a 69 & 4419 & 1163 & 4446 & 328 & 515 & 2949 & 4768 & 744 & 10 \\
70 a 74 & 4323 & 1082 & 4893 & 593 & 596 & 3506 & 6121 & 535 & 11 \\
75 a 79 & 4624 & 1244 & 5188 & 908 & 785 & 4932 & 9645 & 589 & 7 \\
80 a 84 & 3627 & 1019 & 3737 & 895 & 627 & 4871 & 11086 & 481 & 13 \\
85 e + & 2236 & 724 & 1876 & 721 & 436 & 4374 & 10904 & 284 & 1 \\
\hline Total* & 30295 & 8235 & 27967 & 3836 & 4633 & 27202 & 55717 & 12400 & 393 \\
\hline
\end{tabular}

*Excluídos os casos cuja idade e/ou sexo são desconhecidos

**CID 151 - Neoplasma maligno do estômago

CID 153 - Neoplasma maligno do colo

CID 162 - Neoplasma maligno da traquéia, brônquios e pulmão

CID 185 - Neoplasma maligno da próstata

CID 250 - Diabetes mellitus

CID $410-414$ Doença isquêmica do coração

CID 430-438 Doença cerebrovascular

E950-E959 Suicídios e lesōes auto-infligidas

E960-E969 Homicídios e lesōes provocadas intencionalmente por outras pessoas 
$\mathrm{N}^{\circ}$ de óbitos no sexo feminino segundo principais causas básicas de morte e grupos etários, Japão, 1991

\begin{tabular}{lrrrrrrrrrrr}
\hline & \multicolumn{10}{c}{ Causa de morte (CID)** } \\
\cline { 2 - 11 } $\begin{array}{l}\text { Grupo } \\
\text { etário }\end{array}$ & 151 & 153 & 162 & 174 & 180 & 250 & $410-414$ & $430-438$ & E950-E959 & E960-E969 \\
\hline 0 a 4 & - & - & - & - & - & 1 & 2 & 23 & 0 & 44 \\
5 a 9 & - & - & - & - & - & 1 & 1 & 6 & 0 & 14 \\
10 a 14 & - & - & - & - & - & - & 1 & 7 & 14 & 7 \\
15 a 19 & 5 & - & 1 & 1 & - & 4 & 3 & 19 & 124 & 15 \\
20 a 24 & 18 & 6 & 1 & 2 & 3 & 6 & 7 & 28 & 318 & 13 \\
25 a 29 & 62 & 16 & 14 & 26 & 10 & 14 & 11 & 48 & 334 & 10 \\
30 a 34 & 166 & 27 & 22 & 109 & 23 & 5 & 15 & 87 & 303 & 11 \\
35 a 39 & 366 & 84 & 72 & 273 & 47 & 21 & 33 & 163 & 349 & 13 \\
40 a 44 & 734 & 206 & 214 & 640 & 135 & 39 & 78 & 550 & 527 & 22 \\
45 a 49 & 712 & 259 & 286 & 690 & 143 & 65 & 151 & 848 & 512 & 16 \\
50 a 54 & 918 & 456 & 447 & 843 & 168 & 120 & 234 & 1213 & 651 & 19 \\
55 a 59 & 1215 & 605 & 667 & 882 & 197 & 215 & 479 & 1704 & 634 & 27 \\
60 a 64 & 1483 & 822 & 893 & 852 & 237 & 311 & 875 & 2354 & 643 & 13 \\
65 a 69 & 1964 & 908 & 1242 & 672 & 232 & 534 & 1543 & 3603 & 631 & 16 \\
70 a 74 & 2224 & 1057 & 1661 & 481 & 220 & 771 & 2629 & 5779 & 653 & 13 \\
75 a 79 & 2658 & 1235 & 1894 & 352 & 204 & 979 & 4610 & 10177 & 674 & 14 \\
80 a 84 & 2772 & 1226 & 1638 & 266 & 156 & 1111 & 5892 & 14366 & 563 & 9 \\
85 e + & 2303 & 1124 & 1179 & 220 & 98 & 804 & 7681 & 21731 & 450 & 6 \\
\hline Total* & 17600 & 8031 & 10231 & 6309 & 1873 & 5001 & 24245 & 62706 & 7380 & 282 \\
\hline
\end{tabular}

* Excluídos os casos cuja idade e/ou sexo são desconhecidos

**CID 151 - Neoplasma maligno do estômago

CID 153 - Neoplasma maligno do colo

CID 162 - Neoplasma maligno da traquéia, brônquios e pulmão

CID 174 - Neoplasma maligno da mama feminina

CID 180 - Neoplasma maligno do colo do útero

CID 250 - Diabetes mellitus

CID 410-414 Doença isquêmica do coração

CID 430-438 Doença cerebrovascular

E950-E959 Suicídios e lesões auto-infligidas

E960-E969 Homicídios e lesões provocadas intencionalmente por outras pessoas 
$\mathrm{N}^{0}$ de óbitos no sexo masculino segundo principais causas básicas de morte e grupo etário, Estado do Paraná, 1991.

\begin{tabular}{lrrrrrrrrr}
\hline & \multicolumn{7}{c}{ Causa de morte (CID)** } \\
\cline { 2 - 9 } Grupo etário & 151 & 153 & 162 & 185 & 250 & $410-414$ & $430-438$ & E950-E959 & E960-E969 \\
\hline 0 a 4 & - & - & - & - & 4 & - & 1 & - & 7 \\
5 a 9 & - & - & - & - & 1 & - & - & - & 3 \\
10 a 14 & - & - & 1 & - & 2 & - & - & 4 & 10 \\
15 a 19 & - & - & 0 & - & 5 & 4 & 7 & 20 & 99 \\
20 a 24 & - & 1 & 2 & - & 5 & 4 & 9 & 50 & 170 \\
25 a 29 & 4 & 1 & 2 & - & 5 & 19 & 4 & 36 & 190 \\
30 a 34 & 7 & 3 & 4 & - & 4 & 22 & 31 & 36 & 169 \\
35 a 39 & 16 & 4 & 1 & - & 5 & 65 & 50 & 30 & 118 \\
40 a 44 & 11 & 8 & 8 & - & 15 & 98 & 106 & 22 & 97 \\
45 a 49 & 30 & 6 & 14 & - & 21 & 145 & 163 & 38 & 55 \\
50 a 54 & 52 & 18 & 41 & 1 & 24 & 211 & 233 & 18 & 50 \\
55 a 59 & 60 & 5 & 65 & 13 & 34 & 281 & 318 & 29 & 38 \\
60 a 64 & 96 & 20 & 73 & 20 & 58 & 317 & 386 & 23 & 26 \\
65 a 69 & 99 & 12 & 83 & 46 & 65 & 383 & 422 & 10 & 17 \\
70 a 74 & 70 & 17 & 61 & 56 & 50 & 356 & 465 & 8 & 4 \\
75 a 79 & 65 & 16 & 51 & 44 & 42 & 277 & 486 & 10 & 7 \\
80 a 84 & 42 & 9 & 23 & 31 & 24 & 242 & 350 & 3 & 2 \\
85 e + & 28 & 5 & 11 & 25 & 9 & 140 & 241 & - & 3 \\
\hline Total* & 580 & 125 & 440 & 236 & 373 & 2564 & 3272 & 337 & 1065 \\
\hline
\end{tabular}

${ }^{*}$ Excluídos os casos cuja idade e/ou sexo são desconhecidos

**CID 151 - Neoplasma maligno do estômago

CID 153 - Neoplasma maligno do colo

CID 162 - Neoplasma maligno da traquéia, brônquios e pulmāo

CID 185 - Neoplasma maligno da próstata

CID 250 - Diabetes mellitus

CID 410-414 Doença isquêmica do coração

CID 430-438 Doença cerebrovascular

E950-E959 Suicídios e lesōes auto-infligidas

E960-E969 Homicídios e lesōes provocadas intencionalmente por outras pessoas 
$\mathrm{N}^{\circ}$ de óbitos no sexo feminino segundo principais causas básicas de morte e grupos etários, Estado do Paraná, 1991.

\begin{tabular}{|c|c|c|c|c|c|c|c|c|c|c|}
\hline \multirow[b]{2}{*}{ Grupo etário } & \multicolumn{10}{|c|}{ Causa de morte (CID)** } \\
\hline & 151 & 153 & 162 & 174 & 180 & 250 & $410-414$ & $430-438$ & E950-E959 & E960-E969 \\
\hline 0 a 4 & - & - & - & - & - & 1 & - & - & - & 8 \\
\hline 5 a 9 & - & - & - & - & - & - & - & 1 & - & 5 \\
\hline 10 a 14 & - & - & - & - & - & 4 & - & 3 & 4 & 4 \\
\hline 15 a 19 & - & - & 1 & - & - & 4 & 1 & 1 & 22 & 14 \\
\hline 20 a 24 & - & 1 & - & - & 1 & 5 & 2 & 10 & 20 & 24 \\
\hline 25 a 29 & - & - & - & - & 6 & 11 & 4 & 14 & 14 & 22 \\
\hline 30 a 34 & 3 & 5 & 2 & 12 & 11 & 7 & 10 & 35 & 13 & 19 \\
\hline 35 a 39 & 5 & 3 & 2 & 25 & 20 & 10 & 33 & 59 & 9 & 16 \\
\hline 40 a 44 & 6 & 2 & 4 & 24 & 23 & 21 & 53 & 71 & 11 & 10 \\
\hline 45 a 49 & 11 & 6 & 16 & 39 & 41 & 26 & 60 & 114 & 7 & 4 \\
\hline 50 a 54 & 15 & 2 & 19 & 38 & 23 & 30 & 89 & 145 & 9 & 7 \\
\hline 55 a 59 & 20 & 14 & 19 & 45 & 27 & 55 & 122 & 193 & 2 & 5 \\
\hline $60 a 64$ & 31 & 12 & 33 & 29 & 21 & 62 & 167 & 244 & 9 & 5 \\
\hline 65 a 69 & 29 & 16 & 30 & 31 & 22 & 79 & 242 & 287 & 5 & 3 \\
\hline 70 a 74 & 37 & 22 & 29 & 29 & 14 & 99 & 236 & 338 & 3 & - \\
\hline 75 a 79 & 25 & 18 & 28 & 22 & 9 & 83 & 271 & 393 & 2 & 1 \\
\hline 80 a 84 & 27 & 11 & 17 & 17 & 3 & 57 & 222 & 306 & - & - \\
\hline $85 \mathrm{e}+$ & 17 & 11 & 7 & 6 & 0 & 33 & 221 & 283 & - & - \\
\hline Total* & 226 & 123 & 207 & 317 & 221 & 587 & 1733 & 2497 & 130 & 147 \\
\hline $\begin{array}{l}{ }^{*} \text { Excluídos } \\
{ }^{*} \text { CID } 151- \\
\text { CID } 153- \\
\text { CID } 162- \\
\text { CID } 174- \\
\text { CID } 180- \\
\text { CID } 250- \\
\text { CID } 410-41 \\
\text { CID 430-43 } \\
\text { E950-E959 } \\
\text { E960-E969 }\end{array}$ & $\begin{array}{l}\text { casos cl } \\
\text { oplasm } \\
\text { pplasma } \\
\text { oplasma } \\
\text { pplasma } \\
\text { pplasma } \\
\text { betes m } \\
\text { Doença } \\
\text { Doença } \\
\text { dicídios } \\
\text { omicídic }\end{array}$ & $\begin{array}{l}\text { a idade } \\
\text { malign } \\
\text { naligno } \\
\text { naligno } \\
\text { naligno } \\
\text { naligno } \\
\text { llitus } \\
\text {;quêmi } \\
\text { erebro } \\
\text { lesōes } \\
\text { e lesõe }\end{array}$ & $\begin{array}{l}\text { e/ou se } \\
\text { do est } \\
\text { do col } \\
\text { da tra } \\
\text { da ma } \\
\text { do col } \\
\text { ca do c } \\
\text { vascula } \\
\text { auto-in } \\
\text { es prov }\end{array}$ & $\begin{array}{l}\text { sexo são } \\
\text { stômago } \\
\text { lo } \\
\text { aquéia, } \\
\text { ama fen } \\
\text { lo do ú } \\
\text { coração } \\
\text { ar } \\
\text { nfligida } \\
\text { vocadas }\end{array}$ & $\begin{array}{l}\text { brônqu } \\
\text { minina } \\
\text { itero }\end{array}$ & uios e p & ulmăo & & & \\
\hline
\end{tabular}

